\author{
UNIVERSIDADE DE SÃO PAULO \\ ESCOLA DE ENGENHARIA DE SÃO CARLOS \\ DEPARTAMENTO DE ENGENHARIA DE ESTRUTURAS
}

VICTOR ALVES FERNANDES

ANÁLISE ELASTOPLÁSTICA BIDIMENSIONAL DE MEIOS REFORÇADOS COM FIBRAS

SÃO CARLOS 



\section{ANÁLISE ELASTOPLÁSTICA BIDIMENSIONAL DE MEIOS REFORÇADOS COM} FIBRAS

\section{VERSÃO CORRIGIDA}

A versão original encontra-se na Escola de Engenharia de São Carlos

Dissertação apresentada ao Departamento de Engenharia de Estruturas da Escola de Engenharia de São Carlos, Universidade de São Paulo, como parte dos quesitos necessários para obtenção do título de Mestre em Engenharia Civil (Estruturas).

Área de concentração: Estruturas

Orientador: Prof. Dr. Rodrigo Ribeiro Paccola 
AUTORIZO A REPRODUÇÃO TOTAL OU PARCIAL RESTE TRABALHO, POR QUALQUER MEIO CONVENCIONAL OU ELETRONNICO, PARA FINS DE ESTUDO E PESQUISA, DESDE QUE CITADA A FONTE.

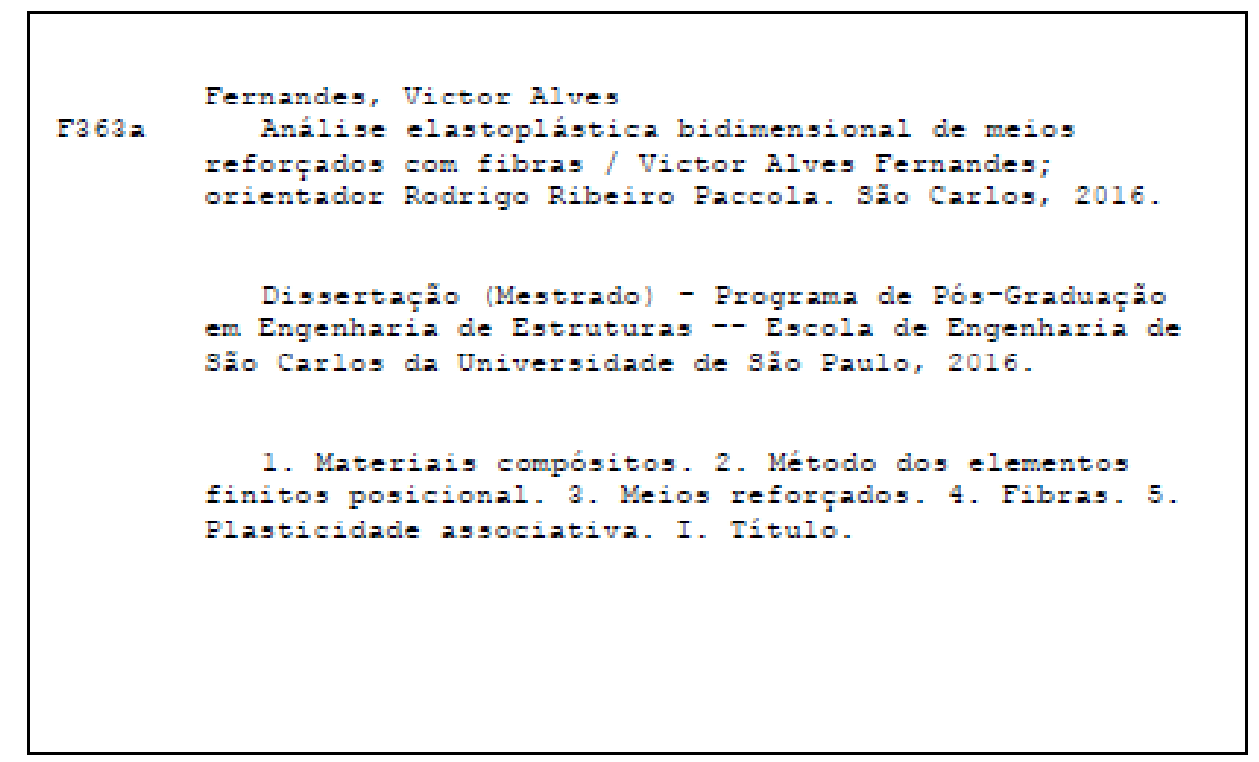




\section{FOLHA DE JULGAMENTO}

Candidato: Engenheiro VICTOR ALVES FERNANDES.

Título da dissertação: "Análise elastoplástica bidimensional de meios reforçados com fibras".

Data da defesa: 20/04/2016

\section{Comissa̋o Julgadora:}

Prof. Dr. Rodrigo Ribeiro Paccola (Orientador)

(Escola de Engenharia de São Carlos/EESC)

Prof. Dr. Ricardo Afonso Angélico

(Escola de Engenharia de São Carlos/EESC)

Prof. Dr. Climar Donizefi Baságlia

(Universidade Estadual de Campinas/UNICAMP)
Resultado:

APNOVAXO

APROVADO

Coordenador do Programa de Pós-Graduação em Engenheira Civil (Engenharia de Estruturas):

Prof. Titular Humberto Breves Coda

Presidente da Comissão de Pós-Graduação:

Prof. Associado Paulo Serglo Lima Segantine 

- Dedico este trabalho à constante busca por conhecimento. 



\section{AGRADECIMENTOS}

Ao professor Dr. Rodrigo Ribeiro Paccola gostaria de agradecer pelo esforço, dedicação e senso de humor em sua orientação.

Ao professor Tit. Humberto Breves Coda e ao professor Dr. Edson Denner Leonel pelas contribuições dadas para a melhoria do trabalho.

A todos os meus amigos do SET. Em especial aos companheiros da ME-01: Fernando Gílio, Jeferson Wiliam, Júlio César, Lucas Buffon, Rodolfo Tessari, Sérgio Andres, Tiago Morkis e Thiago Delfino; pela convivência e ajuda.

Aos meus pais Eliane e Francisco e minha irmã, Paula, por toda compreensão e carinho. A minha namorada, Thélia, por todo amor e incentivo, sem os quais nunca estaria aqui.

À Coordenação de Aperfeiçoamento de Pessoal de Nível Superior (CAPES) pelo apoio financeiro.

À Escola de Engenharia de São Carlos (EESC/USP) e ao Departamento de Engenharia de Estruturas (SET) pela oportunidade. 

"Everything not saved will be lost."

- Nintendo Quit Screen. 



\section{RESUMO}

FERNANDES, V. A. Análise elastoplástica bidimensional de meios reforçados com fibras. 2016. 113 p. Dissertação - Mestrado em Engenharia Civil (Estruturas) - Escola de Engenharia de São Carlos, Universidade de São Paulo, São Carlos, 2016.

De modo a satisfazer aspectos de resistência, custo ou conforto, o aperfeiçoamento do desempenho das estruturas é uma meta sempre almejada na Engenharia. Melhorias têm sido alcançadas dado ao crescente uso de materiais compósitos, pois estes apresentam propriedades físicas diferenciadas capazes de atender as necessidades de projeto. Associado ao emprego de compósitos, o estudo da plasticidade demonstra uma interessante alternativa para aumentar o desempenho estrutural ao conferir uma capacidade resistente adicional ao conjunto. Entretanto, alguns problemas podem ser encontrados na análise elastoplástica de compósitos, além das próprias dificuldades inerentes à incorporação de fibras na matriz, no caso de compósitos reforçados. A forma na qual um compósito reforçado por fibras e suas fases têm sua representação e simulação é de extrema importância para garantir que os resultados obtidos sejam compatíveis com a realidade. À medida que se desenvolvem modelos mais refinados, surgem problemas referentes ao custo computacional, além da necessidade de compatibilização dos graus de liberdade entre os nós das malhas de elementos finitos da matriz e do reforço, muitas vezes exigindo a coincidência das referidas malhas. O presente trabalho utiliza formulações que permitem a representação de compósitos reforçados com fibras sem que haja a necessidade de coincidência entre malhas. Além disso, este permite a simulação do meio e do reforço em regime elastoplástico com o objetivo de melhor estudar o real comportamento. O modelo constitutivo adotado para a plasticidade é o de von Mises 2D associativo com encruamento linear positivo e a solução deste modelo foi obtida através de um processo iterativo. A formulação de elementos finitos posicional é adotada com descrição Lagrangeana Total e apresenta as posições do corpo no espaço como parâmetros nodais. Com o intuito de averiguar a correta implementação das formulações consideradas, exemplos para validação e apresentação das funcionalidades do código computacional desenvolvido foram analisados.

Palavras-chave: Materiais compósitos. Método dos elementos finitos posicional. Meios reforçados. Fibras. Plasticidade associativa. 



\begin{abstract}
FERNANDES, V. A. Bidimensional elastoplastic analysis of fiber reinforced medium. 2016. 113 p. Dissertation (M. Sc. in Civil Engineering (Structures)) - School of Engineering of São Carlos, University of São Paulo, São Carlos, 2016.

In order to satisfy strength, cost or comfort aspects, the improvement of the structural performance is a mark always desired in Engineering. Progress has been achieved due to the use of composite materials, because these present different physical properties capable of attending the needs of projects. Associated to the use of composites, the study of plasticity presents an interesting alternative to raise the structural performance by providing an additional resistance capability to the set. However, some problems may be found in the elastoplastic analysis of composites, besides the inherent difficulties of fiber insertion in the matrix, in the case of fiber reinforced composites. The way that the fiber reinforced composite and its phases are represented and simulated are of extreme importance to assure that the obtained results are compatible to the reality. As more refined models are developed, problems arise concerning computational cost and the need of compatibilization of the degrees of freedom between the nodes of the mashes of the matrix and the reinforcement, many times demanding the coincidence of the refered meshes. The present work utilizes formulations that allow the representation of the fiber reinforced composite without the need of mesh coincidence. It also enables the simulation of the medium and the reinforcement at the elastoplastic regime, with the objective study better the real behaviour. The constitutive model for the plasticity adopted is the von Mises 2D associative with a positive linear hardening and the solution of this model was obtained through an iterative procedure. The positional finite element method is adopted with a Total Lagrangean description and uses the positons of the body in space as nodal parameters. With the aim to ensure the correct implementation of the considered formulations, examples for validation and presentation of the functionalities of the developed computacional code were analized.
\end{abstract}

Keywords: Composite materials. Positional finite element method. Reinforced mediums. Fibers. Associative plasticity. 



\section{LISTA DE FIGURAS}

Figura 1 - a) discretização, b) embutimento, c) homogeneização ..........................................22

Figura 2 - Esquema de classificação dos vários tipos de compósitos ......................................27

Figura 3 - Influência das fibras no concreto tracionado em diferentes estágios......................29

Figura 4 - Rotação de 90 graus de um corpo bidimensional (Fonte: Bonet e Wood, 1997) ...41

Figura 5 - Configurações de um corpo, função mudança de configuração e funções de mapeamento

Figura 6 - Representação gráfica do método de Newton-Raphson 46

Figura 7 - Esquema de mapeamento do elemento finito bidimensional e suas configurações 47 Figura 8 - Esquema de mapeamento do elemento de fibra reta e suas configurações inicial e atual 55

Figura 9 - Esquema de mapeamento do elemento de fibra curvo de ordem qualquer e suas configurações 60

Figura 10 - Arranjo das fibras no domínio bidimensional 67

Figura 11 - (a) tensão normal na fibra, (b) tensão de aderência na fibra 70

Figura 12 - Comportamento elástico vs comportamento plástico de uma viga 74

Figura 13 - Carregamento e descarregamento no modelo elastoplástico perfeito .75

Figura 14 - Comportamento da variação da deformação plástica. .77

Figura 15 - Modelo elastoplástico com encruamento isótropo linear positivo 78

Figura 16 - Demonstração gráfica do módulo elastoplástico tangente (a) e do módulo plástico de encruamento (b) 81

Figura 17 - Representação da associatividade 82

Figura 18 - Superfície de plastificação no espaço bidimensional 83

Figura 19 - Representação do critério de Von Mises bidimensional 84

Figura 20 - Viga engastada e livre horizontal submetida a um carregamento vertical 90

Figura 21 - (a) esquema dos elementos finitos (b) estrutura e condições de contorno e carregamento

Figura 22 - Resultado comparativo para a viga engastada-livre...........................................91

Figura 23 - Barra reforçada submetida a esforço de tração ...................................................92

Figura 24 - Tensão no reforço pelo método dos elementos finitos........................................93

Figura 25 - Passo de carga $\mathrm{x}$ deslocamento horizontal ...........................................................93

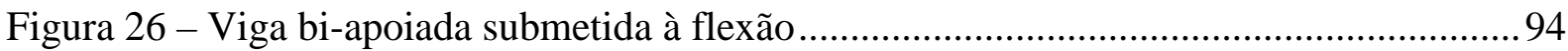

Figura 27 - Comparativo entre os valores de deslocamentos verticais (eixo y) ..................... 95 
Figura 28 - Comparativo entre os valores de tensões na direção x........................................95

Figura 29 - Comparativo entre os valores de deformação plástica na direção x .....................95

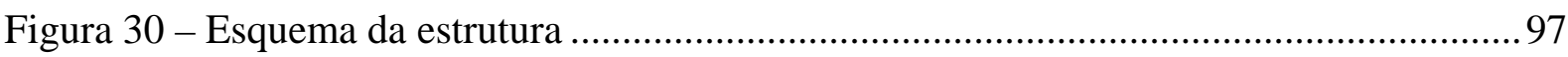

Figura 31 - Gráfico (carga x deformação) em vigas de diferentes comprimentos...................97

Figura 32 - Distribuição de tensão na matriz elastoplástica perfeita ......................................98

Figura 33 - Distribuição da deformação plástica equivalente na matriz elastoplástica perfeita

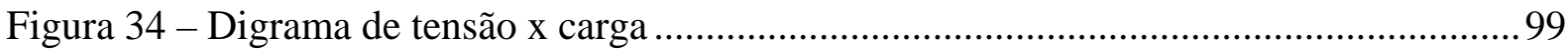

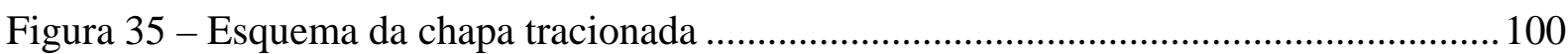

Figura 36 - (a) tensão normal nas fibras elastoplásticas de 3cm, (b) tensão normal nas fibras elastoplásticas de $6 \mathrm{~cm}$ 101

Figura 37 - (a) deslocamentos horizontais com fibras elásticas, (b) deslocamentos horizontais com fibras plásticas 102

Figura 38 - (a) deslocamentos horizontais com fibras elásticas, (b) deslocamentos horizontais

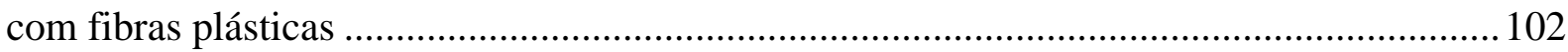

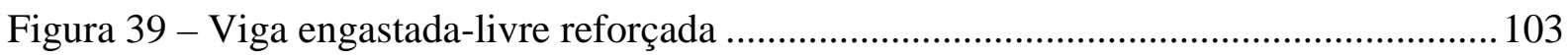

Figura 40 - (a) tensão para a estrutura não reforçada (b) deformação plástica para a estrutura

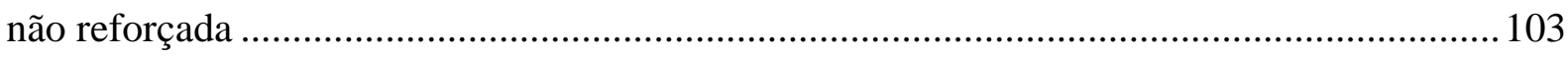

Figura 41 - (a) tensão para a estrutura com reforço elástico (b) deformação plástica para a

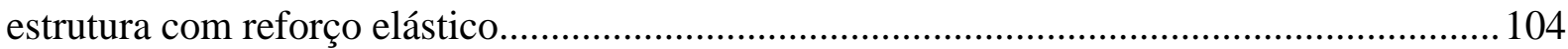

Figura 42 - Gráfico de reação x deslocamento ..................................................................... 104

Figura 43 - Gráfico de tensão no reforço x deslocamento ................................................... 105 


\section{SUMÁRIO}

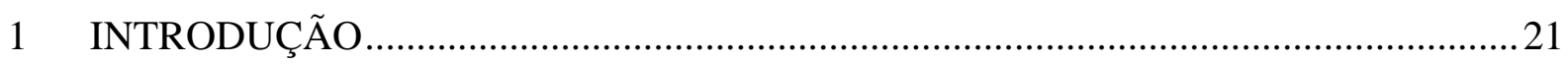

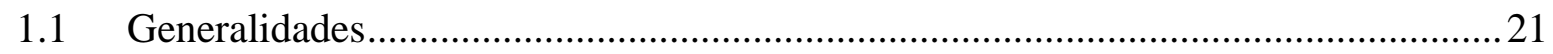

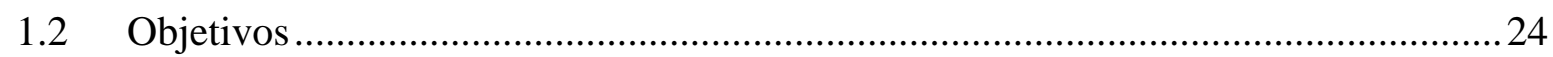

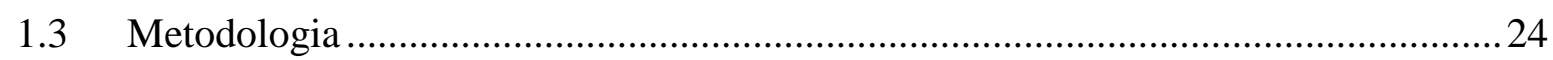

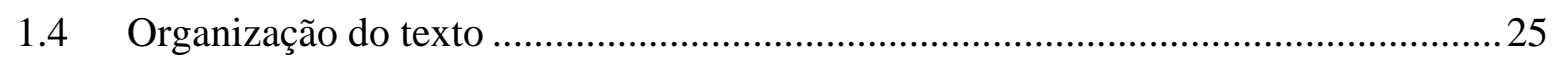

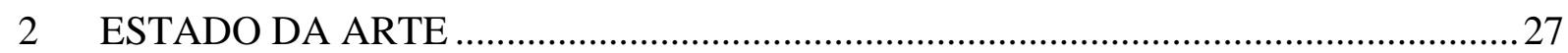

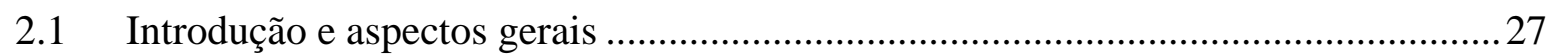

2.2 Compósitos reforçados com fibras ………………………………………….......29

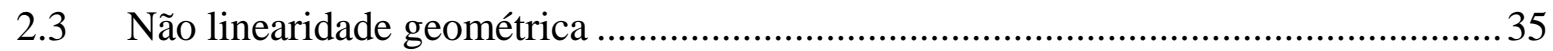

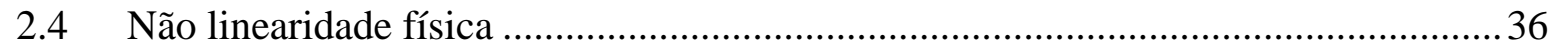

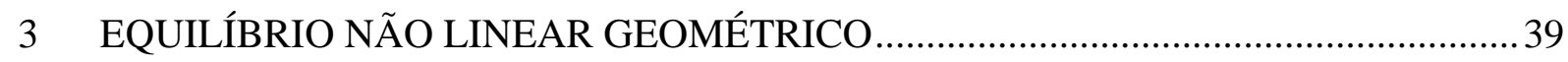

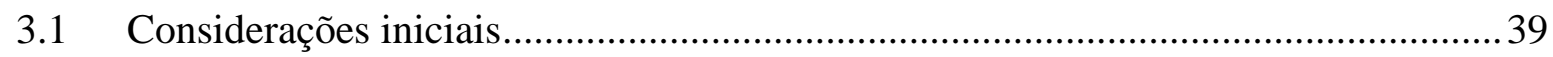

3.2 Formulações do equilíbrio não linear geométrico .....................................................42

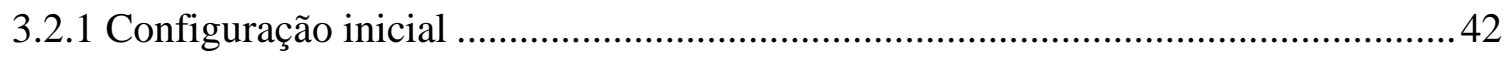

3.2.3 Mapeamento e função mudança de configuração........................................................4

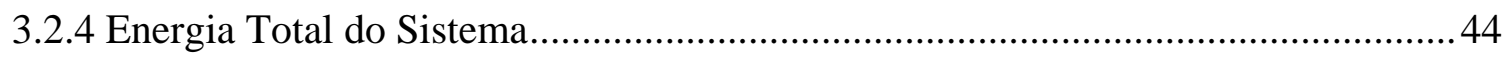

3.2.5 Resolução do sistema não linear..............................................................................4

4 ELEMENTO FINITO BIDIMENSIONAL ....................................................................4

4.1 Cinemática do elemento finito de chapa .....................................................................47

4.2 Energia de deformação ...........................................................................................49

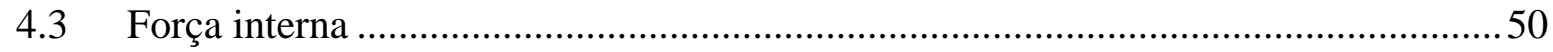

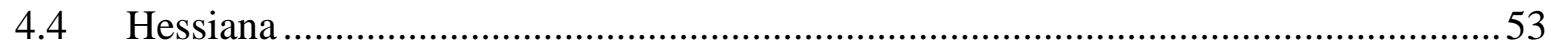

5 ELEMENTO FINITO DE BARRA COMO REFORÇO ....................................................55

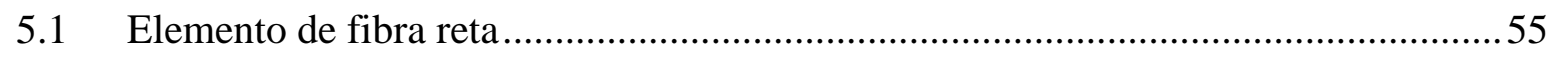

5.1.1 Cinemática do elemento de fibra reta ..................................................................5

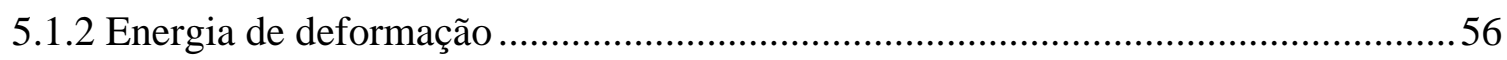


5.1.4 Hessiana. 58

5.2 Elemento de fibra curvo de ordem qualquer.........................................................60

5.2.1 Cinemática do elemento de fibra curvo de ordem qualquer...................................60

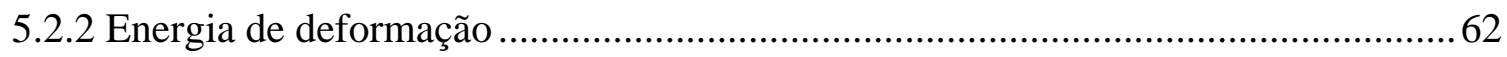

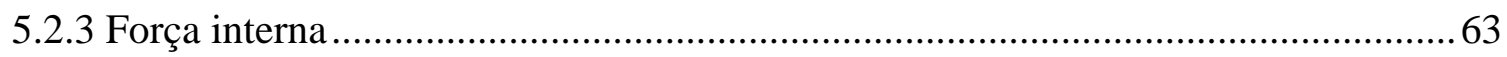

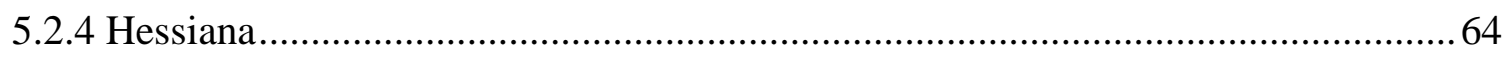

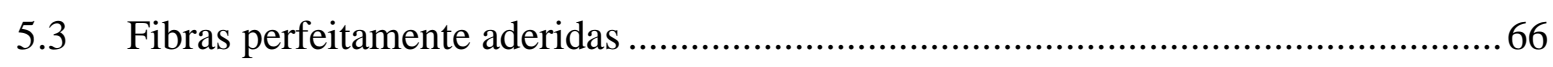

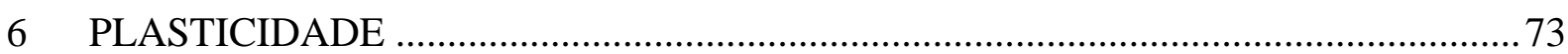

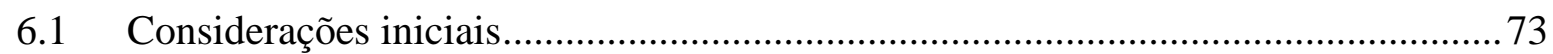

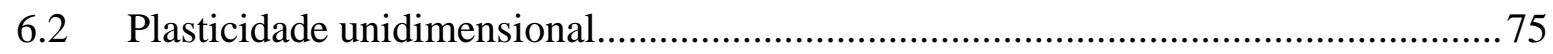

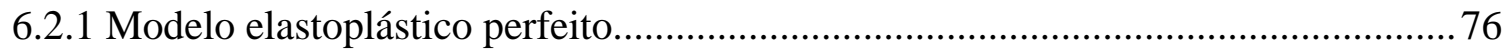

6.2.2 Modelo elastoplástico com encruamento isótropo linear positivo ..........................78

6.3 Plasticidade bidimensional de von Mises associativa............................................81

4.3.1 Algoritmo de Von Mises bidimensional associativo ............................................... 85

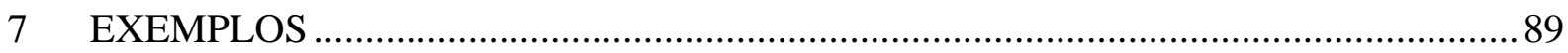

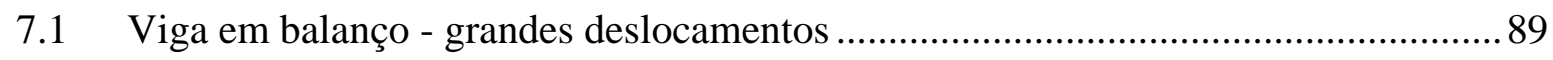

7.2 Comparação com a solução técnica de Resistência dos Materiais ...........................92

7.3 Viga bi-apoiada elastoplástica submetida a carregamento uniformemente distribuído 94

7.4 Momento de plastificação em viga engastada-livre..............................................96

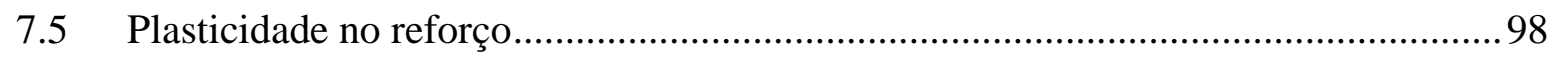

7.6 Análise do mecanismo de plasticidade governante para as fibras ..........................99

7.7 Elastoplasticidade perfeita em viga engastada-livre reforçada ............................... 103

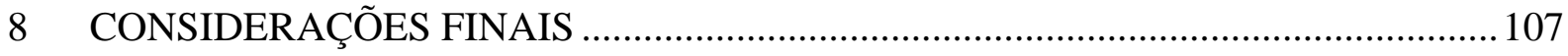

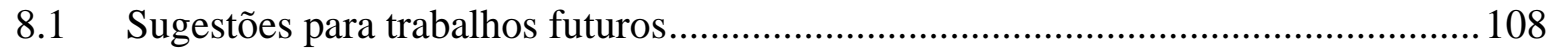

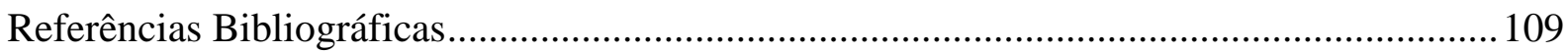




\section{INTRODUÇÃO}

\subsection{Generalidades}

Um material compósito é o resultado da combinação macroscópica entre dois ou mais materiais, no qual as diferentes fases podem ser vistas a olho nu. A vantagem do compósito é que, se bem projetado, costuma apresentar as melhores qualidades de seus materiais constituintes, além de outras novas, das quais nenhum de seus materiais constituintes possui (JONES, 1999).

As propriedades do compósito dependem das características dos seus materiais constituintes, geometria e distribuição das duas fases, denominadas matriz e reforço, sendo um dos parâmetros mais importantes a fração volumétrica do reforço (DANIEL E ISHAI, 2006).

Quando a matriz é associada com fibras, tem-se um tipo específico de compósito, denominado de compósito reforçado com fibras. Um exemplo desta classe de compósitos é o concreto reforçado com fibras. Dependendo da fração volumétrica de fibras, estas desempenham uma função diferente no conjunto. Quando inferior a 1\%, as fibras apresentam a função de redução de fissuração por retração. Entre $1 \%$ e $2 \%$, aumentam o módulo de ruptura, dureza à fratura e resistência ao impacto. Acima de $2 \%$ estas aumentam a rigidez do compósito. Os concretos que se encaixam nessa condição costumam ser chamados de concretos reforçados com fibras de alto desempenho (MEHTA E MONTEIRO, 2006).

De forma a se fazer um bom uso dos materiais na engenharia, a compreensão e previsão do comportamento do material compósito a curto e longo prazo deve ser possível. A grande dificuldade em lidar com materiais compósitos deve-se à grande quantidade de tipos de materiais existentes, havendo a necessidade do estudo de cada classe. Sendo possível realizar a previsão do comportamento de um dado compósito através de uma modelagem numérica, poder-se-ia, então, haver a confiança de que o material projetado irá atender aos requerimentos pelos quais foi projetado (HARRIS, 1999).

Segundo Vanalli et al. (2010), a importância de uma boa representação de meios reforçados por fibras na análise da engenharia pode ser identificada quando observada a grande quantidade de trabalhos relacionados a avaliação do comportamento desse tipo de material e várias alternativas presentes em softwares comerciais e artigos científicos para a solução desse problema. 
Gomes e Awruch (2001) mencionam que, nas últimas décadas, vários modelos para concreto reforçado têm surgido para a representação do comportamento do material até um ponto limite, dado pelo estado limite de serviço ou último, e apresentado resultados satisfatórios para as necessidades as quais foram concebidos. Para situações pós-pico, técnicas de controle de deslocamentos são comumente utilizadas, pois o controle de forças não é capaz de representar este comportamento quando se utiliza Newton-Raphson.

Existem na literatura três métodos para a consideração do reforço no conjunto: homogeneização, discretização e embutimento (Figura 1). A homogeneização é mais apropriada para estruturas de superfície como cascas e placas, que permitem modelar o reforço como uma camada de membrana dentro da seção transversal. Para situações de reforços distribuídos de forma não uniforme, as técnicas de discretização e embutimento são mais apropriadas. Entretanto, é comum em técnicas de discretização a dependência da localização da malha do reforço com a malha da matriz, ocorrendo a dificuldade de geração das malhas do reforço, podendo até haver um constante processo de geração destas até que a essa condição seja satisfeita. Esse problema é ainda mais crítico em casos tridimensionais (Barzegar e Maddipudi, 1994).

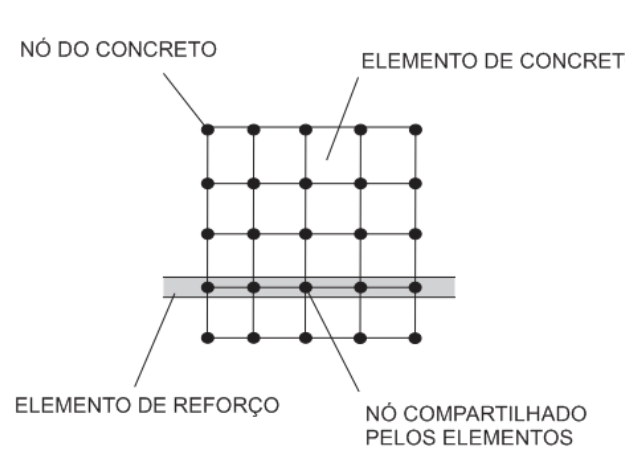

( a )

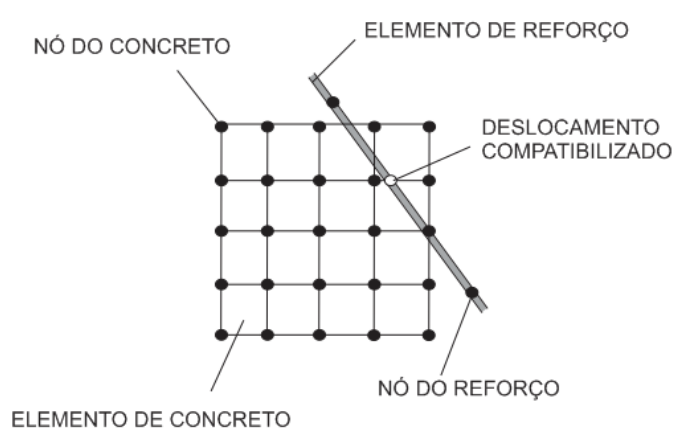

(b)

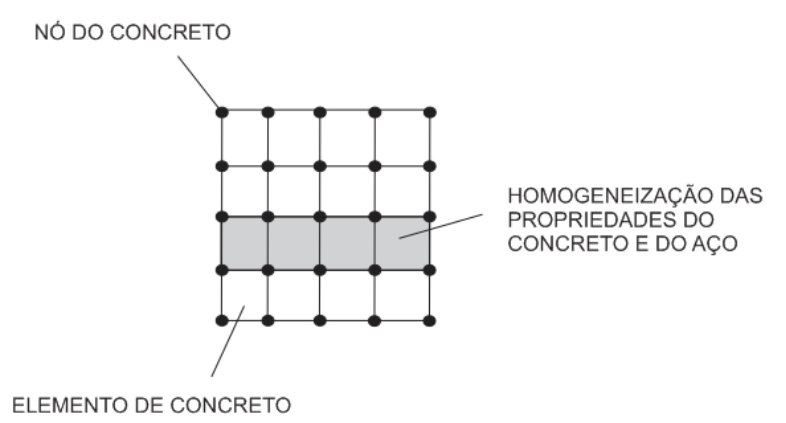

(c)

Figura 1 - a) discretização, b) embutimento, c) homogeneização (Adaptado: Azim et al., 2014) 
No presente trabalho, a formulação de elementos finitos utilizada é a posicional, introduzida pelos trabalhos de Bonet et al. (2000) e Coda (2003). Nesta, utilizam-se as posições como parâmetros nodais, diferindo inicialmente da abordagem clássica por deslocamentos, o que facilita bastante a consideração da não linearidade geométrica da estrutura. Através de uma descrição Lagrangiana Total, em que a configuração de referência adotada é a configuração inicial, o equilíbrio do sistema é estabelecido na posição atual, resultando em equações não lineares. Para a resolução destas, utiliza-se o método incremental-iterativo de Newton-Raphson. Adota-se também o uso da medida de deformação objetiva de Green-Lagrange, cujo conjugado energético é o tensor de tensões de PiolaKirchhoff de segunda espécie, na descrição da cinemática dos corpos.

Para a inserção do reforço no meio, a formulação utilizada é a proposta por Vanalli (2004) e encontrada em trabalhos como Vanalli, Paccola e Coda (2008), Vanalli et al. (2010), Nogueira et al. (2014), Moura (2015) e Pereira (2015). Esta técnica consiste em contribuir os efeitos da fibra para o elemento finito que representa a matriz, sem que haja aumento do número de graus de liberdade ou a necessidade de coincidência entre os nós dos elementos finitos da reforço e da matriz. Entretanto, este método não permite avaliar o deslizamento da fibra, que é considerada perfeitamente aderente.

Dependendo do tipo de fibra e da interface entre a fibra e a matriz, podem ocorrer os seguintes modos de falha: a fissura se desenvolve e a fibra é arrancada da matriz, ocorrendo a ruptura da matriz, ou as fissuras se propagam, mas são controladas pelas fibras. (Hameed et al., 2011)

O trabalho de Nogueira et al. (2014) utiliza alguns mecanismos para avaliar a ruptura da fibra ou ainda o deslizamento desta da matriz através da avaliação da tensão normal da fibra e da tensão de cisalhamento da interface entre a fibra e a matriz, estimando forças para avaliar o mecanismo de plastificação governante.

Com as formulações adotadas, o presente trabalho visa estudar o comportamento de estruturas reforçadas, a distribuição do reforço no meio, de forma aleatória ou alinhada. Considerando o comportamento elastoplástico de ambos, possibilita avaliar a perda de rigidez das estruturas, juntamente com uma redistribuição de esforços e, em alguns casos, a perda de instabilidade por formação de rótulas plásticas e a interação entres os elementos. 


\subsection{Objetivos}

Diante do que foi exposto, o presente trabalha visa implementar um elemento de sólido modelado bidimensionalmente com a discretização do reforço, podendo ambos serem analisados em regime plástico. Dessa forma, garantindo uma melhor representação do problema real de uma estrutura reforçada, visto que algumas técnicas utilizam a homogeneização da seção, ou seja, não havendo a discretização do reforço. A discretização do reforço permite tratar este como um elemento a parte e estudar sua interação com a estrutura. Além de dispensar a constante geração de malhas com a formulação utilizada.

Esse conjunto de ações visa um maior entendimento sobre os efeitos das fibras e sua inserção no meio, possibilitando uma contribuição ao meio científico, além de estimular o senso crítico do mestrando frente à produção científica.

Assim sendo, foram estabelecidos os seguintes objetivos específicos:

- implementação do código do elemento finito de chapa com a formulação posicional para representação da matriz;

- implementação do código do elemento finito de barra simples para representação do reforço;

- inserção da plasticidade tanto no meio como no reforço;

- realização de testes numéricos em casos de interesse para confirmar a correta implementação de todas as formulações utilizadas.

\subsection{Metodologia}

Inicialmente, foi realizada uma revisão bibliográfica sobre compósitos, tratando-se de diferentes tipos, mas destacando-se o reforçado por fibras. Com o intuito de situar o uso, propriedades e definições dos materiais compósitos. Posteriormente, apresentam-se as diversas técnicas e formulações utilizadas para representação do reforço do material compósito.

Aliada à revisão, foi feita uma preparação teórica na forma de um estudo sobre a teoria dos métodos numéricos, não linearidade física e geométrica; e sólidos deformáveis. Sendo esta etapa amplamente ligada ao curso das disciplinas oferecidas pelo Departamento de Engenharia de Estruturas da Escola de Engenharia de São Carlos. 
O elemento finito posicional utilizado é o encontrado no trabalho Coda e Paccola (2008), que tem como referência a configuração inicial, trantando-se portanto de um referencial Lagrangeano Total. Para o presente trabalho, foi adotada a aproximação cúbica para as posições. A implementação do código da matriz foi realizada como parte da disciplina Introdução à Dinâmica Não Linear de Estruturas Reticuladas Bidimensionais: Uma Abordagem Energética Baseada no Método dos Elementos Finitos, oferecida pelo programa de pós-graduação.

Posteriormente, foi implementado o código do reforço, empregando a formulação encontrada nos trabalhos de Vanalli (2004), Sampaio (2014) e Nogueira et al. (2014), tendo a verificação do código sido feita através de comparação com soluções técnicas (com hipóteses simplfificadoras) da Resistência dos Materiais.

Finalmente foi implementada a plasticidade tanto no meio quanto na fibra. A verificação foi feita através da comparação com o software Ansys para o elemento de chapa. Já para a verificação da plasticidade na fibra foi feita com a comparação com soluções técnicas, assim como na fase de implementação do próprio reforço.

A implementação de todo o código foi feita na linguagem FORTRAN. A geração da malha e a visualização dos resultados foram feitos com o auxílio, respectivamente, dos softwares livres AcadMesh e AcadView, disponíveis para acesso público no site do Departamento de Engenharia de Estruturas da Escola de Engenharia de São Carlos.

\subsection{Organização do texto}

O presente tópico visa descrever a organização do trabalho, esclarecendo a sequência e os assuntos de cada capítulo.

Esta introdução discutiu brevemente sobre a definição do que é material compósito e plasticidade, dando uma noção geral sobre os temas aqui abordados. Além de demonstrar as vantagens dos métodos utilizados, os objetivos do trabalho e os meios para que estes sejam alcançados.

A revisão bibliográfica sobre o assunto é feita no Capítulo 2, sendo dividida em quatro partes A introdução e aspectos gerais, em que se trata do compósito de forma geral, tipos, definições e aplicações. A segunda discorre sobre compósitos reforçados com fibras, tratando de suas especificidades, uso e de diversos trabalhos relacionados a este tipo de compósito, sejam experimentais, analíticos ou numéricos. A terceira parte trata da não linearidade 
geométrica, apresentando trabalhos com diferentes abordagens para o estudo do movimento de corpo. A última parte contém trabalhos que relacionem a plasticidade com materiais compósitos.

O elemento finito de chapa, utilizado para simular a matriz, é abordado no quarto capítulo. Apresentam-se suas formulações segundo o método posicional pela descrição Lagrangeana Total. Analogamente, é descrito, no Capítulo 5, o elemento finito de barra para simular o reforço e as técnicas de inserção na matriz.

O sexto capítulo apresenta conceitos sobre a plasticidade unidimensional e bidimensional, além de um algoritmo adotado para introdução desse fenômeno no código computacional desenvolvido. O Capítulo 7 apresenta diversos exemplos numéricos do trabalho de modo a validar e demonstrar as possibilidades de aplicação das diversas formulações adotadas e do programa desenvolvido. O oitavo e último capítulo apresenta as considerações finais acerca do trabalho e sugestões para trabalhos futuros. 


\section{ESTADO DA ARTE}

\subsection{Introdução e aspectos gerais}

Callister (2013) define que os materiais compósitos são materiais multifásicos com propriedades significativamente melhores em relação aos componentes de cada fase, obtendose uma combinação de propriedades que seja satisfatória ao uso que se pretende. O projeto de um material compósito pode ser feito para manipular as seguintes características: resistência estática e à fadiga, rigidez, resistência à corrosão e à abrasão, redução do peso, capacidade de trabalho a diferentes temperaturas, condutividade térmica, elétrica e acústica, dureza, ductilidade, aparência estética, entre outras.

A classificação dos materiais compósitos difere de autor para autor. Callister (2013) divide esses materiais em três grandes grupos. São eles: compósitos reforçados com fibras, reforçados com partículas e híbridos, conforme Figura 2. O autor indica ainda as características de cada tipo de material, fazendo um comparativo de vantagens e desvantagens entre os diferentes tipos, além de discutir sobre propriedades elétricas, magnéticas, ópticas e térmicas, sobre a corrosão e degradação e sobre a seleção e considerações a serem tomadas em projetos.

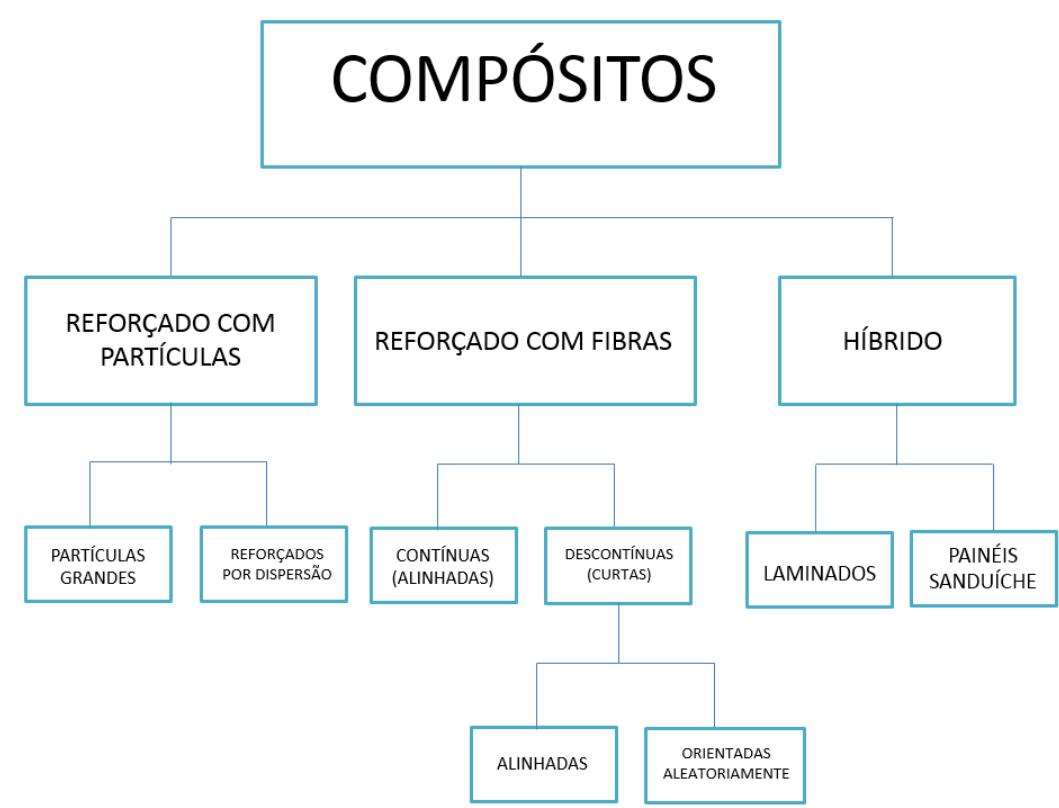

Figura 2 - Esquema de classificação dos vários tipos de compósitos

(Adaptado: Callister, 2013) 
Os materiais convencionais, apesar de características vantajosas, apresentam limitações, tais como. Os plásticos, por exemplo, apesar de sua baixa densidade, têm instabilidade térmica. As cerâmicas, apesar da baixa densidade, apresentam boa estabilidade térmica e boa rigidez, mas são de baixa ductilidade e difíceis de serem formados e moldados. Já os metais apresentam alta ductilidade e estabilidade térmica (esta consiste na capacidade do material de manter sua integridade sob mudanças de temperatura), mas têm média e alta densidade (HARRIS, 1999).

Os materiais compósitos, entretanto, apresentam grande versatilidade, o que tem conferido destaque em seu uso nos dias de hoje, devido ao fato de possuírem uma grande variedade de propriedades obtidas pela combinação entre diversos materiais, resultando um vasto campo de aplicações, que vão desde aplicações simples como bandejas farmacêuticas até aplicações estruturais como em aeronaves e perfis estruturais (CALLISTER, 2013).

Segundo Jones (1999), o uso de materiais compósitos tem evoluído muito desde os anos 60. Atualmente, quase toda companhia aeroespacial desenvolve materiais compósitos reforçados com fibras. Enquanto as ligas metálicas apresentam uma relação resistênciadensidade de 5:1, as fibras de plástico e metal podem apresentar uma relação de 16:1. Já é fato que as aeronaves apresentam alta porcentagem de componentes feitos de materiais compósitos.

Na indústria espacial, dois fatores muito importantes são a temperatura que o material atinge durante o lançamento e a redução de peso dado o custo que demanda o lançamento da estrutura ao espaço, sendo a baixa densidade uma das vantagens que o material compósito apresenta.

Ainda segundo o mesmo autor, no setor espacial, quando se deseja evitar qualquer tipo de interferência nos sinais eletromagnéticos, compósitos com fibras de grafite-epóxi podem ser usados, pois têm um coeficiente de dilatação térmica nulo, tornando-se assim ideais como componentes em grandes antenas, que estão constantemente submetidas ao sol e ainda devem manter sua estabilidade térmica.

Na indústria automobilística, os materiais compósitos apresentam uma alternativa de baixo custo e alta taxa de produção, quando comparada com as indústrias espacial e aeroespacial. Sendo que cerca de um quinto das partes dos automóveis são feitas com esses materiais (JONES, 1999).

No comércio em geral, a fibra de vidro pode ser utilizada na fabricação de varas de pescar, pranchas de surfe, barcos, raquetes de tênis, entre outros. Fibras de boro-epóxi e 
grafite-epóxi em golfe e raquetes de tênis, ainda que apresentem um sistema mais caro de produção (JONES, 1999).

\subsection{Compósitos reforçados com fibras}

Na construção civil, o compósito reforçado com fibras mais conhecido e utilizado é o concreto reforçado com fibras, sendo utilizado com fibras curtas ou longas. Para o concreto, são comumente utilizadas as fibras de aço e de polipropileno.

Estudos e definições de materiais compósitos são encontrados na literatura, como em Mehta e Monteiro (2006), tratando do concreto reforçado com fibras, destacando suas vantagens em relação ao concreto convencional. O reforço ocasiona aumento de tenacidade (energia), resistência ao impacto, maior ductilidade, um pequeno acréscimo de resistência, diminuição da propagação de fissuras, o que evita perda de rigidez e deformações maiores. E ainda que haja a propagação de fissuras, as fibras permitem que o concreto suporte fissuras maiores que o concreto convencional antes do rompimento (como ilustrado na Figura 3). Entretanto apresenta a desvantagem de diminuir a trabalhabilidade (capacidade de manusear e adensar o concreto), devendo-se assim estabelecer uma porcentagem ideal (ou ótima) de fibras a serem adicionadas ao concreto quando do seu uso.

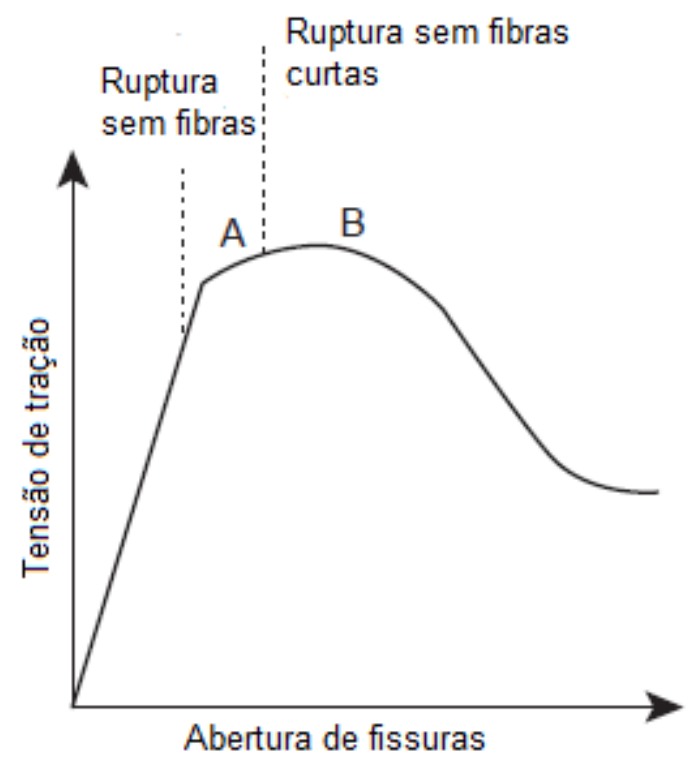

Figura 3 - Influência das fibras no concreto tracionado em diferentes estágios

(Fonte: Mehta e Monteiro, 2006) 
Compósitos reforçados por fibras podem conter fibras contínuas, longas ou curtas, podendo estar orientadas unidirecionalmente, bidirecionalmente ou ainda de forma aleatória, formando uma espécie de nuvem. Uma das vantagens de se utilizar um material na forma de fibra é que apresentam resistência à tração maior quando utilizados na forma de fibra, pois, tendo estas dimensões reduzidas, não se desenvolvem tantas falhas e fissuras, como ocorre em um sólido com maiores dimensões, além de que o próprio processo de produção das fibras torna a estrutura do material mais organizada (MENDONÇA, 2005).

Ainda de acordo com Mendonça (2005), existem vários tipos de fibras, sendo algumas delas: vidro; carbono e grafite; aramida; amianto. As fibras de vidro apresentam baixo custo em relação às demais fibras e alta relação resistência/densidade, mas apresentam baixa relação módulo de elasticidade/densidade, baixa resistência à abrasão (o que reduz a resistência à ruptura), baixa adesão às resinas.

As fibras de carbono e de grafite diferem uma da outra pelo percentual de carbono, sendo uma com mais de $98,8 \%$ e a outra entre $80 \%$ e $95 \%$, respectivamente. Em relação às fibras de vidro, essas apresentam maior rigidez, maior resistência às altas temperaturas e menor densidade, porém possuem um custo maior, mesmo que esse tenha diminuído devido ao crescimento da produção e demanda mundial. São predominantemente utilizadas em aplicações de alto desempenho, tendo sido empregadas inicialmente na indústria aeroespacial, mas difundindo-se para outras áreas. Perante inúmeros tipos de fibras encontrados, cada um com suas vantagens e desvantagens em relação aos outros, cabe ao projetista do material compósito analisar e assim escolher o tipo de fibra que melhor se encaixa em suas necessidades.

O concreto, por exemplo, é um material frágil quando submetido à tração e com pouca capacidade de deformação, sendo que o reforço por fibras tem a principal finalidade de controle de fissuração da matriz e melhorar seu desempenho (BENTUR E MINDESS, 2007).

A matriz faz a ligação de todas as fibras, mantendo-as alinhadas nas direções das tensões mais importantes. Os carregamentos são transferidos às fibras através da matriz, permitindo que o compósito seja capaz de suportar carregamentos de compressão, flexão, cisalhamento e até de tração. (HARRIS, 1999)

O estudo experimental dos materiais compósitos se faz indispensável tanto para a comprovação de teorias e métodos já desenvolvidos sobre a mecânica desses materiais, quanto para auxílio no entendimento de seu comportamento e posterior desenvolvimento de novas teorias cada vez mais refinadas. 
Magagnin Filho (1996) apresenta um estudo de placas laminadas em materiais compósitos de fibras longas no qual se constatou por simulações numéricas que o comportamento mecânico destes compostos deve ser analisado pela micromecânica, relacionando-a com a análise macromecânica. Ao analisar a resistência obtida pelas simulações, obteve-se uma predominância de ruptura devido às tensões longitudinais para ângulos pequenos de inclinações das fibras, predominância da ruptura devida às tensões transversais às fibras para fibras com grandes ângulos de inclinação e predominância da ruptura por tensões tangenciais para as fibras com ângulos intermediários.

Furlan (1995) realizou ensaios em vigas de concreto de seção quadrada e de duplo T com taxas reduzidas de armaduras de cisalhamento, avaliando a possibilidade de melhoria no desempenho, pelo uso de fibras curtas de aço e propileno e pela aplicação de protensão. A análise de pilares de concreto, com adição de fibras metálicas, submetidos à compressão centrada foi feita por Guimarães (1999). Bastos (1999) apresenta um estudo experimental do comportamento de dormentes de concreto protendido reforçados com fibras de aço. O estudo da resistência e ductilidade das ligações laje-pilar em lajes-cogumelo de concreto de alta resistência armado com fibras de aço e armadura transversal de pinos pode ser encontrado em Azevedo (1999). Já Ekane (1999) estudou a fissuração em concreto armado com fibras e armadura convencional.

A análise de mecanismos resistentes e das similaridades de efeitos da adição de fibras de aço na resistência e na ductilidade à punção de lajes-cogumelo e ao cisalhamento de vigas de concreto foi feita por Holanda (2002). Reis (2003) estudou o reforço de vigas de concreto armado submetidas à pré-carregamento e ações de longa duração com aplicação de concretos de alta resistência e concretos de fibras de aço.

O estudo experimental da superfície de falha em concretos usuais, de alta resistência e reforçados com fibras é realizado por Seow e Swaddiwudhipong (2005). Foram testados concretos entre 20 e $130 \mathrm{MPa}$. O modelo analítico da superfície de falha do concreto simples foi modificado para considerar a presença de fibras metálicas.

Ferrari (2007) estuda o reforço à flexão de vigas de concreto armado com manta de polímero reforçado com fibras de carbono aderido a substrato de transição constituído por compósito cimentício de alto desempenho. O reforço e incremento da rigidez à flexão de ligações de concreto pré-moldado com polímero reforçado com fibras de carbono são estudados por Fonseca (2007), enquanto que o estudo da fluência em vigas de concreto reforçado com fibras de aço é feito por Miller (2008). Já Arquez (2010) estuda a aplicação de 
polímero reforçado com fibras de carbono inserido em substratos de microconcreto com fibras de aço para reforço à flexão de vigas de concreto armado.

Na literatura, são encontrados modelos analíticos desenvolvidos para a representação do comportamento de materiais compósitos reforçados por fibras, sendo estes geralmente limitados ou restritos devido às geometrias utilizadas nas deduções, demandando ainda trabalho excessivo para implementações.

A determinação do módulo de elasticidade efetivo de um compósito assumido como isotrópico e homogêneo em termos das frações volumétricas e módulos de elasticidade dos materiais constituintes é realizada por Hashin e Shtrikman (1963). O módulo efetivo foi definido por via de energia de deformação armazenada no material quando submetido à deformação ou tensão uniforme.

O comportamento de duas fases sólidas firmemente ligadas é estudado por Hill (1964), não havendo restrição no tipo de geometria da inclusão a ser feita na matriz, podendo ser fibrosa, esférica ou semelhante à chapa. Por considerar a tarefa de determinação dos campos de tensões para formatos e concentrações arbitrárias, apenas as propriedades elásticas macroscópicas foram determinadas, tais como: dependência do módulo de elasticidade perante as concentrações, o arranjo e grau da organização, a distribuição dos tamanhos de um determinado formato de fibra.

Naaman et al. (1991) realizam o estudo da ligação entre a fibra e a matriz com a implementação de um modelo matemático que descre a resposta de materiais cimentícios com fibras embutidas quando solicitados pela carga de arrancamento das fibras, pois até então não havia modelo analítico completo sobre o assunto.

Como o concreto é um material pouco resistente à tração, Li e Li (2001) desenvolvem um modelo analítico de dano em concreto reforçado com fibras submetido à tração unidirecional.

Os trabalhos numéricos, por sua vez, apresentam a possibilidade de estudo do comportamento mecânico destes materiais de forma menos onerosa, visto que seus custos são computacionais, promovendo assim uma alternativa interessante e cada vez mais viável com o avanço dos métodos numéricos e na tecnologia da computação.

No Brasil, os primeiros registros de trabalhos com elementos finitos datam da década de 60 em São Paulo e visavam analisar a eficiência do método, ainda pouco divulgado na época.

Ainda com o avanço tecnológico e nos métodos numéricos, muito esforço é despendido na tentativa de diminuir o custo computacional, principalmente em casos 
tridimensionais. Seja através da paralelização dos códigos, da formulação aplicada ou até do tipo de elemento finito adotado, como em casos que se pode representar satisfatoriamente uma estrutura por um elemento finito bidimensional ao invés do tridimensional.

Como visto anteriormente, dependendo da formulação adotada, um dos problemas encontrados é a necessidade da coincidência entre nós, que acaba gerando a necessidade de um constante processo de geração de malha, aumentando assim o custo computacional.

De modo a evitar a necessidade da coincidência entre nós do reforço e da matriz, Barzegar e Maddipudi (1994) adotam uma formulação, denominada de embutida, possibilitando qualquer ângulo entre o reforço e os eixos locais do elemento finito isoparamétrico bidimensional adotado.

Peng e Meyer (2000) adotam um escalar variável de dano para evitar a complexidade do método analítico. O modelo tratado por eles considera o efeito da fibra no dano e tensão volumétrica na resposta desviadora inelástica. Os autores ainda fizeram as seguintes considerações: o dano ocorre no começo das deformações inelásticas numa taxa inicialmente muito baixa e acelera conforme o processo dessas deformações, sendo que a evolução do dano está associada ao presente estado de tensões.

A formulação proposta por Vanalli (2004) consiste em uma técnica para a consideração do reforço da fibra sem que haja a coincidência de nós entre fibra e matriz, sendo válida apenas para fibras tidas como perfeitamente aderentes, já que as posições podem ser escritas em função dos parâmetros do elemento finito bidimensional. Calcula-se a hessiana e a força interna do elemento de fibra, realizando então uma compatibilização entre os graus de liberdade da fibra com a da chapa, multiplicando-se pelas funções de forma do elemento finito da matriz. Em seguida, pode-se realizar a contribuição normalmente pela incidência na hessiana e força interna do elemento finito da matriz.

Pasa (2007) estuda o comportamento de estruturas de concreto reforçado com fibras metálicas pelo método dos elementos finitos, considerando leis elastoviscoplásticas e elastoplásticas, além de considerar a fissuração do concreto.

Dutra et al. (2010) estudam aspectos constitutivos do concreto reforçado com fibras com ênfase na fluência dos materiais. O comportamento linear elástico foi examinado pela implementação do esquema de homogeneização de Mori-Tanaka. A validação dos conceitos micromecânicos foi feita segundo comparações com experimentos.

O tratamento discreto das fibras permite o estudo da influência da distribuição dessas na matriz. O tratamento da discretização das fibras é feito de forma não explícita por Radtke, Simone e Sluys (2010), sendo modeladas através da aplicação de uma força na malha. Esta 
força representa a interação entre as fibras e a matriz, sendo as forças consideradas iguais à força de arrancamento no intuito de incorporar ao modelo informações acerca da interface fibra-matriz. O concreto foi modelado como linear elástico com surgimento de fissuras a partir de lugares frágeis como poros, defeitos e outras fissuras existentes à medida que o carregamento vai aumentando.

A consideração de um tensor de dano baseado no conceito de tensão efetiva, que representa a degradação média do material referente ao dano em micro-escala, é utilizada por Voyiadjis e Kattan (2010) para posterior comparação entre a mecânica de pequenos danos com a mecânica do dano contínuo em materiais compósitos reforçados com fibras. As fibras foram consideradas perfeitamente alinhas e contínuas com aderência perfeita com a matriz.

O uso de um modelo de dano associado ao concreto reforçado com fibras deslizantes por Hameed et al. (2013) com o objetivo de demonstrar que se um modelo de concreto simples é capaz de determinar a fissuração localizada de forma realista em elementos tridimensionais, então é possível criar uma lei constitutiva de concreto reforçado com fibras usável nesses casos. Em seu trabalho, os autores consideram que a fibra só começa a contribuir no sistema a partir do momento em que há fissuração.

Nogueira et al. (2014) realizam o estudo de compósitos reforçados com fibras aderentes e deslizantes, comparando os resultados obtidos entre as fibras elásticas e fibras elastoplásticas. Através da consideração de um elemento de contato entre a fibra e a matriz e da técnica de penalização, foi possível desenvolver um deslocamento relativo entre os diferentes tipos de elementos finitos, modelados, respectivamente, como barra simples e chapa.

No campo da biomecânica, há trabalhos de fibras para simular tecidos, como mostram os trabalhos de Pandolfi e Vasta (2012) e Vasta, Gizzi e Pandolfi (2013, 2014). Lanir (2014) desenvolveu uma teoria mecânica para simular o crescimento de tecidos macios e seu remodelamento, baseada nas propriedades e cinemática da dobra de cada constituinte, considerando fibras unidirecionais. Lanir e Nanami (2015) estudam a confiabilidade de tensores na representação da estrutura de tecidos macios através da comparação entre os dados obtidos pela representação de tensor com uma forma alternativa de representação por séries de Fourier. 


\subsection{Não linearidade geométrica}

Com o avanço na tecnologia dos materiais, tal como o uso de materiais compósitos, tem-se alcançado resistências cada vez maiores, o que possibilita diminuir as dimensões das peças para uma mesma solicitação, resultando assim em menores gastos com materiais. Entretanto, a diminuição das dimensões torna a estrutura mais esbelta e suscetível ao fenômeno de instabilidade devido aos maiores deslocamentos e bifurcações.

Sendo assim, de modo a garantir a segurança e desempenho dos projetos e seus materiais constituintes, estudos foram realizados para obter um maior entendimento do comportamento das estruturas sob o efeito da não linearidade geométrica.

Kant e Kommineni (1992) estudam o comportamento linear e o não linear geométrico de compósitos reforçados com fibras com uma descrição Lagrangeana Total e um elemento finito quadrilátero de classe $C^{0}$.

Ao utilizar a função de von Karman, Chandrashekhara e Bangera (1993) incorporam em sua formulação a não linearidade geométrica para que então fosse realizado o estudo de vigas laminadas reforçadas com fibras deformações por cisalhamento de alta ordem.

A formulação de elementos finitos posicional é introduzida nos trabalhos de Bonet et al. (2000) e Coda (2003), que estuda grandes deslocamentos em membranas e pórticos planos, respectivamente. Nesta formulação, os parâmetros nodais passam a ser as posições dos nós em detrimento aos deslocamentos com uma descrição Lagrangeana Total.

Outros trabalhos contribuem para a disseminação deste método: análise dinâmica de multi-corpos flexíveis por Greco e Coda (2006); análise de treliça espacial por Greco et al. (2006); análise não linear geométrica de estruturas formadas por cascas por Coda e Paccola (2008); análise não linear com impacto de domínios elásticos bidimensionais por Marques (2006); análise não linear geométrica de impacto bidimensional entre estruturas reticuladas e anteparo rígido curvo por Minski (2008); análise não linear geométrica de problemas modelados por pórticos planos e sólidos tridimensionais por Maciel (2008); consideração do deslizamento na análise de sólidos elásticos bidimensionais reforçados por fibras por Nogueira et al. (2014); análise não linear geométrica de cascas laminadas reforçadas com fibras por Sampaio (2014); modelagem de pórticos planos constituídos por compósitos laminados por Nogueira (2015); e análise elástico de meios bidimensionais de compósitos particulados por Moura (2015). 
Panda e Ray (2009) desenvolveram a formulação de um elemento finito para análise não linear dinâmica de compósitos laminados com gradação funcional com uma camada restringida para amortização. Esta é feita de um material compósito piezoelétrico reforçado com fibra. Análises foram feitas para investigar o desempenho da constritora para controle de vibrações não lineares nesses compósitos.

Rafiee et al. (2014) estudam a vibração livre não linear geométrica de compósitos com nanotubos/fibras/polímeros de carbono, utilizando a teoria de deformação por cisalhamento de primeira ordem em placas. Com a utilização da função de von Karman para a consideração da não linearidade geométrica.

\subsection{Não linearidade física}

Quando os níveis de tensões atingem valores críticos, acontece a dissipação de energia, caracterizada por deformações irreversíveis, a chamada plasticidade. Assunto debatido na literatura, como em Khan e Huang (1995), Lubliner (2005) e Doltsinis (2010).

O comportamento elastoplástico fica evidente ao analisar ciclos de deformação e tensão, pois surgem deformações ou tensões residuais, que são irreversíveis, devido à dissipação de energia. Em qualquer um dos ciclos, considera-se que o descarregamento se dê por uma reta com inclinação igual a da resposta elástica. Nos modelos elásticos, a relação tensão-deformação é biunívoca, ou seja, cada nível de deformação está sempre associado a um único nível de tensão. Para o modelo elastoplástico, deve-se conhecer a "história” da deformação plástica para a determinação da intensidade da tensão associada à certa deformação (Khan e Huang, 1995).

Feenstra e Borst (1996) formularam um critério de plastificação de compósito para uso em concreto simples e concreto reforçado, em particular com o estado biaxial de traçãocompressão. Este caso é muito comum nas regiões críticas, como viga com alto cisalhamento, e início de propagação de fissura que podem levar a um colapso progressivo e frágil em estruturas de concreto.

Embora a fibra confira propriedades com significativa melhoria ao compósito, pode gerar concentrações de tensão que resultem em deformações plásticas, o que não aconteceria numa matriz não reforçada. Por essa razão, Fish et al. (1997) desenvolveram uma formulação de plasticidade para compósitos através de uma técnica de homogeneização matemática. 
Utilizando um elemento finito de casca plana em camadas para representação do concreto reforçado com fibras e baseado na teoria da viscoplasticidade, Cachim (2002) realiza a modelagem numérica da fadiga de concreto reforçado com fibras submetido à flexão, subtituindo o comportamento dependente do tempo por um comportamento cíclico.

Encontram-se também trabalhos como o de Vanalli (2004) que trata do método dos elementos de contorno e o método dos elementos finitos aplicados à análise de problemas viscoplásticos em meios anisotrópicos e ortotrópicos. Paccola (2004), que trata da análise não linear física de placas e cascas anisotrópicas laminadas acopladas ou não com meio contínuo tridimensional viscoleástico através da combinação entre o método dos elementos finitos e o método dos elementos de contorno. O uso de modelos constitutivos não lineares para materiais com gradação funcional exibindo grandes deformações é encontrado em Pascon (2012).

Devido ao seu grande limite elástico, os compósitos de aço com vidro metálico têm ganhado destaque em seu uso. Entretanto, logo após a plastificação proveniente pela propagação de bandas de cisalhamento altamente concentrada, o material falha. Com isto em vista, Shakur Shahabi et al. (2014) estudam uma maneira de melhorar o comportamento do compósito após plastificar sob compressão. Os autores utilizaram um aço disponível comercialmente para fortalecer o vidro metálico.

Além da plastificação, os crescentes níveis de tensão podem ocasionar a aparição de fissuras, tema estudado pela mecânica do dano. Assunto presente em estudos como de Yazdani e Schreyer (1990) que tratam de um modelo de plasticidade e dano para o concreto simples. Maire e Chaboche (1997) que propõem uma nova formulação para mecânica do dano em materiais compósitos. A análise do comportamento dinâmico não linear de vigas com emprego de dano pode ser vista em Araújo (2003).

O presente trabalho utiliza as formulações de elementos finitos para a chapa e para o reforço encontradas de forma mais específica em trabalhos como Coda e Paccola (2010), Sampaio (2014); além de avaliar o mecanismo de plastificação do reforço conforme Nogueira et al. (2014), associados à formulação proposta por Mesquita (1998) para avaliação da plasticidade geral na chapa. Com isto, é possível analisar o comportamento elastoplástico da matriz e de seu reforço, sendo este disposto de forma alinhada ou até mesmo gerado aleatoriamente no domínio da estrutura. 


\section{EQUILÍBRIO NÃO LINEAR GEOMÉTRICO}

\subsection{Considerações iniciais}

As estruturas projetadas e encontradas habitualmente apresentam uma relação linear entre carregamento aplicado e a deformação sofrida. Entretanto, as estas podem não mais apresentar este comportamento, apresentando não linearidade que pode ser de natureza física, geométrica e de contato. A não linearidade geométrica inclui a mudança de comportamento da estrutura à medida que se desloca, dependendo de fatores como a geometria, condições de contorno e condições de carregamento.

Apesar do sucesso da suposição da linearidade na análise de engenharia, há situações que a superposição de efeitos deixa de ser válida e demandam a consideração deste tipo de não linearidade: análise do estado limite último de estruturas envolve a não linearidade física e talvez geométrica; a instabilidade estrutural é um fenômeno inerentemente não linear geométrico; o comportamento do corpo humano, quando em situações como de impacto, apresenta ambos os tipos de não linearidade (Bonet e Wood, 1997). Portanto, em certas situações, a desconsideração do caráter não linear geométrico, que as estruturas podem apresentar, possibilita a ocorrência de um comportamento não previsto e projetado, resultando na subestimação das deformações, tensões e da configuração de equilíbrio, que podem levar à ruína do sistema, especialmente por perda de estabilidade.

A escolha da suposição de estruturas lineares se dá, portanto, pelas simplificações resultantes em seus cálculos. Entretanto, a análise não linear das estruturas é certamente mais exata e, com o avanço dos métodos numéricos e da tecnologia, o custo computacional para cálculo dessas estruturas tem diminuído gradativamente.

Há dois métodos de formulação para descrição de movimento de um corpo amplamente divulgados. A descrição material ou lagrangeana possui como variáveis independentes as partículas ou pontos do corpo e o tempo, sendo conceitualmente a descrição mais natural. A descrição espacial possui a localização atual da partícula e o tempo como suas variáveis independentes, sendo também conhecida como descrição Euleriana (Gadala e Oravas, 1984).

A Mecânica dos Fluídos trabalha usualmente com a descrição espacial, pois não é apropriada a descrição do comportamento de uma partícula material em situações como escoamento estacionário. Isto é devido ao fato de que o fluído pode apresentar deformações muito superiores ao do sólido. Mecanismos sólidos, por sua vez, geralmente em algum estágio 
da formulação, deverão considerar o comportamento constitutivo da partícula material, o que envolve a descrição material (Bonet e Wood, 1997).

Portanto, dependendo do tipo de problema tratado, uma determinada formulação de descrição de um corpo pode apresentar vantagens ou desvantagens em relação a outras. Sendo que, em geral, para a descrição do comportamento não linear geométrico dos elementos finitos, a descrição Lagrangeana é mais utilizada, sendo uma descrição material.

Há três principais tipos de descrições lagrangenas. A descrição Lagrangeana Total, em que a deformação do elemento é medida pela configuração inicial como referência e apresenta a desvantagem de não poder distinguir deslocamento de corpo rígido de deformação local. A descrição Lagrangeana Atualizada, em que a configuração atual do elemento é a de referência. E por fim a descrição Lagrangeana Parcialmente Atualizada, que difere da Lagrangeana Atualizada pela atualização das coordenadas dos elementos ser feita apenas no início de cada passo de carga (Wong e Tin-Loi, 1990).

A descrição Parcialmente Atualizada porposta por Peterson e Petersson (1985) foi desenvolvida como uma forma de diminuir o custo e demonstrar que a Descrição Lagrangeana Atualizada pode apresentar erros significativos, principalmente em estruturas delgadas como vigas e cascas finas, ao negligenciar a contribuição das deformações locais dos elementos.

A precisão das soluções dos passos atuais da formulação Lagrangeana Total não é afetada pela precisão das soluções obtidas pelo passo anterior, e os deslocamentos, tensões e deformações obtidas não precisam de transformação antes da atualização. Em geral, os passos de carga nesta formulação são geralmente maiores que na Lagrangeana atualizada, pois a atualizada apresenta uma limitação referente ao método utilizado para aproximar grandes rotações. Para a formulação total, não deverá haver perda de precisão para passos de carga grandes arbitrários em uma solução incremental/iterativa (Pai, Anderson e Wheater, 2000).

Segundo Miller et al. (2006), a grande maioria dos softwares comerciais de elementos finitos utiliza a formulação Lagrangeana atualizada com tensões de Cauchy e deformação de Almans. Inicialmente, a formulação Total não era tão utilizada quanto a Lagrangeana Atualizada, pois apresenta um custo computacional maior e na época de desenvolvimentos dos códigos, a memória era custosa e causava mais problemas do que a velocidade das computações dos dados.

Os mesmos autores falam que a vantagem da formulação atualizada é a simplicidade da descrição incremental da deformação. A desvantagem é que todas as derivadas 
relacionadas às coordenadas espaciais devem ser recomputadas a cada passo, pois a configuração de referência muda.

A formulação Lagrangeana Total apresenta a vantagem de que todas as derivadas em relação às coordenadas espaciais são calculadas para uma configuração de referência fixa, necessitando serem computadas apenas uma vez. A desvantagem é a impossibilidade de distinguir a deformação do movimento e giro de corpo rígido.

A formulação Total utiliza tensões de Piola-Kirchhoff e deformação de Green e por isso, segundo Crisfield (2000), é apropriada para grandes rotações e pequenas rotações, podendo ser aplicada nos casos elastoplásticos para pequenas deformações plásticas.

Desta maneira, a escolha da decomposição aditiva das parcelas de deformação no regime elastoplástico, que permite representar pequenas e moderadas deformações plásticas, entra em consonância com a formulação Lagrangeana Total.

A deformação de Green, utilizada no presente trabalho, é indicada para situações de não linearidade geométrica. O uso de uma medida de deformação correta é essencial, pois, dependendo da medida de deformação utilizada, ao impormos um movimento ou giro de corpo rígido, nenhum tipo de deformação deverá aparecer.

É fácil demonstrar que a medida de deformação de engenharia somente é válida para situações de pequenos deslocamentos, cujas posições inicial e final são praticamente as mesmas.

Bonet e Wood (1997) demonstram (Figura 4) em um corpo que sofre uma rotação de corpo livre de 90 graus para a esquerda. Durante este giro de corpo rígido, o ponto $P$ se deslocou horzontalmente para a esquerda $u_{x}=-X-Y$ e verticalmente para baixo $u_{y y}=X-Y$ :

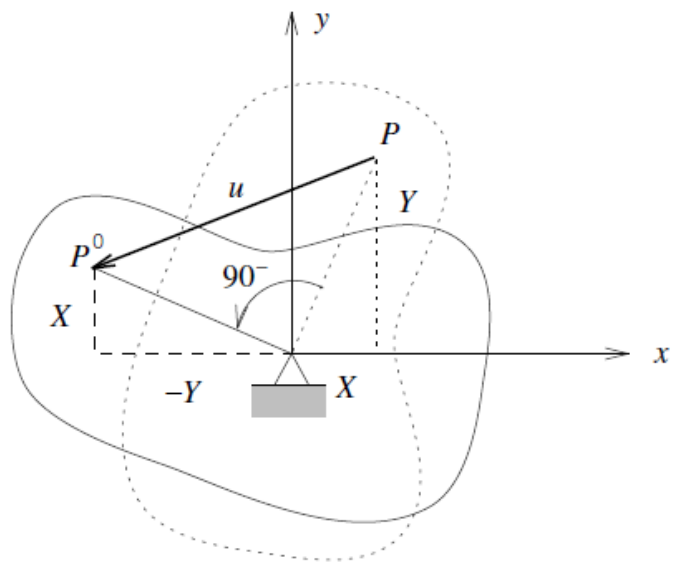

Figura 4 - Rotação de 90 graus de um corpo bidimensional (Fonte: Bonet e Wood, 1997) 
Dadas as seguintes equações que relacionam a deformação de engenharia em $\varepsilon$ com os deslocamentos $u$ :

$$
\begin{gathered}
\varepsilon_{x x}=\frac{\partial u_{x}}{\partial x} \\
\varepsilon_{y y}=\frac{\partial u_{y}}{\partial y} \\
\varepsilon_{x y}=\frac{1}{2}\left(\frac{\partial u_{x}}{\partial y}+\frac{\partial u_{y}}{\partial x}\right)
\end{gathered}
$$

é possível calcular o campo de deformações pelas equações 3.1, 3.2 e 3.3 e obter $\varepsilon_{x x}=\varepsilon_{y y}=-1$ e $\varepsilon_{x y}=0$. Ao avaliar as deformações obtidas, nota-se um estado não condizente com a realidade, pois o giro de corpo rígido não ocasiona o surgimento de tensões e deformações, o que leva à conclusão que a medida de deformação linear de engenharia não é adequada à situação.

\subsection{Formulações do equilíbrio não linear geométrico}

Os desenvolvimentos apresentados neste item podem ser encontrados mais detalhadamente nos trabalhos de Holzapfel (2000), Coda e Paccola (2008), Sampaio (2014).

\subsubsection{Configuração inicial}

Um corpo contínuo está contido no espaço Euclidiano tridimensional. As posições de suas partículas no espaço em um dado instante $t=0$, prévio a qualquer ação de forças os movimentos de corpo rígido, denotam uma configuração tida como $\Omega_{0}$, conhecida como configuração indeformada.

A configuração $\Omega_{0}$ é a configuração inicial e, ao tratar da formulação Lagrangeana Total, é a configuração de referência fixa, portanto, serão sempre iguais. A partícula nesse dado instante é denotada pela coordenada material $\vec{X}$. 


\subsubsection{Configuração atual}

Para o mesmo corpo contínuo em um dado instante posterior $t$, as posições de suas partículas apresentam a configuração $\Omega$, conhecida como configuração atual.

A configuração $\Omega$ varia de acordo e pode assumir infinitas formas. Para esta configuração, a partícula do corpo é identificada pelo vetor posição $\vec{Y}$ em relação à origem.

\subsubsection{Mapeamento e função mudança de configuração}

Um estado auxiliar adimensional é usado para o mapeamento de um ponto do corpo através de funções denotadas respectivamente por $\vec{f}^{0}$ e $\vec{f}^{1}$. Ambas podem ser escritas como funções dependentes de coordenadas adimensionais $\xi_{i}, i=1,2,3$ e das funções de forma $\phi_{n}$, com $n$ indicando o somatório sobre os nós do elemento finito (notação indicial):

$$
\begin{aligned}
& f_{i}^{1}=Y_{n}^{i} \phi_{n}\left(\xi_{1}, \xi_{2}, \xi_{3}\right) \\
& f_{i}^{0}=X_{n}^{i} \phi_{n}\left(\xi_{1}, \xi_{2}, \xi_{3}\right)
\end{aligned}
$$

Para um instante $t>0$ a configuração assume o valor da configuração atual. Seus pontos no espaço podem ser escritos por uma função mudança de configuração $\vec{f}$ que realiza transição do corpo da configuração inicial para seu ponto de equilíbrio na configuração atual, assim como ilustrado na Figura 5:
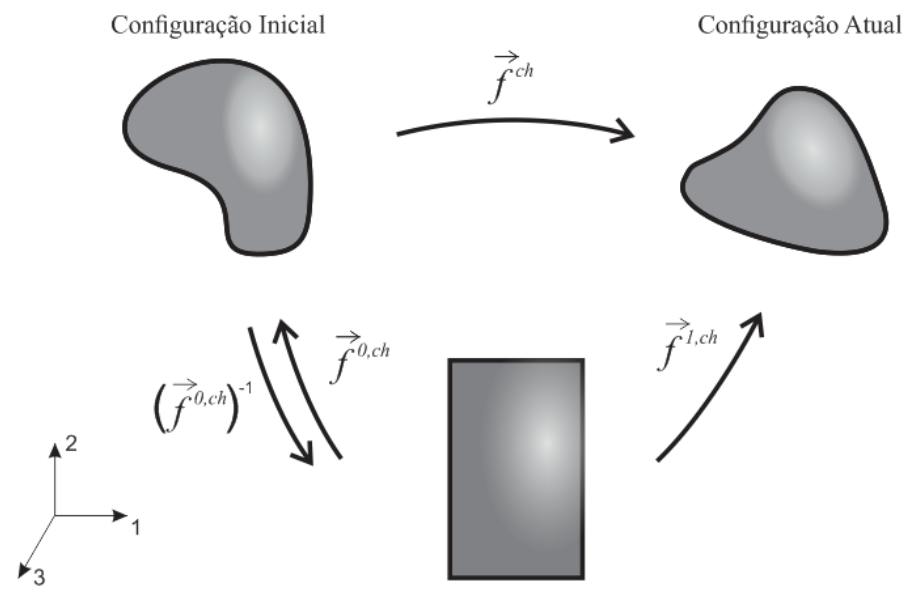

Configuração Auxiliar

Figura 5 - Configurações de um corpo, função mudança de configuração e funções de mapeamento 
É possível relacionar a função mudança de configuração $\vec{f}$ com as funções de mapeamento. Como ambas utilizam a configuração auxiliar para mapear as configurações, é possível fazer o caminho inverso do mapeamento da configuração inicial, chegando assim ao corpo adimensional auxiliar, e posteriormente utilizando o mapeamento da configuração atual. Em outras palavras, relacionam-se assim as configurações inicial e final da seguinte forma:

$$
\vec{f}=\vec{f}^{1} \circ\left(\vec{f}^{0}\right)^{-1}
$$

\subsubsection{Energia Total do Sistema}

Segundo a Primeira Lei da Termodinâmica, em um sistema conservativo, desconsiderando-se a contribuição da energia cinética e sendo o sistema, sua energia total é dada por:

$$
\Pi=W+P
$$

Sendo $\Pi$ a energia total do sistema, $W$ a energia de deformação acumulada no sistema e $P$ o trabalho realizado pelas forças aplicadas. Ambos escritos em função das posições, sendo:

$$
P=-F_{i}^{n} Y_{i}^{n}
$$

Em que $F_{i}^{n}$ são as forças externas aplicadas e $Y_{i}^{n}$ são as posições em que as respectivas forças estão sendo aplicadas.

\subsubsection{Resolução do sistema não linear}

Sendo as forças aplicadas conservativas, ou seja, independentes das posições de atuação, utiliza-se o princípio da energia total estacionária, $\delta \Pi=0$, na equação (3.7) para estabelecer o equilíbrio do sistema. Deste, resulta uma equação não linear: 


$$
\vec{g}=\frac{\partial \Pi(\vec{Y})}{\partial \vec{Y}}=\frac{\partial W}{\partial \vec{Y}}-\vec{F}=\vec{F}^{\text {int }}-\vec{F}=\overrightarrow{0}
$$

O termo $\vec{F}^{\text {int }}$ é o vetor das forças internas do elemento finito, dado pela primeira derivada da energia de deformação, e $\overrightarrow{\boldsymbol{g}}$ é o vetor de desbalanceamento mecânico, que deve ser nulo na posição de equilíbrio do sistema. Com as forças conservativas, a única configuração do corpo que resulta um mínimo na energia total do corpo é a configuração de equilíbrio e $\partial \vec{F} / \partial Y=0$.

Para a resolução do sistema não linear, utiliza-se a técnica incremental-iterativa de Newton-Raphson através de uma expansão em série de Taylor da expressão 3.9:

$$
g\left(\overrightarrow{\mathrm{Y}}_{k+i}\right)=g\left(\vec{Y}_{k}\right)+\left.\frac{\partial \vec{g}}{\partial \vec{Y}}\right|_{\vec{Y}_{k}} \Delta \vec{Y}_{k+i}+\vec{O}^{2}=0
$$

Desprezando o termo de ordem superior, a equação 3.10 pode ser reescrita como:

$$
\Delta \vec{Y}_{k+1}=-\left(\left.\frac{\partial \vec{g}}{\partial \vec{Y}}\right|_{\vec{Y}_{k}}\right)^{-1} g\left(\vec{Y}_{k}\right)
$$

O operador tangente do problema é a matriz hessiana dada por:

$$
H=\frac{\partial W}{\partial \vec{Y} \partial \vec{Y}}=\left.\frac{\partial \vec{g}}{\partial \vec{Y}}\right|_{\vec{Y}_{k}}
$$

Ao calcular o increment de poisção $\Delta \vec{Y}_{k+i}$, atualiza-se a solução tentativa:

$$
\vec{Y}_{k+1}=\vec{Y}_{k}+\Delta \vec{Y}_{k+1}
$$

Como o procedimento de Newton-Raphson é iterativo, o processo é repetido até que o incremento de posição ou o desbalanceamento sejam suficientemente pequenos para 
atenderem à tolerância estabelecida. O método consiste em calcular a derivada em um ponto conhecido, calculando o incremento no valor da posição para que seja satisfeita a equação de equilíbrio. A Figura 6 - Representação gráfica do método de Newton-RaphsonFigura 6 representa o esquema gráfico do processo de convergência por Newton-Raphson para um grau de liberdade:

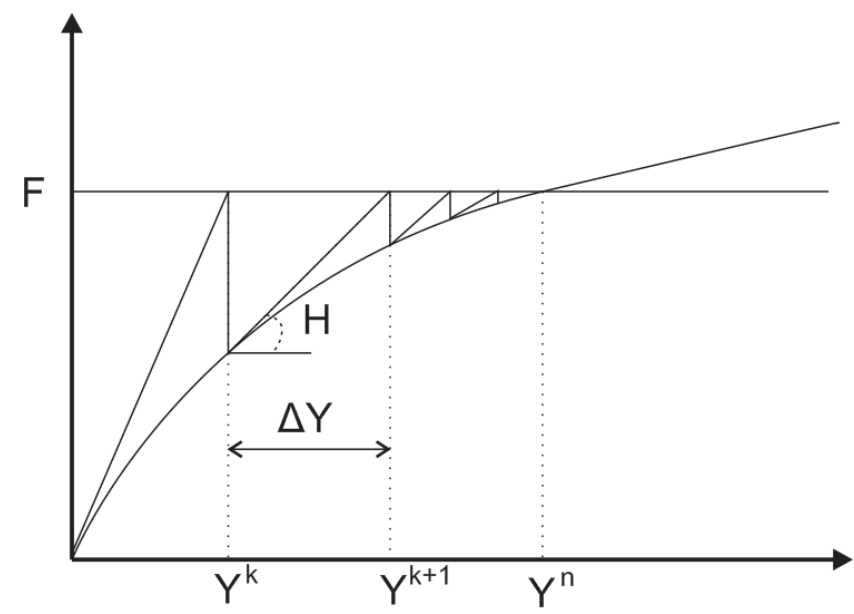

Figura 6 - Representação gráfica do método de Newton-Raphson

Para avaliar a convergência pelo incremento de posição, utiliza-se a seguinte expressão como critério de parada, que utiliza uma medida relativa de erro, evitando problemas de convergência por ordem de grandeza:

$$
\sqrt{\frac{\Delta \vec{Y} \cdot \Delta \vec{Y}}{\vec{X} \cdot \vec{X}}} \leq \text { tolerância }
$$




\section{ELEMENTO FINITO BIDIMENSIONAL}

As formulações acerca do elemento finito bidimensional de chapa segundo a formulação posicional podem ser encontradas mais detalhadamente em trabalhos como Coda e Paccola (2010), Sampaio (2014), Moura (2015).

\subsection{Cinemática do elemento finito de chapa}

A Figura 7 representa os diferentes estados que um elemento finito bidimensional e seus nós podem assumir e suas relações com o estado adimensional auxiliar:
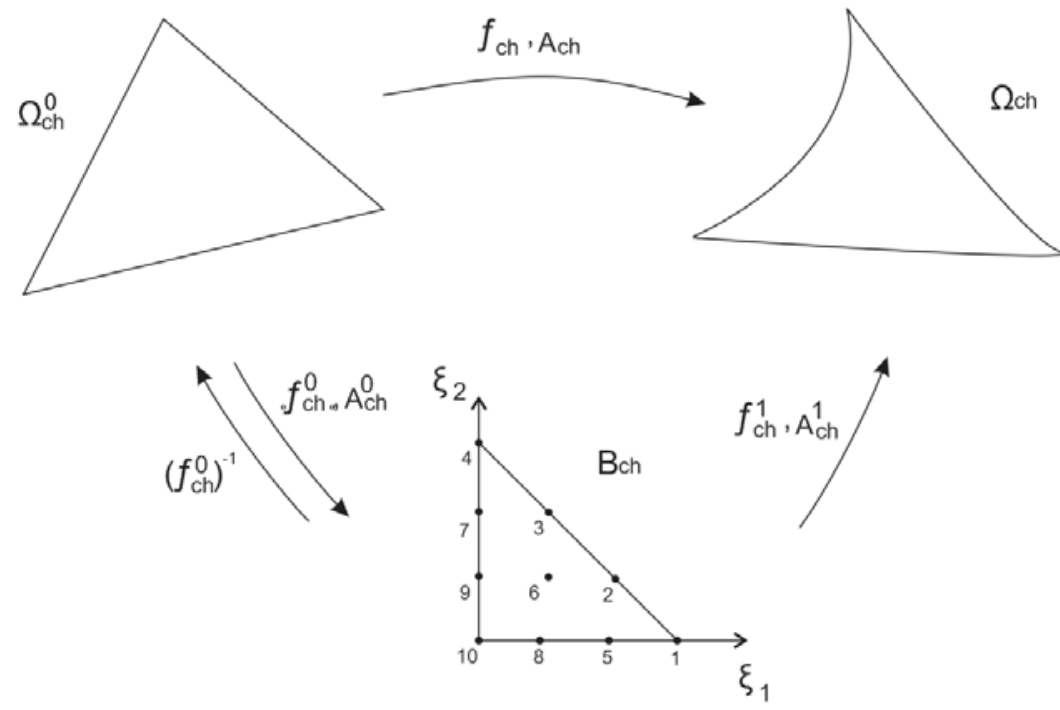

Figura 7 - Esquema de mapeamento do elemento finito bidimensional e suas configurações

Um ponto qualquer na configuração inicial ou indeformada $\Omega_{c h}^{0}$ apresenta coordenadas $x_{i}^{\text {ch }}$ no espaço Euclidiano, sendo mapeadas através do estado adimensional auxiliar $B_{c h}$ com coordenadas $\xi_{i}$, utilizando funções de forma $\phi_{n}^{\text {ch }}$ para interpolação através das posições dos nós do elemento finito $X_{n}^{i, c h}$. Sendo $n$ o número de nós do elemento finito, $i=1,2$ as direções para o caso bidimensional e $c h$ a referência ao elemento de chapa. Para o presente trabalho adotou-se um elemento finito bidimensional com dez nós e aproximação cúbica. Portanto, tem-se: 


$$
x_{i}^{c h}=\phi_{n}^{c h}\left(\xi_{1}, \xi_{2}\right) X_{i}^{n, c h}
$$

Para a configuração final ou deformada $\Omega_{c h}$, as coordenadas $y^{c h}$ do ponto qualquer são mapeadas através do espaço adimensional auxiliar de forma análoga à configuração inicial. Sendo $Y_{i}^{n, c h}$ as posições atuais dos nós, pode-se escrever:

$$
y_{i}^{c h}=\phi_{n}^{c h}\left(\xi_{1}, \xi_{2}\right) Y_{i}^{n, c h}
$$

A função mudança de configuração $\vec{f}_{c h}$, que realiza a transição da configuração inicial para a configuração final, ou seja, que faz a transição das coordenadas $x_{i}^{\text {ch }}$ para $y_{i}^{\text {ch }}$, pode ser obtida segundo uma composição entre os mapeamentos dos dois estados em relação ao estado adimensional da seguinte forma:

$$
\vec{f}^{c h}=\vec{f}^{1, c h} \circ\left(\vec{f}^{0, c h}\right)^{-1}
$$

Os gradientes das funções de mapeamento da configuração inicial e final são dados respectivamente por:

$$
A_{i j}^{0, c h}=\frac{\partial x_{i}^{c h}}{\partial \xi_{j}}=\frac{\partial \phi_{n}^{c h}}{\partial \xi_{j}} \cdot X_{i}^{n, c h} \quad e \quad A_{i j}^{1, c h}=\frac{\partial y_{i}^{c h}}{\partial \xi_{j}}=\frac{\partial \phi_{n}^{c h}}{\partial \xi_{j}} \cdot Y_{i}^{n, c h}
$$

Pela regra da cadeia, o gradiente da função mudança de configuração é calculado pela seguinte expressão (Coda e Paccola, 2010):

$$
\mathbf{A}^{\mathrm{ch}}=\mathbf{A}^{\mathbf{1 , c h}} \cdot\left(\mathbf{A}^{\mathbf{0 , c h}}\right)^{-1}
$$




\subsection{Energia de deformação}

A lei constitutiva empregada é a de Saint-Venant-Kirchhoff, que relaciona a medida de deformação objetiva de Green-Lagrange ao tensor de tensões de Piola-Kirchhoff de Segunda Espécie. Esta lei permite aplicações em grandes deslocamentos e deformações moderadas (OGDEN, 1984; CODA, PACCOLA, 2010).

O tensor de deformações e o tensor de tensões são dados respectivamente por:

$$
\mathbf{E}^{\mathbf{c h}}=\frac{1}{2}(\hat{\mathbf{C}}-\mathbf{I})=\frac{1}{2}\left(\left(\mathbf{A}^{\mathrm{ch}}\right)^{t} \cdot \mathbf{A}^{\mathrm{ch}}-\mathbf{I}\right)
$$

sendo $\hat{\mathbf{C}}$ o tensor de segunda ordem do alongamento de Cauchy-Green à direita e I o tensor identidade de segunda ordem.

A equação (4.6) ainda pode ser reescrita para as componentes do tensor de deformações da seguinte forma:

$$
E_{i j}^{c h}=\frac{1}{2}\left(\hat{C}_{i j}-\delta_{i j}\right)=\frac{1}{2}\left(A_{k i}^{c h} A_{k j}^{c h}-\delta_{i j}\right)
$$

sendo $\delta_{i j}$ o delta de Kroenecker.

A expressão da energia específica de deformação $w^{\text {ch }}$ associada a essa lei constitutiva é dada de forma geral por:

$$
w^{c h}=\frac{1}{2} E_{i j}^{c h} \mathfrak{C}_{i j k l} E_{k l}^{c h}
$$

sendo $\mathfrak{C}_{i j k l}$ o tensor constitutivo elástico de quarta ordem e suas componentes são dadas por:

$$
\mathfrak{C}_{i j k l}=\frac{2 G v}{1-2 v} \delta_{i j} \delta_{k l}+G\left(\delta_{i k} \delta_{j l}+\delta_{i l} \delta_{j k}\right)
$$

Um sólido modelado bidimensionalmente pode ser analisado tanto em um estado plano de deformações (EPD) quanto em um estado plano de tensões (EPT), e suas energias específicas de deformação são escritas, respectivamente, por: 


$$
\begin{aligned}
& w^{c h}=\frac{G}{1-2 v}\left\{(1-v)\left(\left(E_{11}^{c h}\right)^{2}+\left(E_{22}^{c h}\right)^{2}\right)+2 v E_{11}^{c h} E_{22}^{c h}+(1-2 v)\left(\left(E_{12}^{c h}\right)^{2}+\left(E_{21}^{c h}\right)^{2}\right)\right\} \\
& w^{c h}=\frac{G}{\left(1-v^{2}\right)}\left\{\left(E_{11}^{c h}\right)^{2}+\left(E_{22}^{c h}\right)^{2}+2 v E_{11}^{c h} E_{22}^{c h}+\left(1-v^{2}\right)\left(\left(E_{12}^{c h}\right)^{2}+\left(E_{21}^{c h}\right)^{2}\right)\right\}
\end{aligned}
$$

sendo o coeficiente de Poisson denotado por $V$ e o módulo de elasticidade transversal por $G$.

Conforme descrito no Capítulo 3, a energia total do sistema П é a soma da energia de deformação e do potencial das cargas externas, que escrita para o caso bidimensional, em função das posições nodais da chapa, é dada pela seguinte expressão:

$$
\Pi\left(\vec{Y}^{c h}\right)=W^{c h}\left(\vec{Y}^{c h}\right)-\vec{F} \cdot \vec{Y}^{c h}
$$

sendo $W^{\text {ch }}$ a energia de deformação de um elemento finito de chapa e $\vec{F}$ o vetor das forças externas. A energia de deformação $W^{\text {ch }}$ em um elemento finito de chapa pode ser obtida pela integração da energia específica no volume inicial $V_{0}$, dada esta ser uma formulação Lagrangeana Total, conforme a equação (4.12):

$$
W^{c h}=\int_{V_{0}} w^{c h}\left(\vec{Y}^{c h}\right) d V_{0}
$$

\subsection{Força interna}

De acordo com o capítulo anterior, partindo do princípio da energia potencial total estacionária, como condição de equilíbrio, a primeira variação da energia total é dada por:

$$
\delta \Pi\left(\vec{Y}^{c h}\right)=\int_{V_{0}} \frac{\partial w^{c h}}{\partial \vec{Y}^{c h}} . \delta \vec{Y}^{c h} d V_{0}-\frac{\partial\left(\vec{F} \cdot \vec{Y}^{c h}\right)}{\partial \vec{Y}^{c h}} \cdot \delta \vec{Y}^{c h}=0
$$

Como a energia específica de deformação pode ser escrita em função das posições nodais por meio da deformação de Green $\mathbf{E}^{\mathbf{c h}}$, e sendo $\mathbf{S}^{\mathbf{c h}}$ o tensor de Piola-Kirchhoff de segunda espécie, pode-se reescrever a expressão (4.13) como: 


$$
\delta \Pi\left(\vec{Y}^{c h}\right)=\int_{V_{0}} \frac{\partial w^{c h}}{\partial \mathbf{E}^{\text {ch }}}: \frac{\partial \mathbf{E}^{\text {ch }}}{\partial \vec{Y}^{c h}} \delta \vec{Y}^{c h} d V_{0}-\vec{F} \cdot \delta \vec{Y}^{c h}=0
$$

A equação anterior ainda pode ser escrita na forma:

$$
\delta \Pi\left(\vec{Y}^{c h}\right)=\int_{V_{0}} \mathbf{S}^{\text {ch }}: \frac{\partial \mathbf{E}^{\text {ch }}}{\partial \vec{Y}^{c h}} \delta \vec{Y}^{c h} d V_{0}-\vec{F} \cdot \delta \vec{Y}^{c h}=0
$$

Dada a arbitrariedade da variação $\delta \vec{Y}^{c h}$, é possível reescrever a equação (4.15) como:

$$
\vec{g}\left(\vec{Y}^{c h}\right)=\int_{V_{0}} \mathbf{S}^{\text {ch }}: \frac{\partial \mathbf{E}^{\text {ch }}}{\partial \vec{Y}^{c h}} d V_{0}-\vec{F}=\overrightarrow{0}
$$

ou ainda, de modo mais compacto:

$$
\vec{g}\left(\vec{Y}^{c h}\right)=\vec{F}^{\text {int }}\left(\vec{Y}^{c h}\right)-\vec{F}=\overrightarrow{0}
$$

sendo $\vec{g}$ o vetor desbalanceamento e $\vec{F}^{\text {int }}$ o vetor de forças interna conforme descrito no capítulo anterior.

De modo a calcular o valor da força interna, aplica-se a regra de quadratura com pontos de Hammer, de modo a substituir a integração analítica por uma integração numérica. Portanto, a força interna em um nó $\beta$ em uma direção $\alpha$ é dada por:

$$
F_{\alpha}^{\mathrm{int}, \beta}=\sum_{i h=1}^{\mathrm{nph}}\left[\left(f_{\alpha}^{\mathrm{int}, \beta}\right)_{i h} c_{i h} J_{i h}\right] e^{e f}
$$

Cada parcela $f_{\alpha}^{\beta}$ representa a contribuição de um ponto de Hammer ih para a força interna. O termo $C_{i h}$ representa o peso de cada ponto de Hammer e $e^{e f}$ é a espessura do elemento finito em questão. Sendo:

$$
J_{i h}^{c h}=\operatorname{det}\left(A_{i h}^{0, c h}\right)
$$




$$
\left(f_{\alpha}^{\mathrm{int}, \beta}\right)_{i h}=\left(\frac{\partial \mathbf{E}^{\mathrm{ch}}}{\partial Y_{\alpha}^{\beta, c h}}\right)_{i h}:\left(\mathbf{S}^{\mathbf{c h}}\right)_{i h}
$$

e o termo $\frac{\partial \mathbf{E}^{\mathrm{ch}}}{\partial Y_{\alpha}^{\beta, c h}}$ é dado por:

$$
\frac{\partial \mathbf{E}^{\text {ch }}}{\partial Y_{\alpha}^{\beta, c h}}=\frac{1}{2}\left\{\left[\left(\mathbf{A}^{\mathbf{0 , c h}}\right)^{-t} \cdot\left(\mathbf{A}^{1}\right)^{t} \cdot \frac{\partial \mathbf{A}^{1, \mathbf{c h}}}{\partial Y_{\alpha}^{\beta, c h}} \cdot\left(\mathbf{A}^{\mathbf{0}}\right)^{-1}\right]^{t}+\left[\left(\mathbf{A}^{\mathbf{0 , c h}}\right)^{-t} \cdot\left(\mathbf{A}^{1}\right)^{t} \cdot \frac{\partial \mathbf{A}^{1, \text { ch }}}{\partial Y_{\alpha}^{\beta, c h}} \cdot\left(\mathbf{A}^{0}\right)^{-1}\right]\right\}
$$

A equação a seguir indica as componentes do tensor $\mathbf{S}^{\text {ch }}$ para o estado plano de deformações:

$$
\begin{aligned}
& S_{11}^{c h}=\frac{\mathbb{E}}{(1+v)(1-2 v)}\left\{(1-v) E_{11}^{c h}+v E_{22}^{c h}\right\} \\
& S_{22}^{c h}=\frac{\mathbb{E}}{(1+v)(1-2 v)}\left\{(1-v) E_{22}^{c h}+v E_{11}^{c h}\right\} \\
& S_{12}^{c h}=2 G E_{12}^{c h} \\
& S_{21}^{c h}=2 G E_{21}^{c h}
\end{aligned}
$$

Sendo $\mathbb{E}$ o modo de elasticidade longitudinal do material e $G$ o módulo de elasticidade transveral dado por:

$$
G=\frac{\mathbb{E}}{2(1+v)}
$$

Pode-se utilizar a mesma expressão (4.22) para o estado plano de tensões, alterando-se os valores dos seguintes coeficientes (Assan, 2002):

$$
\begin{gathered}
v_{E P T}=\frac{v_{E P D}}{1+v_{E P D}} \\
\mathbb{E}_{E P T}=\mathbb{E}_{E P D}\left(1-v_{E P T}^{2}\right)
\end{gathered}
$$




\subsection{Hessiana}

Conforme indicado no Capítulo 3, ao estabelecer-se o equilíbrio pela primeira variação da energia potencial total, obtém-se uma equação não linear. Ao realizar a expansão em série de Taylor para a resolução dessas equações por meio do método de Newton-Raphson, surge a necessidade de calcular a segunda derivada da energia de deformação.

Aplicando a regra de quadratura sobre a expressão (3.12), substitui-se a integral analítica por uma integração numérica com pontos de Hammer de forma análoga à força interna:

$$
H_{\alpha \beta \gamma z}^{c h}=\sum_{i h=1}^{n p h}\left[\left(h_{\alpha \beta \gamma z}\right)_{i h} c_{i h} J_{i h}\right] e^{e f}
$$

O termo $h_{\alpha \beta \gamma z}$ é a contribuição de cada ponto de Hammer para a hessiana do elemento, conforme:

$$
\begin{aligned}
h_{\alpha \beta \gamma z}^{c h}= & \frac{1}{2}\left[\left(\mathbf{A}^{\mathbf{0 , c h}}\right)^{-t} \cdot\left(\frac{\partial \mathbf{A}^{1, \mathbf{c h}}}{\partial Y_{\alpha}^{\beta, c h}}\right)^{t} \cdot \frac{\partial \mathbf{A}^{\mathbf{1 , c h}}}{\partial Y_{\gamma}^{z, c h}} \cdot\left(\mathbf{A}^{\mathbf{0 , c h}}\right)^{-1}+\left(\mathbf{A}^{\mathbf{0 , c h}}\right)^{-t} \cdot\left(\frac{\partial \mathbf{A}^{\mathbf{1 , c h}}}{\partial Y_{\gamma}^{z, c h}}\right)^{t} \cdot \frac{\partial \mathbf{A}^{\mathbf{1 , c h}}}{\partial Y_{\alpha}^{\beta, c h}} \cdot\left(\mathbf{A}^{\mathbf{0 , c h}}\right)^{-1}\right]: \mathbf{S}^{\mathbf{c h}} \\
& +\frac{\partial \mathbf{E}^{\mathrm{ch}}}{\partial Y_{\alpha}^{\beta, c h}}: \frac{\partial \mathbf{S}^{\mathrm{ch}}}{\partial Y_{\gamma}^{z, c h}}
\end{aligned}
$$

sendo $\frac{\partial \mathbf{A}^{\mathbf{1}, \mathbf{c h}}}{\partial Y_{\gamma}^{z, c h}}$ e $\frac{\partial \mathbf{S}^{\text {ch }}}{\partial Y_{\gamma}^{z, c h}}$ dados a seguir:

$$
\begin{gathered}
\frac{\partial \mathbf{A}^{\mathbf{1 , c h}}}{\partial Y_{1}^{z, c h}}=\left[\begin{array}{cc}
\phi_{\beta, 1}^{c h} & \phi_{\beta, 2}^{c h} \\
0 & 0
\end{array}\right] \text { e } \frac{\partial \mathbf{A}^{\mathbf{1 , c h}}}{\partial Y_{2}^{z, c h}}=\left[\begin{array}{cc}
0 & 0 \\
\phi_{\beta, 1}^{c h} & \phi_{\beta, 2}^{c h}
\end{array}\right] \\
\frac{\partial \mathbf{S}^{\mathbf{c h}}}{\partial Y_{\gamma}^{z, c h}}=\mathbf{C} \frac{\partial \mathbf{E}^{\mathbf{c h}}}{\partial Y_{\gamma}^{z, c h}}
\end{gathered}
$$


sendo $\phi_{\beta, \mathrm{i}}=\frac{\partial \phi_{\beta}}{\partial \xi_{i}}$ e o termo $\frac{\partial \mathbf{E}^{\mathrm{ch}}}{\partial Y_{\gamma}^{z, c h}}$ da equação (4.29) é calculado de forma análoga à equação (4.21).

Segundo Ogden (1984), para o cálculo da tensão real de Cauchy $\boldsymbol{\sigma}$ a partir da tensão de Piola Kirchhoff, tem-se:

$$
\boldsymbol{\sigma}=\frac{1}{J} \mathbf{A}^{\mathbf{c h}} \cdot \mathbf{S}^{\mathbf{c h}} \cdot\left(\mathbf{A}^{\mathbf{c h}}\right)^{t}
$$




\section{ELEMENTO FINITO DE BARRA COMO REFORÇO}

As formulações descritas nesse capítulo consistem em simular as fibras como elemento finito de barra, tendo como parâmetros nodais as posições em cada direção. As fibras são consideradas através de duas formulações. A primeira delas, considera as fibras como perfeitamente aderidas ao meio, podendo ser encontrada nos trabalhos de Vanalli (2004), Vanalli et al. (2010) e Sampaio (2014).

Os itens 5.1 e 5.2 são referentes ao cálculo das forças internas e hessianas das fibras, sendo que a única diferença entre estes tópicos é o grau de aproximação do elemento. O primeiro item trata da fibra com apenas dois nós (aproximação linear) e o segundo com uma regra mais geral válida para qualquer grau de aproximação da fibra. A formulação do item 5.2 pode ser usada para a fibra de dois nós, mas o contrário não é válido.

Após os cálculos das forças internas e hessianas, utiliza-se a técnica apresentada no item 5.3 para a contribuição das fibras ao meio. Esta dispensa a coincidência dos nós da malha da fibra com a malha da matriz, considerando as fibras como perfeitamente aderidas ao meio e não acrescenta graus de liberdade ao sistema.

\subsection{Elemento de fibra reta}

\subsubsection{Cinemática do elemento de fibra reta}

A Figura 8 representa as diferentes configurações que um elemento finito undimensional com aproximação linear e seus nós podem assumir, e suas relações com a configuração adimensional auxiliar:

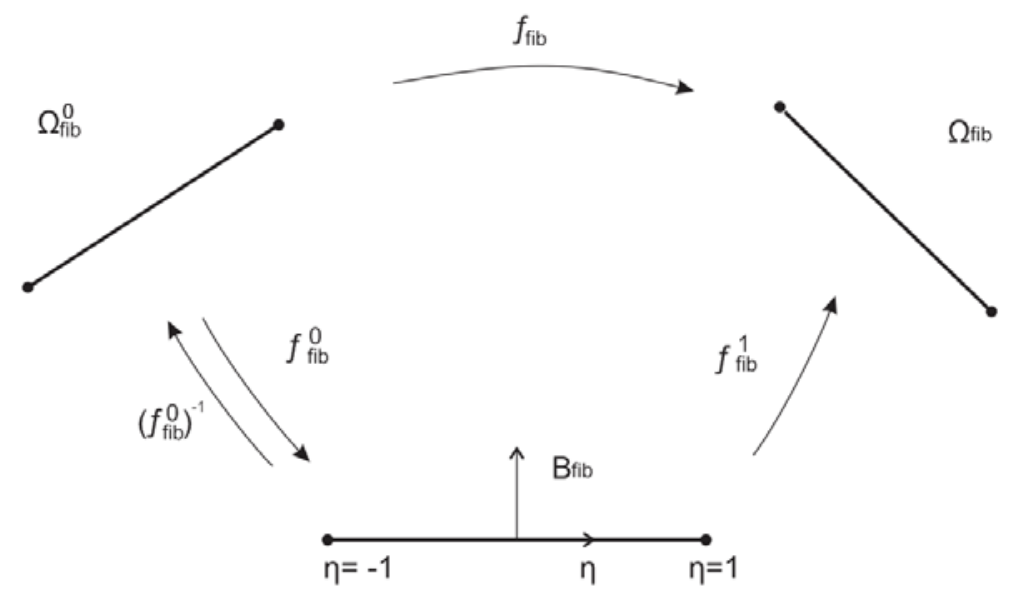

Figura 8 - Esquema de mapeamento do elemento de fibra reta e suas configurações inicial e atual 
Um ponto qualquer na configuração inicial ou indeformada $\Omega_{\text {fib }}^{0}$ apresenta as coordenadas $x_{i}^{\text {fib }}$ no espaço Euclidiano, sendo mapeado através da configuração adimensional auxiliar $B_{\text {fib }}$ com coordenada $\eta$ que varia de -1 a 1 , utilizando funções de forma $\phi_{n}^{\text {fib }}$ para interpolação através das posições dos nós do elemento finito $X_{i}^{n \text {, fib }}$. Sendo o índice $i=1,2$ as direções, fib a referência ao elemento de fibra, e o índice $n$ o número de nós, no caso da fibra reta igual a dois. Portanto, tem-se:

$$
X_{i}^{f i b}=\phi_{n}^{f i b}(\eta) X_{i}^{n, f i b}
$$

Para a configuração atual ou deformada $\Omega_{\text {fib }}$, as coordenadas $y_{i}^{\text {fib }}$ do ponto qualquer são mapeadas através do espaço adimensional auxiliar com as posições nodais atuais $Y_{i}^{n \text {,fib }}$ como:

$$
y_{i}^{f i b}=\phi_{n}^{f i b}(\eta) Y_{i}^{n, f i b}
$$

A função mudança de configuração $\vec{f}^{\text {fib }}$ é quem realiza a transição da configuração inicial para a configuração final, ou seja, que faz o mapeamento das coordenadas $X_{i}^{\text {fib }}$ para $y_{i}^{\text {fib }}$. De forma análoga ao elemento de chapa, essa função pode ser obtida segundo uma composição entre os mapeamentos das duas configurações em relação à configuração de referência adimensional da seguinte forma:

$$
\vec{f}^{f i b}=\vec{f}^{1, f i b} \circ\left(\vec{f}^{0, f i b}\right)^{-1}
$$

\subsubsection{Energia de deformação}

Considerando $\mathbb{E}^{f i b}$ o módulo de elasticidade da fibra reta e $E^{\text {fib }}$ a deformação de Green, assim como no elemento finito bidimensional, utiliza-se a lei constitutiva de SaintVenant-Kirchhoff, cuja energia de deformação específica $w^{\text {fib }}$ para este elemento é: 


$$
w^{f i b}=\frac{1}{2} \mathbb{E}^{f i b}\left(E^{f i b}\right)^{2}
$$

A energia de deformação total $W^{\text {fib }}$ para um elemento de fibra é dada pela integração da energia específica de deformação no volume da fibra:

$$
W^{f i b}=\int_{V_{0}} w_{f i b} d V_{0}=\frac{1}{2} \mathbb{E}^{f i b}\left(E^{f i b}\right)^{2} V_{0}
$$

sendo $V_{0}$ o volume inicial, por se tratar de uma formulação Lagrangeana Total.

Considerando que o volume inicial é $V_{0}=A_{T} \mathrm{~L}_{0}$, sendo $A_{T}$ a área da seção transversal da fibra, assumida como constante, a equação (5.5) pode ser reescrita na forma:

$$
W^{f i b}=\frac{1}{2} \mathbb{E}^{f i b}\left(E^{f i b}\right)^{2} A_{T} L_{0}
$$

A deformação de Green para o caso unidimensional é apenas um escalar, medida na direção da fibra:

$$
E^{\text {fib }}=\frac{1}{2}\left(\frac{L^{2}}{L_{0}^{2}}-1\right)
$$

sendo $L$ e $L_{0}$ o comprimento final e inicial do elemento, respectivamente, os quais são dados pelas seguintes expressões em função das posições nodais:

$$
\begin{gathered}
\left(L_{0}\right)^{2}=\left(X_{1}^{1, f i b}-X_{1}^{2, f i b}\right)^{2}+\left(X_{2}^{1, f i b}-X_{2}^{2, f i b}\right)^{2} \\
(L)^{2}=\left(Y_{1}^{1, f i b}-Y_{1}^{2, f i b}\right)^{2}+\left(Y_{2}^{1, f i b}-Y_{2}^{2, f i b}\right)^{2}
\end{gathered}
$$

sendo os índices numéricos superiores referentes aos nós de uma fibra, enquanto os índices numéricos inferiores referentes às direções. 


\subsubsection{Força interna}

Conforme o Capítulo 3, as forças internas para o elemento de fibra são dadas pela primeira variação da energia total, que resulta num sistema não linear, sendo expressas por:

$$
F_{i}^{\mathrm{int,j}}=\frac{\partial W^{f i b}}{\partial Y_{i}^{j, f i b}}=\frac{\partial}{\partial Y_{i}^{j, f i b}}\left(\frac{1}{2} \mathbb{E}^{f i b}\left(E^{f i b}\right)^{2} A_{T} L_{0}\right)=\mathbb{E}^{f i b} E^{f i b} A_{T} L_{0} \frac{\partial E^{f i b}}{\partial Y_{i}^{j, f i b}}
$$

Realizando a derivada $\frac{\partial E^{f i b}}{\partial Y_{i}^{j, f i b}}$, reescreve-se a equação (5.10), já explicitando os termos do vetor, na forma:

$$
\begin{aligned}
& F_{1}^{\mathrm{int,1}}=\frac{\mathbb{E}^{f i b} A_{T}}{L_{0}} E^{f i b}\left(Y_{1}^{1, f i b}-Y_{1}^{2, \text { fib }}\right), \quad F_{2}^{\mathrm{int,1}}=\frac{\mathbb{E}^{f i b} A_{T}}{L_{0}} E^{f i b}\left(Y_{2}^{1, \text { fib }}-Y_{2}^{2, \text { fib }}\right) \\
& F_{1}^{\mathrm{int,2}}=\frac{\mathbb{E}^{\text {fib }} A_{T}}{L_{0}} E^{\text {fib }}\left(Y_{1}^{2, \text { fib }}-Y_{1}^{1, \text { fib }}\right), F_{2}^{\mathrm{int,2}}=\frac{\mathbb{E}^{\text {fib }} A_{T}}{L_{0}} E^{\text {fib }}\left(Y_{2}^{2, \text { fib }}-Y_{2}^{1, \text { fib }}\right)
\end{aligned}
$$

sendo que, como adotado anteriormente, os índices numéricos inferiores são referentes às direções e os índices numéricos superiores referentes ao nós da fibra reta.

\subsubsection{Hessiana}

Também de acordo com o Capítulo 3, o cálculo da segunda derivada da energia de deformação é parte do procedimento para resolução das equações não lineares pelo método de Newton-Raphson. A hessiana do elemento de fibra é dada pela segunda derivada da energia de deformação:

$$
H_{i k j m}^{f i b}=\frac{\partial W^{f i b}}{\partial Y_{i}^{k, f i b} \partial Y_{j}^{m, f i b}}=\frac{\partial}{\partial Y_{i}^{k, f i b}}\left(\mathbb{E}^{f i b} E^{f i b} A_{T} L_{0} \frac{\partial E^{f i b}}{\partial Y_{j}^{m, f i b}}\right)
$$

De forma análoga à força interna, resolvendo a derivada $\frac{\partial E^{f i b}}{\partial Y_{j}^{f i b}}$, reescreve-se a expressão (5.12), já explicitando cada termo da matriz, na forma: 


$$
\begin{aligned}
& H_{1111}^{f i b}=\frac{\mathbb{E}^{f i b} A_{T}}{L_{0}}\left[\frac{\left(Y_{1}^{1, f i b}-Y_{1}^{2, \text { fib }}\right)^{2}}{L_{0}^{2}}+E^{f i b}\right], H_{1121}^{f i b}=\frac{\mathbb{E}^{f i b} A_{T}}{L_{0}}\left[\frac{\left(Y_{2}^{1, \text { fib }}-Y_{2}^{2, \text { fib }}\right)\left(Y_{1}^{1, \text { fib }}-Y_{1}^{2, \text { fib }}\right)}{L_{0}^{2}}\right] \\
& H_{1112}^{f i b}=\frac{\mathbb{E}^{f i b} A_{T}}{L_{0}}\left[\frac{\left(Y_{1}^{1, f i b}-Y_{1}^{2, \text { fib }}\right)^{2}}{L_{0}^{2}}+E^{f i b}\right], H_{1122}^{f i b}=\frac{\mathbb{E}^{f i b} A_{T}}{L_{0}}\left[\frac{\left(Y_{2}^{2, \text { fib }}-Y_{2}^{1, \text { fib }}\right)\left(Y_{1}^{1, \text { fib }}-Y_{1}^{2, \text { fib }}\right)}{L_{0}^{2}}\right] \\
& H_{2121}^{f i b}=\frac{\mathbb{E}^{f i b} A_{T}}{L_{0}}\left[\frac{\left(Y_{2}^{1, f i b}-Y_{2}^{2, f i b}\right)^{2}}{L_{0}^{2}}+E^{f i b}\right], H_{2111}^{f i b}=\frac{\mathbb{E}^{f i b} A_{T}}{L_{0}}\left[\frac{\left(Y_{1}^{1, f i b}-Y_{1}^{2, f i b}\right)\left(Y_{2}^{1, f i b}-Y_{2}^{2, f i b}\right)}{L_{0}^{2}}\right] \\
& H_{2122}^{f i b}=\frac{\mathbb{E}^{f i b} A_{T}}{L_{0}}\left[\frac{\left(Y_{2}^{1, \text { fib }}-Y_{2}^{2, \text { fib }}\right)^{2}}{L_{0}^{2}}+E^{f i b}\right], H_{2112}^{f i b}=\frac{\mathbb{E}^{f i b} A_{T}}{L_{0}}\left[\frac{\left(Y_{1}^{2, \text { fib }}-Y_{1}^{1, \text { fib }}\right)\left(Y_{2}^{1, \text { fib }}-Y_{2}^{2, \text { fib }}\right)}{L_{0}^{2}}\right] \\
& H_{1211}^{f i b}=\frac{\mathbb{E}^{f i b} A_{T}}{L_{0}}\left[\frac{\left(Y_{1}^{2, f i b}-Y_{1}^{1, \text { fib }}\right)^{2}}{L_{0}^{2}}+E^{f i b}\right], H_{1221}^{f i b}=\frac{\mathbb{E}^{f i b} A_{T}}{L_{0}}\left[\frac{\left(Y_{2}^{1, f i b}-Y_{2}^{2, f i b}\right)\left(Y_{1}^{2, \text { fib }}-Y_{1}^{1, \text { fib }}\right)}{L_{0}^{2}}\right] \\
& H_{1212}^{f i b}=\frac{\mathbb{E}^{f i b} A_{T}}{L_{0}}\left[\frac{\left(Y_{1}^{2, \text { fib }}-Y_{1}^{1, \text { fib }}\right)^{2}}{L_{0}^{2}}+E^{f i b}\right], H_{1222}^{f i b}=\frac{\mathbb{E}^{f i b} A_{T}}{L_{0}}\left[\frac{\left(Y_{2}^{2, f i b}-Y_{2}^{1, f i b}\right)\left(Y_{1}^{2, f i b}-Y_{1}^{1, f i b}\right)}{L_{0}^{2}}\right] \\
& H_{2221}^{f i b}=\frac{\mathbb{E}^{f i b} A_{T}}{L_{0}}\left[\frac{\left(Y_{2}^{2, \text { fib }}-Y_{2}^{1, f i b}\right)^{2}}{L_{0}^{2}}+E^{f i b}\right], H_{2211}^{f i b}=\frac{\mathbb{E}^{f i b} A_{T}}{L_{0}}\left[\frac{\left(Y_{1}^{1, f i b}-Y_{1}^{2, \text { fib }}\right)\left(Y_{2}^{2, f i b}-Y_{2}^{1, \text { fib }}\right)}{L_{0}^{2}}\right] \\
& H_{2222}^{f i b}=\frac{\mathbb{E}^{f i b} A_{T}}{L_{0}}\left[\frac{\left(Y_{2}^{2, \text { fib }}-Y_{2}^{1, f i b}\right)^{2}}{L_{0}^{2}}+E^{f i b}\right], H_{2212}^{f i b}=\frac{\mathbb{E}^{f i b} A_{T}}{L_{0}}\left[\frac{\left(Y_{1}^{2, f i b}-Y_{1}^{1, f i b}\right)\left(Y_{2}^{2, f i b}-Y_{2}^{1, f i b}\right)}{L_{0}^{2}}\right]
\end{aligned}
$$

Organizando a hessiana de forma matricial, tem-se:

$$
\mathbf{H}^{\mathbf{f i b}}=\left[\begin{array}{cccc}
H_{1111}^{f i b} & H_{1121}^{f i b} & H_{1112}^{f i b} & H_{1122}^{f i b} \\
H_{21111}^{f i b} & H_{2121}^{f i b} & H_{2112}^{f i b} & H_{2122}^{f i b} \\
H_{121}^{f i b} & H_{122}^{f i b} & H_{1212}^{f i b} & H_{1222}^{f i b} \\
H_{2211}^{f i b} & H_{2221}^{f i b} & H_{2212}^{f i b} & H_{2222}^{f i b}
\end{array}\right]
$$




\subsection{Elemento de fibra curvo de ordem qualquer}

\subsubsection{Cinemática do elemento de fibra curvo de ordem qualquer}

A Figura 9 representa as diferentes configurações que um elemento finito undimensional curvo e seus nós podem assumir e suas relações com a configuração adimensional auxiliar:

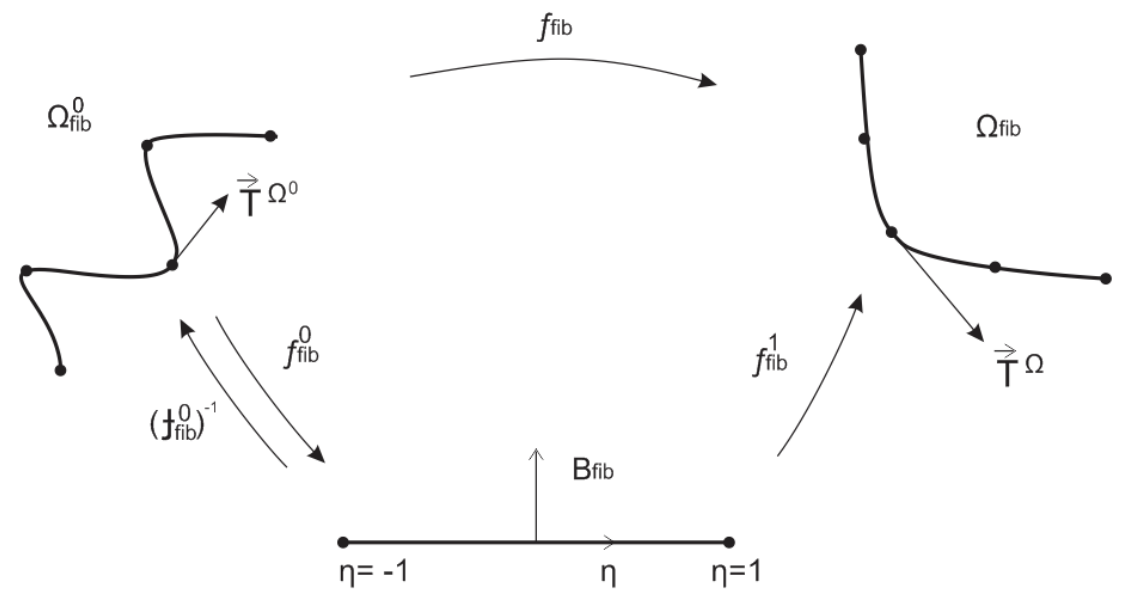

Figura 9 - Esquema de mapeamento do elemento de fibra curvo de ordem qualquer e suas configurações

De modo análogo à fibra reta, um ponto qualquer na configuração inicial ou indeformada $\Omega_{\text {fib }}^{0}$ apresenta as coordenadas $x_{i}^{\text {fib }}$ no espaço Euclidiano, sendo mapeado através da configuração adimensional auxiliar $\boldsymbol{B}_{\text {fib }}$ com coordenada $\boldsymbol{\eta}$ que varia de -1 a 1 , utilizando funções de forma $\phi_{p}^{\text {fib }}$ para interpolação através das posições dos nós do elemento finito $X_{i}^{p, \text { fib }}$. Sendo $p$ o número de nós, $i=1,2$ as direções e fib a referência ao elemento de fibra, tem-se:

$$
X_{i}^{\text {fib }}=\phi^{\text {fib }}(\eta) X_{i}^{p, \text { fib }}
$$


Para a configuração final ou deformada $\Omega_{\text {fib }}$, as coordenadas $y_{i}^{\text {fib }}$ do ponto qualquer são mapeadas através do espaço adimensiona auxiliar com as posições nodais atuais $Y_{i}^{p \text {, fib }}$ como:

$$
y_{i}^{f i b}=\phi_{p}^{f i b}(\eta) Y_{i}^{p, f i b}
$$

A função mudança de configuração $\vec{f}^{\text {fib }}$, que realiza a transição da configuração inicial para a configuração final, ou seja, que faz o mapeamento da mudança das coordenadas $X_{i}^{\text {fib }}$ para $y_{i}^{\text {fib }}$, pode ser obtida segundo uma composição entre os mapeamentos das duas configurações em relação à configuração de referência adimensional da seguinte forma:

$$
\vec{f}^{f i b}=\vec{f}^{1, f i b} \circ\left(\vec{f}^{0, f i b}\right)^{-1}
$$

Para o elemento finito curvo de ordem qualquer, associa-se a cada ponto da configuração inicial um vetor tangente e seu módulo para calcular a deformação de Green. Ao contrário da fibra reta, aqui, dada a curvatura, os comprimentos final e inicial da fibra não podem ser obtidos diretamente pelas posições nodais. Tem-se assim:

$$
\begin{gathered}
T_{i}^{\Omega^{0}}=\frac{d \phi_{p}^{f i b}(\eta)}{d \eta} X_{i}^{p, f i b} \\
\left|\vec{T}_{i}^{\Omega^{0}}\right|^{2}=\left(\frac{d \phi_{p}^{f i b}(\eta)}{d \eta} X_{1}^{p, f i b}\right)^{2}+\left(\frac{d \phi_{p}^{f i b}(\eta)}{d \eta} X_{2}^{p, f i b}\right)^{2}
\end{gathered}
$$

Analogamente para a configuração atual, associa-se um vetor tangente e seu módulo, expressos respectivamente por:

$$
\begin{gathered}
T_{i}^{\Omega}=\frac{d \phi_{p}^{f i b}(\eta)}{d \eta} Y_{i}^{p, f i b} \\
\left|\vec{T}_{i}^{\Omega}\right|^{2}=\left(\frac{d \phi_{p}^{f i b}(\eta)}{d \eta} Y_{1}^{p, f i b}\right)^{2}+\left(\frac{d \phi_{p}^{f i b}(\eta)}{d \eta} Y_{2}^{p, f i b}\right)^{2}
\end{gathered}
$$




\subsubsection{Energia de deformação}

A energia específica de deformação do elemento curvo é igual a do elemento reto, expressa segundo a lei de Saint-Venant-Kirchhoff por:

$$
w^{f i b}=\frac{1}{2} \mathbb{E}^{f i b}\left(E^{f i b}\right)^{2}
$$

E a energia total é dada pela integral da energia específica de deformação no volume da fibra, como:

$$
W^{f i b}=\int_{V_{0}} w^{f i b} d V_{0}=\frac{1}{2} \mathbb{E}^{f i b}\left(E^{f i b}\right)^{2} V_{0}
$$

sendo $V_{0}$ o volume inicial do elemento finito, por se tratar de uma formulação Lagrangeana Total.

Para o elemento curvo de ordem qualquer, a deformação de Green pode ser escrita em função dos vetores tangentes:

$$
E^{f i b}=\frac{1}{2}\left(\frac{\left|\vec{T}^{\Omega}\right|^{2}-\left|\vec{T}^{\Omega^{0}}\right|^{2}}{\left|\vec{T}^{\Omega^{0}}\right|^{2}}\right)
$$

Ou ainda pode ser escrita sob a forma:

$E^{f i b}=\frac{1}{2} \frac{\left[\left(\frac{d \phi_{p}^{f i b}(\eta)}{d \eta} Y_{1}^{p, f i b}\right)^{2}+\left(\frac{d \phi_{p}^{f i b}(\eta)}{d \eta} Y_{2}^{p, f i b}\right)^{2}\right]-\left[\left(\frac{d \phi_{p}^{f i b}(\eta)}{d \eta} X_{1}^{p, f i b}\right)^{2}+\left(\frac{d \phi_{p}^{f i b}(\eta)}{d \eta} X_{2}^{p, f i b}\right)^{2}\right]}{\left(\frac{d \phi_{p}^{f i b}(\eta)}{d \eta} X_{1}^{p, f i b}\right)^{2}+\left(\frac{d \phi_{p}^{f i b}(\eta)}{d \eta} X_{2}^{p, f i b}\right)^{2}}$ 


\subsubsection{Força interna}

Conforme demonstrado no Capítulo 3, as forças internas surgem do equilíbrio estabelecido pela primeira variação da energia potencial total. Para o elemento curvo de ordem qualquer são dadas por:

$$
F_{k}^{\mathrm{int}, j}=\frac{\partial W^{\text {fib }}}{\partial Y_{k}^{j, f i b}}=\int_{V_{0}} \frac{\partial w^{\text {fib }}}{\partial Y_{k}^{j, f i b}} d V_{0}
$$

Substituindo as expressões (5.22) e (5.25) na expressão (5.26), obtém-se:

$$
F_{k}^{\mathrm{int}, j}=\int_{V_{0}} \mathbb{E}^{f i b} E^{f i b} \frac{\left(\frac{d \phi_{p}^{f i b}(\eta) Y_{k}^{p, f i b}}{d \eta}\right) \frac{d \phi_{j}^{f i b}(\eta)}{d \eta}}{\left|\vec{T}^{\Omega^{0}}\right|^{2}} d V_{0}
$$

Sabendo que $V_{0}=A_{T} L_{0}$ e a área da seção transversal da fibra $A_{T}$ é constante, é possível mudar o limite de integração para o comprimento inicial $L_{0}$, obtendo assim a seguinte expressão:

$$
F_{k}^{j}=\int_{0}^{L_{0}} \mathbb{E}^{f i b} E^{f i b} \frac{\left(\frac{d \phi_{p}^{f i b}(\eta) Y_{k}^{p, f i b}}{d \eta}\right) \frac{d \phi_{j}^{f i b}(\eta)}{d \eta}}{\left|\vec{T}^{\Omega^{0}}\right|^{2}} A_{T} d s
$$

Realizando a mudança dos limites de integração para o espaço adimensional, tem-se:

$$
F_{j}^{\mathrm{int}, k}=\int_{-1}^{1} \mathbb{E}^{f i b} E^{f i b} \frac{\left(\frac{d \phi_{p}^{f i b}(\eta) Y_{k}^{p, f i b}}{d \eta}\right) \frac{d \phi_{j}^{f i b}(\eta)}{d \eta}}{\left|\vec{T}^{\Omega^{0}}\right|^{2}} J_{0}^{f i b}(\eta) A_{T} d \eta
$$

sendo $J_{0}^{\text {fib }}(\eta)$ o jacobiano da mudança de domínio de integração para a configuração inicial $\Omega^{0}$, dado em função do vetor tangente como: 


$$
J_{0}^{f i b}(\eta)=\left|\vec{T}^{\Omega^{0}}\right|=\sqrt{\left(\frac{d x_{1}}{d \eta}\right)^{2}+\left(\frac{d x_{2}}{d \eta}\right)^{2}}
$$

Aplicando a regra de quadratura com pontos de Gauss-Legendre, subtitui-se a integral analítica de (5.29) por uma integração numérica:

$$
F_{k}^{j}=\left.\sum_{i=1}^{n p h} \frac{\mathbb{E}^{f i b} E^{f i b}}{\left|\vec{T}^{\Omega^{0}}\right|^{2}}\left(\frac{d \phi_{p}^{f i b}(\eta) Y_{k}^{p, f i b}}{d \eta}\right) \frac{d \phi_{j}^{f i b}(\eta)}{d \eta}\right|_{\eta=\eta_{i}} J_{0}^{f i b}\left(\eta_{i}\right) c_{i h} A_{T}
$$

sendo $c_{i h}$ os pesos correspondentes aos pontos de integração da quadratura de GaussLegendre.

\subsubsection{Hessiana}

Segundo o Capítulo 3, aplica-se a segunda derivada da energia de deformação para a resolução das equações não lineares provenientes do equilíbrio estabelecido pela primeira variação da energia potencial total em função dos parâmetros nodais da fibra. A matriz hessiana é dada por:

$$
H_{k j \alpha \beta}^{f i b}=\frac{\partial^{2} W^{f i b}}{\partial Y_{k}^{j, f i b} \partial Y_{\alpha}^{\beta, f i b}}=\int_{V_{0}} \frac{\partial^{2} w^{f i b}}{\partial Y_{k}^{j, f i b} \partial Y_{\alpha}^{\beta, f i b}} d V_{0}
$$

Substituindo as equações (5.22) e (5.25) em (5.32), obtém-se:

$$
H_{k j \alpha \beta}^{f i b}=\int_{V_{0}}\left[\begin{array}{l}
\frac{E^{f i b}}{\left|\vec{T}^{\Omega^{0}}\right|^{4}}\left(\frac{d \phi_{r}^{f i b}(\eta)}{d \eta} Y_{\alpha}^{r, f i b}\right) \frac{d \phi_{\beta}^{f i b}(\eta)}{d \eta}\left(\frac{d \phi_{r}^{f i b}(\eta)}{d \eta} Y_{k}^{r, f i b}\right) \frac{d \phi_{j}^{f i b}(\eta)}{d \eta} \\
+\frac{\mathbb{E}^{f i b} E^{f i b}}{\left|\vec{T}^{\Omega^{0}}\right|^{2}} \frac{d \phi_{\beta}^{f i b}(\eta)}{d \eta} \frac{d \phi_{j}^{f i b}(\eta)}{d \eta} \delta_{k \alpha}
\end{array}\right] d V_{0}
$$


Considerando que o volume inicial é $V_{0}=A_{r} L_{0}$ e substituindo na equação (5.33) obtém-se:

$$
H_{k j \alpha \beta}^{f i b}=\int_{0}^{L_{0}}\left[\begin{array}{l}
\frac{E^{f i b}}{\left|\vec{T}^{\Omega^{0}}\right|^{4}}\left(\frac{d \phi_{r}^{f i b}(\eta)}{d \eta} Y_{\alpha}^{r, f i b}\right) \frac{d \phi_{\beta}^{f i b}(\eta)}{d \eta}\left(\frac{d \phi_{r}^{f i b}(\eta)}{d \eta} Y_{k}^{r, f i b}\right) \frac{d \phi_{j}^{f i b}(\eta)}{d \eta} \\
+\frac{\mathbb{E}^{f i b} E^{f i b}}{\left|\vec{T}^{\Omega^{0}}\right|^{2}} \frac{d \phi_{\beta}^{f i b}(\eta)}{d \eta} \frac{d \phi_{j}^{f i b}(\eta)}{d \eta} \delta_{k \alpha}
\end{array}\right]
$$

sendo $d s$ o diferencial de comprimento da fibra.

Ao realizar a mudança dos limites de integração:

$$
H_{k j \alpha \beta}^{f i b}=\int_{-1}^{1}\left[\begin{array}{l}
\frac{E^{f i b}}{\left|\vec{T}^{\Omega^{0}}\right|^{4}}\left(\frac{d \phi_{r}^{f i b}(\eta)}{d \eta} Y_{\alpha}^{r, f i b}\right) \frac{d \phi_{\beta}^{f i b}(\eta)}{d \eta}\left(\frac{d \phi_{r}^{f i b}(\eta)}{d \eta} Y_{k}^{r, f i b}\right) \frac{d \phi_{j}^{f i b}(\eta)}{d \eta} \\
+\frac{\mathbb{E}^{f i b} E^{f i b}}{\left|\vec{T}^{\Omega^{0}}\right|^{2}} \frac{d \phi_{\beta}^{f i b}(\eta)}{d \eta} \frac{d \phi_{j}^{f i b}(\eta)}{d \eta} \delta_{k \alpha}
\end{array}\right] J_{0}^{f i b}(\eta) A_{T} d \eta \text { (5.35) }
$$

Aplicando a regra de quadratura, subtitui-se a integração analítica pela integração numérica com pontos de Gauss-Legendre para a resolução da integral de (5.35), obtendo-se:

$$
H_{k j \alpha \beta}^{f i b}=\sum_{i=1}^{n p g}\left[\begin{array}{l}
\left.\left.\frac{E^{f i b}}{\left|\vec{T}^{\Omega^{0}}\right|^{4}}\left(\left.\frac{d \phi_{r}^{f i b}(\eta)}{d \eta}\right|_{\eta=\eta_{i}} Y_{\alpha}^{r, \text { fib }}\right) \frac{d \phi_{\beta}^{f i b}(\eta)}{d \eta}\right|_{\eta=\eta_{i}}\left(\left.\frac{d \phi_{r}^{f i b}(\eta)}{d \eta}\right|_{\eta=\eta_{i}} Y_{k}^{r, f i b}\right) \frac{d \phi_{j}^{f i b}(\eta)}{d \eta}\right|_{\eta=\eta_{i}} \\
+\left.\left.\frac{\mathbb{E}^{f i b} E^{f i b}}{\left|\vec{T}^{\Omega^{0}}\right|^{2}} \frac{d \phi_{\beta}^{f i b}(\eta)}{d \eta}\right|_{\eta=\eta_{i}} \frac{d \phi_{j}^{f i b}(\eta)}{d \eta}\right|_{\eta=\eta_{i}} \delta_{k \alpha}
\end{array}\right] A c_{i h} J_{0}
$$




\subsection{Fibras perfeitamente aderidas}

Devido à hipótese de que as fibras são perfeitamente aderidas, ou seja, que não há deslocamento relativo entre os nós das fibras e os pontos do domínio da chapa associados nos estados inicial e atual, as coordenadas dos nós das fibras podem ser escritas em função das funções de foma da chapa e não mais do próprio elemento de barra, como mostra a equação:

$$
X_{i}^{r, f i b}=\phi_{p}^{c h}\left(\xi_{1}^{(r)}, \xi_{2}^{(r)}\right) X_{i}^{p, c h}
$$

em que $X_{i}^{r \text {, fib }}$ é a posição referente a um dado nó $r$ da fibra numa direção $i$ na configuração inicial, $\phi^{\text {ch }}$ são as funções de forma do elemento bidimensional e $X_{i}^{p, c h}$ é a posição de um nó $p$ do elemento bidimensional numa direção $i$.

Analogamente para a configuração final, em que $Y_{i}^{r \text {, fib }}$ é a posição referente a um dado nó $r$ da fibra numa direção $i$ na configuração deformada, $\phi^{c h}$ são as funções de forma do elemento bidimensional e $Y_{i}^{p, c h}$ é a posição de um nó $p$ do elemento bidimensional numa direção $i$, como indicado em:

$$
Y_{i}^{r, f i b}=\phi_{p}^{c h}\left(\xi_{1}^{(r)}, \xi_{2}^{(\mathrm{r})}\right) Y_{i}^{p, \mathrm{ch}}
$$

A equação (5.38) pode ser diferenciada em relação aos parâmetros nodais do elemento bidimensional, sendo que quando o nó da fibra pertence ao elemento bidimensional o diferencial é a própria função de forma, $\phi_{\beta}^{c h}\left(\xi_{1}^{(r)}, \xi_{2}^{(r)}\right)$. De maneira geral, tem-se a equação (5.39):

$$
\frac{\partial Y_{i}^{r, f i b}}{\partial Y_{\alpha}^{\beta, c h}}=\frac{\partial Y_{i}^{p, c h}}{\partial Y_{\alpha}^{\beta, c h}} \phi_{p}^{c h}\left(\xi_{1}^{(r)}, \xi_{2}^{(r)}\right)=\delta_{\alpha i} \delta_{\beta p} \phi_{p}^{c h}\left(\xi_{1}^{(r)}, \xi_{2}^{(r)}\right)=\delta_{\alpha i} \phi_{\beta}^{c h}\left(\xi_{1}^{(r)}, \xi_{2}^{(r)}\right)
$$

Como não é necessária a coincidência dos nós da malha da fibra com os nós da malha da chapa, as fibras são geradas independentemente na configuração indeformada $\Omega_{\text {fib }}^{0}$, desde que seu domínio esteja contido no domínio da malha da matriz. 
Entretanto, isso não garante que os nós de uma fibra estejam no mesmo elemento de chapa, podendo assim surgir as seguintes situações (Figura 10): os nós da fibra encontram-se em um elemento de chapa (fibra 1), os nós da fibra podem estar em elementos adjacentes com nós em comum (fibra 2), os nós da fibra podem estar em elementos adjacentes com apenas um nó em comum (fibra 3) e fibras com nós em elementos não adjacentes (fibra 4). Para o caso de fibras como a 4, os elementos que a fibra atravessa, mas que não possuem o nó da fibra, não terão a contribuição desta no vetor de forças internas e da matriz hessiana do elemento em si. A contribuição pode ocorrer de forma indireta quando houver coincidência dos graus de liberdade entre estes elementos e os que possuem os nós da fibra. Sendo assim, é importante atentar para a discretização da fibra, para evitar resultados ruins por considerar reforços muito grandes numa malha de chapa refinada.

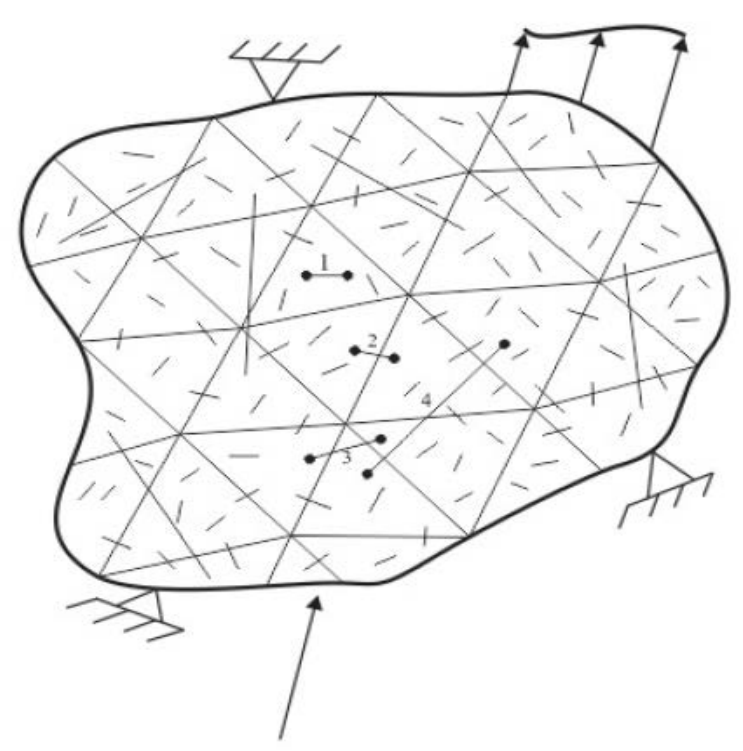

Figura 10 - Arranjo das fibras no domínio bidimensional

(Fonte: Sampaio, 2014)

Podendo o nó da fibra estar contido no domínio da chapa e não coincidir com os nós desta, associa-se a cada nó da fibra um par de coordenadas adimensionais tentativa $\left(\xi_{1}^{\text {ten }}, \xi_{2}^{\text {ten }}\right)$ no espaço adimensional de um determinado elemento de chapa. Como não se conhecem as reais coordenadas adimensionais, uma vez que as fibras foram geradas diretamente no espaço cartesiano, realiza-se um processo de localização iterativo para identificação do elemento de chapa onde se encontram inseridos os nós da fibra e a consequente correção das coordenadas adimensionais. 
Considerando que o elemento bidimensional tem aproximação cúbica e as coordenadas adimensionais referentes às fibras possuem valores ainda desconhecidos, equações não lineares em função das coordenadas adimensionais surgem no mapeamento proposto na equação (5.37). A resolução do sistema pode ser feita através do método de Newton-Raphson por uma expansão em série de Taylor:

$$
X_{i}^{r, f i b} \cong \phi_{p}^{c h}\left(\xi_{1}^{(\mathrm{r},) \text { ten }}, \xi_{2}^{(\mathrm{r}), \text { ten }}\right) X_{i}^{p, c h}+\left.\frac{\partial \phi_{p}^{c h}\left(\xi_{1}^{(\mathrm{r}), \text { ten }}, \xi_{2}^{(\mathrm{r}), \text { ten }}\right)}{\partial \xi_{j}}\right|_{\left(\xi_{1}^{(\mathrm{r}), \text { ten }}, \xi_{2}^{(\mathrm{r}), \text { ten }}\right)} X_{i}^{p, c h} \Delta \xi_{j}
$$

O que ainda pode ser reescrito como:

$$
X_{i}^{r, f i b}=\left(X_{i}^{r, f i b}\right)^{\text {tentativa }}+H_{i j} \Delta \xi_{j}
$$

sendo $H_{i j}$ uma matriz hessiana e $\left(X_{i}^{r, \text { fib }}\right)^{\text {tentativa }}$ a posição tentativa dos nós da fibra calculada a partir da geometria do elemento bidimensional. O cálculo de $\Delta \xi_{j}$ é dado pela resolução do sistema de equações:

$$
H_{i j} \Delta \xi_{j}=X_{i}^{r, f i b}-\left(X_{i}^{r, f i b}\right)^{\text {tentativa }}
$$

É importante notar que para o caso com aderência perfeita, tanto na configuração inicial quanto na final, as posições dos nós da fibra serão sempre dadas pelas coordenadas adimensionais calculadas no processo de localização.

Para o acoplamento entre a fibra e a matriz, sem que haja um aumento de graus de liberdade e sem a necessidade de coincidência dos nós na discretização das fibras e da matriz, faz-se uma compatibilização entre os graus de liberdade da chapa e o da fibra.

Na expressão seguinte, é mostrado o procedimento de compatibilização da hessiana para o caso da fibra reta:

$$
\left[H^{f i b}\right]_{4 N \times 4 N}=\left[\phi_{\beta}^{c h}\right]_{4 N \times 4}^{T} \cdot\left[H^{f i b}\right]_{4 \times 4} \cdot\left[\phi_{\beta}^{c h}\right]_{4 \times 4 N}
$$


O termo $\left[H^{\text {fib }}\right]_{4 \times 4}$ é a hessiana do elemento de fibra, calculada pelas expressões (5.12) ou (5.36); $N$ é o número de nós que cada elemento de chapa possui, $\left[\phi_{\beta}^{c h}\right]_{4 \times 4 N}$ é uma matriz que contém as funções de forma da chapa para as coordenadas adimensionais as quais estão associados aos nós da fibra, $\left[H^{\text {fib }}\right]_{4 N \times 4 N}$ é uma matriz compatibilizada, em que já podem ser feitas contribuições diretas na hessiana global da estrutura baseada nos elementos de chapa e segundo as incidências desses.

De forma mais geral para uma fibra curva de ordem qualquer, a expressão (5.43) resulta em:

$$
\left[H^{f i b}\right]_{2\left(G P^{f}+1\right) N \times 2\left(G P^{f}+1\right) N}=\left[\phi^{c h, \beta}\right]_{2\left(G P^{f}+1\right) N \times 2\left(G P^{f}+1\right)}^{T} \cdot\left[H^{f i b}\right]_{2\left(G P^{f}+1\right) \times 2\left(G P^{f}+1\right)} \cdot\left[\phi^{c h, \beta}\right]_{2\left(G P^{f}+1\right) \times 2\left(G P^{f}+1\right) N}
$$

O termo $\left[H^{f i b}\right]_{2\left(G P^{f}+1\right) \times 2\left(G P^{f}+1\right)}$ é a matriz hessiana calculada pela expressão (5.36), $N$ é o número de nós que cada elemento de chapa possui, $G P^{f}$ é o grau do polinômio que descreve a fibra, $\left[\phi^{c h, \beta}\right]_{2\left(G P^{f}+1\right) \times 2\left(G P^{f}+1\right) N}$ é uma matriz que contém as funções de forma da chapa para as coordenadas adimensionais a quais estão associados os nós, $\left[H^{f i b}\right]_{2\left(G P^{f}+1\right) N \times 2\left(G P^{f}+1\right) N}$ é uma matriz compatibilizada, em que já podem ser feitas contribuições diretas na hessiana global da estrutura baseada nos elementos de chapa e segundo as incidências desses.

A equação seguinte mostra a matriz com as funções de forma:

$$
\left[\phi^{\beta}\right]=\left[\begin{array}{cccccccccccc}
\phi_{1}^{i} & 0 & \phi_{2}^{i} & \ldots & \phi_{n}^{i} & 0 & 0 & 0 & 0 & \ldots & 0 & 0 \\
0 & \phi_{1}^{i} & 0 & \ldots & 0 & \phi_{n}^{i} & 0 & 0 & 0 & \ldots & 0 & 0 \\
0 & 0 & 0 & \ldots & 0 & 0 & \phi_{1}^{j} & 0 & \phi_{2}^{j} & \ldots & \phi_{n}^{j} & 0 \\
0 & 0 & 0 & \ldots & 0 & 0 & 0 & \phi_{2}^{j} & 0 & \ldots & 0 & \phi_{n}^{j}
\end{array}\right]=\left[\begin{array}{cc}
{\left[\phi_{1}^{i}\right]} & {[0]} \\
{[0]} & {\left[\phi_{n}^{j}\right.}
\end{array}\right]
$$

Utilizando a mesma matriz de funções de forma, a compatibilização das forças internas é feita de forma análoga à hessiana para a fibra reta:

$$
\left\{F_{f i b}\right\}_{4 N \times 1}=\left[\phi^{c h, \beta}\right]_{4 N \times 4}^{T} \cdot\left\{F^{f i b}\right\}_{4 \times 1}
$$


O termo $\left\{F^{f i b}\right\}_{4 \times 1}$ é a força interna do elemento de fibra, calculada pelas expressões (5.10) ou (5.31); $\left\{F_{f i b}\right\}_{4 N \times 1}$ é um vetor compatibilizado, em que já podem ser feitas contribuições diretas na força interna global da estrutura segundo as incidências.

Mais uma vez, para o caso de uma fibra de ordem qualquer:

$$
\left\{F_{f i b}\right\}_{2\left(G P^{f}+1\right) N \times 1}=\left[\phi^{c h, \beta}\right]_{2\left(G P^{f}+1\right) N \times 2\left(G P^{f}+1\right)}^{T} \cdot\left\{F^{f i b}\right\}_{2\left(G P^{f}+1\right) \times 1}
$$

O termo $\left\{F^{f i b}\right\}_{2\left(G P^{f}+1\right) \times 1}$ é a força interna calculada pela expressão (5.31), $\left\{F_{f i b}\right\}_{2\left(G P^{f}+1\right) N \times 1}$ é um vetor compatibilizado, em que já podem ser feitas contribuições diretas na hessiana global da estrutura segundo as incidências.

Para as fibras perfeitamente aderidas, foram idealizadas as distribuições de tensões normais e de aderência na interface fibra-matriz. As fibras são modeladas como barras simples, apresentando, portanto, apenas esforço normal, sendo feita uma equivalência desse esforço na fibra com a tensão de aderência atuante na ligação fibra-matriz e, tendo-se como base as tensões admissíveis para os casos de tensão normal e de aderência, pode-se determinar qual o mecanismo que resultará na falha da fibra e o valor do esforço associado a este, como demonstrado na Figura 11.

(a)

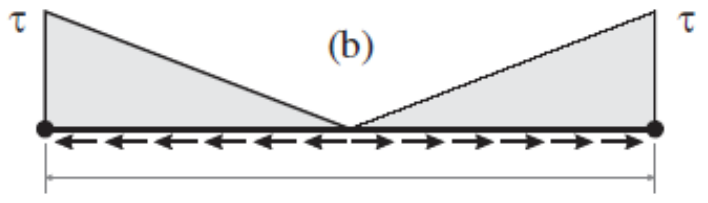

Figura 11 - (a) tensão normal na fibra, (b) tensão de aderência na fibra

(Fonte: Nogueira et al., 2014)

$$
\begin{gathered}
\bar{N}_{1} \leq \sigma_{a d m} A \\
\bar{N}_{2} \leq \tau_{a d m} \frac{l}{2} \rho_{f i b}
\end{gathered}
$$


sendo $\sigma_{a d m}$ a tensão normal admissível para a fibra, $A$ a área da fibra, $\tau_{a d m}$ a tensão de cisalhamento admissível para a ligação da fibra com a matriz, $L$ o comprimento da fibra e $\rho_{\text {fib }}$ o perímetro da fibra.

No caso de $\bar{N}_{1} \leq \bar{N}_{2}$, por exemplo, adota-se a curva tensão-deformação para o critério de plastificação para as tensões normais, caso contrário, adota-se a curva para as tensões de aderência no material. 


\section{PLASTICIDADE}

O presente tópico e suas considerações feitas acerca de comportamento elastoplástico da estrutura e de seus materiais constituintes são amplamente debatidos na literatura e podem ser encontradas, por exemplo, em Khang e Huang (1995), Lubliner (2005), Doltsinis (2010) e Proença (2013). O foco será dado às importâncias do estudo da plasticidade e suas diferenças do comportamento elástico.

\subsection{Considerações iniciais}

A plasticidade é um fenômeno observável durante o estudo da microestrutura dos materiais, que indica que o mecanismo físico responsável pela plasticidade é a movimentação irreversível em defeitos nas ligações atômicas, ainda que não haja perda de coesão ou rupturas nas ligações. Enquanto que o encruamento pode ocorrer por incompatibilidades entre as deformações dos grãos da rede cristalina (PROENÇA, 2013).

Ainda segundo Proença (2013), a elasticidade está relacionada ao desaparecimento completo das deformações da estrutura após a retirada da força, ou seja, as deformações são reversíveis e se mantém apenas enquanto o carregamento é aplicado. Há também a viscoelasticidade, que apresenta deformações reversíveis, mas dependentes do tempo, que aumentam com o tempo após a aplicação da carga e diminuem lentamente após o descarregamento.

O surgimento de deformações permanentes, provenientes da dissipação de energia, é característico da plasticidade, tratando-se de um processo irreversível. A recuperação das deformações após o descarregamento é parcial. Este fenômeno da deformação residual fica mais evidente em ciclos de carregamento e descarregamento. Durante o descarregamento no regime plástico, a inclinação é a mesma do carregamento e descarregamento no regime elástico.

O comportamento elastoplástico é de interesse em termos de capacidade resistente de uma estrutura. Isto porque ainda que os cálculos e detalhamentos de algumas estruturais usuais não permitam que estas se comportem plasticamente, devendo ser limitadas ao regime elástico, sua desconsideração resulta em um desperdício da capacidade resistente adicional que o regime plástico possui. 
Existem várias leis constitutivas para a plasticidade e, dependendo do modelo adotado, o material pode ou não suportar níveis de tensão superiores ao limite do regime elástico, o que por si só conferiria um ganho na capacidade resistente. Entretanto a simples redistribuição de esforços pode apresentar a mesma vantagem, ainda que não permita maiores níveis de tensão como demonstrado por Doltsinis (2010) no exemplo ilustrado na Figura 12.
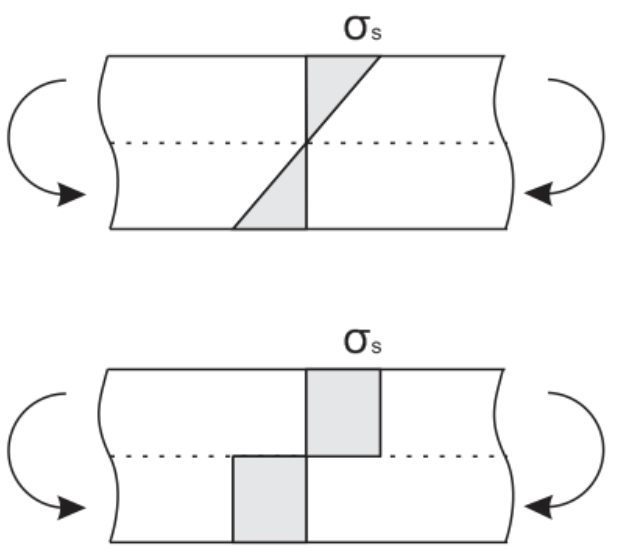
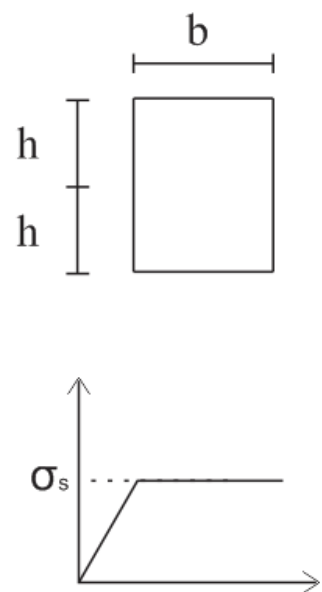

Figura 12 - Comportamento elástico vs comportamento plástico de uma viga (Adaptado: Doltsinis, 2010)

Para o caso elástico em uma viga reta e submetida à flexão pura, sendo $M$ o momento sob condições de serviço, $n M$ o momento crítico, $\sigma_{S}$ a tensão que limita o regime elástico, $b_{e}$ a largura da viga para o regime elástico, $b_{p}$ a largura para o regime plástico, $h$ a metade da altura da viga e $n$ um fator de segurança, é possível obter a seguinte relação de equilíbrio:

$$
n M=\frac{2}{3} b_{e} h^{2} \sigma_{S}
$$

Segundo a lei de plasticidade escolhida, é permitido que a intensidade da tensão aumente até o limite de $\sigma_{S}$ em toda a seção da viga, assim como mostra o segundo caso da Figura 12. Pela distribuição de tensões ao longo da seção, o momento $M$ para o caso plástico pode ser calculado por:

$$
n M=b_{p} h^{2} \sigma_{S}
$$


Igualando as duas expressões anteriores, é possível obter a relação:

$$
b_{p}=\frac{2}{3} b_{e}
$$

Em suma, é possível concluir que para um mesmo momento atuante, foi possível diminuir uma das dimensões da viga, o que acarreta em menor peso da estrutura e um menor custo em materiais para sua construção ao considerar o comportamento plástico. Em casos em que a estrutura não puder realizar a redistribuição de esforços, o aumento da capacidade resistente da estrutura só será possível pelas propriedades do material.

\subsection{Plasticidade unidimensional}

Primeiramente são apresentados os conceitos relacionados à plasticidade unidimensional, por ser esta de mais fácil entendimento. Pretende-se com isso facilitar o entendimento dos casos mais gerais de plasticidade multiaxial apresentados na sequência.

Nos modelos elásticos, uma tensão $\sigma_{1}$ estará sempre associada a uma deformação $\varepsilon_{1}$, bem como uma tensão $\sigma_{2}$ estará sempre associada a uma deformação $\varepsilon_{2}$, ainda que haja constantes ciclos de carregamento e descarregamento.

Para a plasticidade, certo nível de tensão pode estar associado a várias deformações diferentes, dependentes das condições anteriores de carregamento e descarregamento, assim como mostra a curva tensão vs deformação elastoplástica perfeita ilustrada na Figura 13.

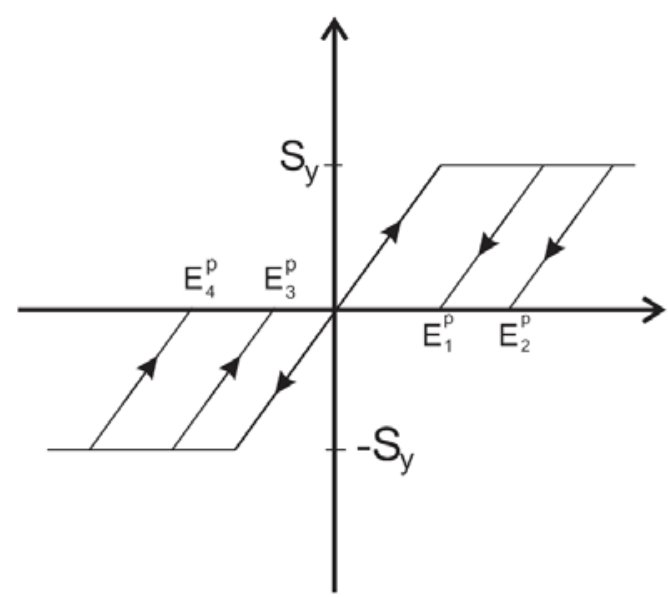

Figura 13 - Carregamento e descarregamento no modelo elastoplástico perfeito 
Este modelo é o mesmo usado no exemplo anterior e demonstra que o material não consegue suportar uma tensão superior a $\sigma_{y}$ e que, ao manter este nível de tensão, a deformação cresce indefinidamente. Portanto, a deformação associada a este nível de tensão é dependente do ponto alcançado durante o escoamento.

Para o modelo elastoplástico a deformação total de um elemento ou estrutura é composta por parcelas reversíveis (elásticas) e irreversíveis (plásticas).

\subsubsection{Modelo elastoplástico perfeito}

O presente trabalho utiliza um regime de deformações plásticas pequenas, e, ao fazermos essa consideração, a deformação total apresenta uma composição de soma entre suas parcelas elástica e plástica, a chamada composição aditiva da deformação, conforme demonstra a equação (6.1):

$$
\begin{aligned}
& E=E^{e}+E^{p} \\
& d E=d E^{e}+d E^{p}
\end{aligned}
$$

sendo $E$ a deformação de Green total, $E^{e}$ a parcela elástica e $E^{p}$ a parcela plástica. A tensão de Piola-Kirchhoff $S$ é dependente apenas da parcela elástica de deformação:

$$
S=\mathbb{E} E^{e}=\mathbb{E}\left(E-E^{p}\right)
$$

sendo $\mathbb{E}$ o módulo de elasticidade do material.

A relação elastoplástica confere uma não linearidade física à estrutura. $\mathrm{Na}$ elastoplasticidade perfeita, a partir do ponto de escoamento, a deformação elástica atinge seu máximo, e todo acréscimo de deformação resulta num acréscimo direto da deformação plástica. Em toda modelagem constitutiva elastoplástica, antes do material atingir a tensão de plastificação pela primeira vez, todo acréscimo de deformação é elástico.

$$
d S=\mathbb{E}\left(d E-d E^{p}\right)
$$


Para o caso elastoplástico perfeito após o escoamento com $d E^{e}=0$, é possível se escrever:

$$
d S=0
$$

Em outras palavras, a tensão não pode ser superior à tensão de escoamento. Por isso os estados admissíveis de tensão devem sempre obedecer à condição do chamado critério de plastificação, dado por:

$$
f(S)=|S|-S_{y} \leq 0
$$

sendo $|S|$ o módulo da tensão aplicada e $S_{y}$ a tensão de plastificação do material.

É possível escrever a variação da deformação plástica segundo uma lei de plastificação como:

$$
d E^{p}=d \lambda \operatorname{sign}(S)
$$

sendo $\operatorname{sign}(\mathrm{S})$ o sinal da tensão e $d \lambda$ o módulo da variação da deformação plástica.

A Figura 14 exemplifica o comportamento da variação da deformação plástica segundo o critério de plastificação:

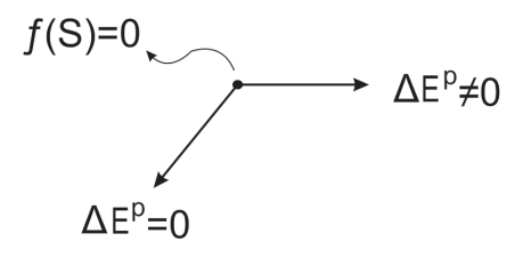

Figura 14 - Comportamento da variação da deformação plástica

Com a Figura 14, é possível analisar que para o regime elástico $f(S)<0$, já para o plástico, tem-se que $f(S)=0$. Logo, quando $f(S)<0, d E^{p}=0, d S \neq 0$ e quando $f(S)=0, d \varepsilon^{p} \neq 0, d S=0$. Segundo as conclusões obtidas, é possível chegar à condição de complementaridade: 


$$
f d \lambda=0
$$

No regime elástico, $f(S) \leq 0$ (podendo assumir qualquer valor negativo) e não há variação da deformação plástica, pois será sempre nula, logo, $d \lambda=0$. Já para o regime plástico, o critério deverá ser sempre nulo, portanto tem-se $d f=0$ e há incremento na deformação plástica, portanto, $d \lambda \neq 0$. Dadas essas considerações, é possível chegar à chamada condição de consistência:

$$
d \lambda d f=0
$$

\subsubsection{Modelo elastoplástico com encruamento isótropo linear positivo}

O encruamento caracteriza a alteração do tamanho e/ou posição do intervalo elástico inicial de tensões. A alteração do tamanho ocorre quando o modelo é isótropo, a da posição quando o modelo é cinemático e quando ambas as alterações ocorrem, tem-se o modelo misto. A Figura 15 demonstra a representação gráfica do modelo isótropo com encruamento linear:

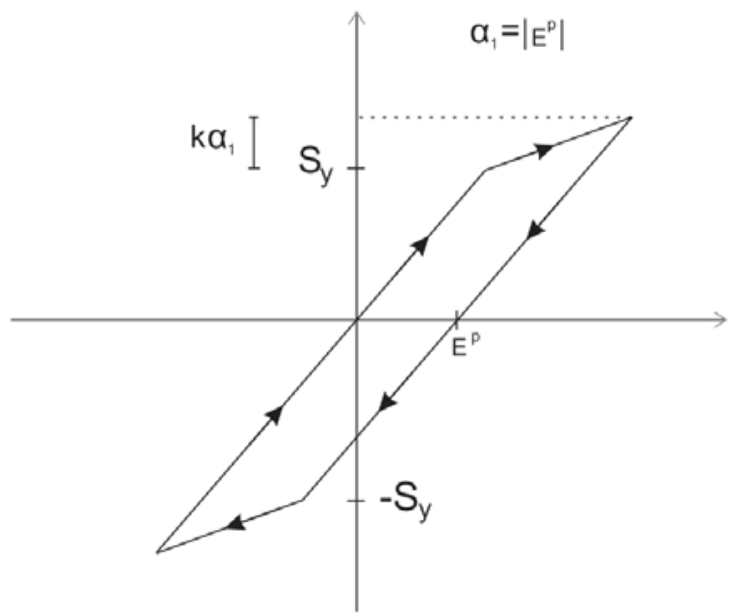

Figura 15 - Modelo elastoplástico com encruamento isótropo linear positivo

No caso do modelo com encruamento isótropo, a expansão do intervalo elástico inicial de tensões acontece simetricamente em relação ao seu centro quando houver a evolução de deformações plásticas. 
É possível observar através da figura anterior que, após o carregamento, o limite elástico passou de $S_{y}$ para $\left(S_{y}+k \alpha_{1}\right)$, resultando na evolução de deformação plástica $E^{p}$. O parâmetro k é uma propriedade do material, chamado de módulo plástico de encruamento isótropo e $\alpha$ é uma medida que registra a "história” de carregamento de um ciclo.

Para o modelo elastoplástico com encruamento isótropo adotado no presente trabalho, são válidas as equações de (6.1) a (6.3), e de (6.6) a (6.8).

Segundo a lei de evolução do encruamento por deformação, é possível obter a seguinte relação:

$$
d \alpha=\left|d \varepsilon^{p}\right|
$$

E considerando a validade da equação (6.6), é possível obter:

$$
d \lambda=d \alpha
$$

Para o encruamento, ao contrário do modelo elastoplástico perfeito, há variação na tensão conforme surgem deformações plásticas. Sendo assim, novos níveis de tensões são admissíveis, o que resulta numa nova fórmula para o critério de plastificação:

$$
f(S, \alpha)=|S|-\left(S_{y}+k \alpha\right) \leq 0
$$

Admitindo uma linearização da função do critério de plastificação, é possível escrever:

$$
d f=\frac{\partial f}{\partial S} d S+\frac{\partial f}{\partial \alpha} d \alpha
$$

e aplicando as seguintes derivadas, obtém-se:

$$
\begin{gathered}
\frac{\partial f}{\partial S}=\frac{\partial\left(|S|-\left(S_{y}+k \alpha_{1}\right)\right)}{\partial S}=\operatorname{sign}(S) \\
\frac{\partial f}{\partial \alpha}=\frac{\partial\left(|S|-\left(S_{y}+k \alpha_{1}\right)\right)}{\partial \alpha}=k
\end{gathered}
$$


Substituindo as equações (6.3), (6.13) e (6.14) em (6.12), obtém-se:

$$
d f=\operatorname{sign}(S) \mathbb{E}\left(d E-d E^{p}\right)-k d \alpha
$$

Utilizando a equação (6.6) e (6.10) em (6.15), resulta em:

$$
d f=\operatorname{sign}(S) \mathbb{E} d E-\operatorname{sign}^{2}(S) \mathbb{E} d \lambda-k d \lambda
$$

Independentemente do valor de $\operatorname{sign}(S)$, o termo $\operatorname{sign}^{2}(S)$ resulta em valor positivo, podendo ser retirado da equação (6.16), resultando em:

$$
d f=\operatorname{sign}(S) \mathbb{E} d E-d \lambda(\mathbb{E}+k)
$$

Partindo da equação de consistência (6.8) e assumindo $d f=0$, resulta em $d \lambda>0$. Com estas considerações, pode-se reorganizar a equação (6.17) como:

$$
d \lambda=\frac{\operatorname{sign}(S) \mathbb{E} d E}{(\mathbb{E}+k)}
$$

Como, pela condição de consistência, $d \lambda>0$ e o termo $(\mathbb{E}+k)$ possui somente parâmetros do material, que são sempre positivos, o termo sign(S) $\mathbb{E} d E$ deverá ser positivo. Multiplicando ambos os lados da equação por $\operatorname{sign}(S)$ :

$$
d \lambda \operatorname{sign}(S)=\frac{\operatorname{sign}^{2}(S) \mathbb{E} d E}{(\mathbb{E}+k)}
$$

Levando em consideração novamente que $\operatorname{sign}^{2}(S)$ é sempre positivo, pode-se eliminar o termo. Empregando a equação (6.6), reescreve-se a equação (6.19) sob a forma: 


$$
d E^{p}=\frac{\mathbb{E} d E}{(\mathbb{E}+k)}
$$

Substituindo a equação (6.20) na equação (6.3), obtém-se:

$$
d S=\mathbb{E}\left(d E-\frac{\mathbb{E} d E}{(\mathbb{E}+k)}\right)=\frac{\mathbb{E} k}{(\mathbb{E}+k)} d E
$$

O termo $\frac{\mathbb{E} k}{(\mathbb{E}+k)}$ é chamado de módulo elastoplástico tangente e relaciona matematicamente a variação da tensão com a variação da deformação total do sistema no regime plástico. Enquanto o termo $k$ relaciona a variação da tensão com a variação da parcela plástica de deformação. Ambas as interpretações estão demonstradas graficamente na Figura 16 a seguir:
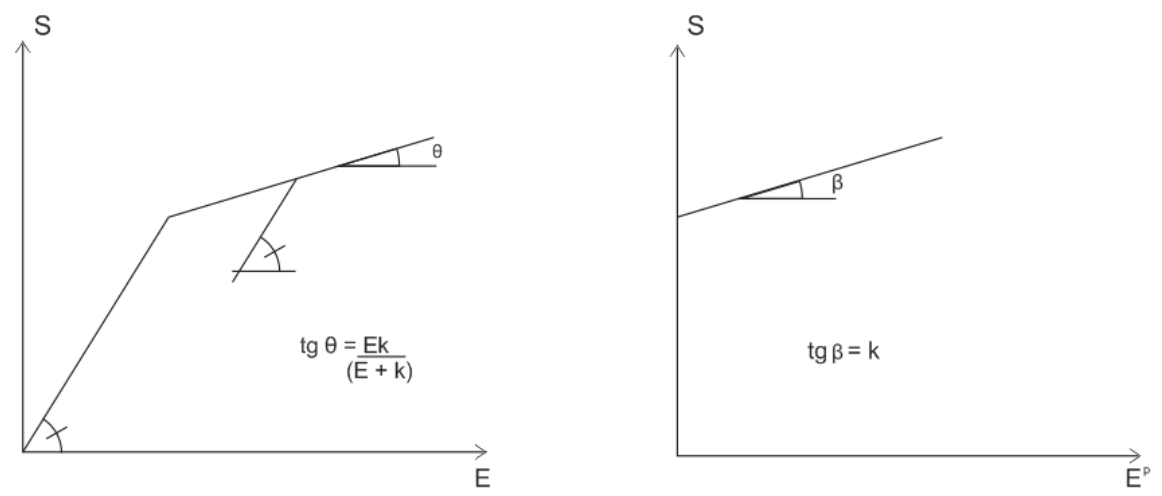

Figura 16 - Demonstração gráfica do módulo elastoplástico tangente (a) e do módulo plástico de encruamento (b)

\subsection{Plasticidade bidimensional de von Mises associativa}

A plasticidade multiaxial é desenvolvida como uma generalização do modelo uniaxial e por isso os critérios estabelecidos para o desenvolvimento da formulação seguem o mesmo padrão: decomposição aditiva da deformação, tem-se estabelecido um critério de plastificação, e são estabelecidas leis de evolução das deformações plásticas e do encruamento. As condições de complementaridade e consistência também são válidas. 
Entretanto, as grandezas e parâmetros envolvidos como tensões, deformações e variáveis de encruamento deixam de ser simplesmente escalares e passam a ter caráteres tensoriais ou vetoriais.

O tensor de deformações total também é tido como uma composição aditiva entre os tensores das parcelas elástica e plástica de deformação, para regime de pequenas deformações:

$$
\begin{aligned}
& E_{i j}=E_{i j}^{e}+E_{i j}^{p} \\
& d E_{i j}=d E_{i j}^{e}+d E_{i j}^{p}
\end{aligned}
$$

A evolução das deformações plásticas é dada segundo um vetor $\vec{r}$, que quando adotado como tangente à superfície de plastificação, é dita como plasticidade associativa, como ilustrado na Figura 17:

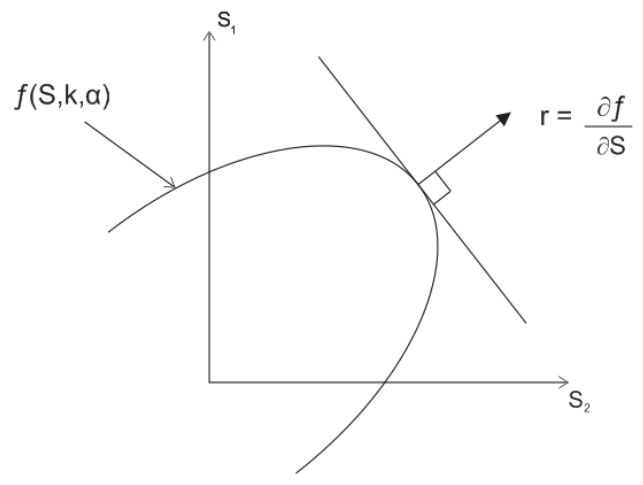

Figura 17 - Representação da associatividade

A evolução da deformação plástica é dada por:

$$
d E^{p}=\lambda \vec{r}
$$

sendo $\lambda$ o multiplicador plástico.

O critério de plastificação no caso unidimensional corresponde a um intervalo de tensão, enquanto no caso bidimensional tem por representação uma superfície representada no espaço das tensões principais. O interior da superfície caracteriza o domínio elástico e, caso 
haja uma mudança no carregamento que gere estados inadmissíveis de tensão, ocorre a expansão da superfície, de modo a obter um estado admissível de tensão, como ilustrado na Figura 18:

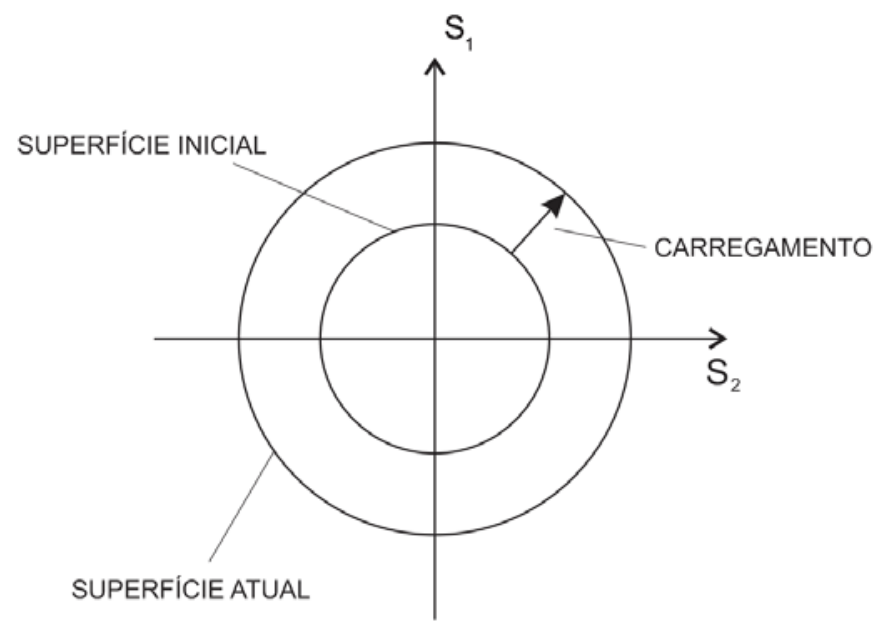

Figura 18 - Superfície de plastificação no espaço bidimensional

No modelo de plasticidade bidimensional adotado, considera-se que o material começa a desenvolver deformações plásticas quando a tensão equivalente do critério de von Mises se iguala à tensão de plastificação do material. Para o caso bidimensional, a tensão equivalente $S_{V}$ do critério é dada por:

$$
S_{V}=\sqrt{S_{11}^{2}-S_{11} S_{22}+S_{22}^{2}+3 S_{12}^{2}}
$$

A representação gráfica do critério de Von Mises está ilustrada na Figura 19: 


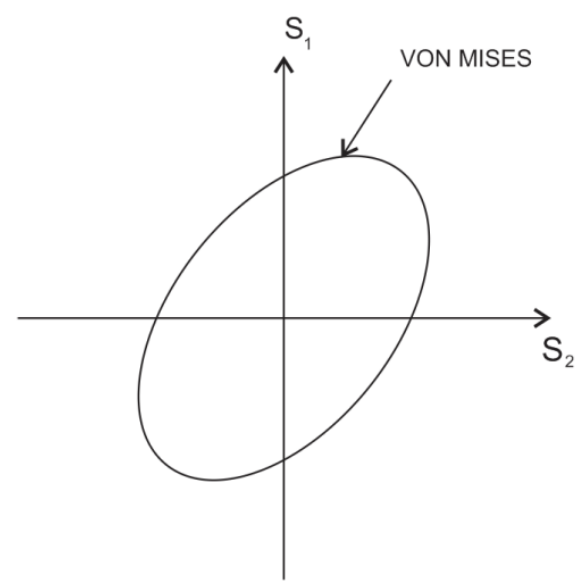

Figura 19 - Representação do critério de Von Mises bidimensional

O critério de plastificação adotado pode ser escrito matricialmente como:

$$
F=\frac{1}{2}\{S\}^{t}[P]\{S\}-\bar{S}(p) \leq 0
$$

sendo que o termo $f=\left(\frac{1}{2}\{S\}^{t}[P]\{S\}\right)$ representa matricialmente o quadrado da tensão equivalente de Von Mises. A matriz $P$ é uma matriz de valor fixo, dada por:

$$
P=\left[\begin{array}{ccc}
2 / 3 & -1 / 3 & 0 \\
-1 / 3 & 2 / 3 & 0 \\
0 & 0 & 2
\end{array}\right]
$$

O vetor $\{S\}$ é a representação vetorial do tensor de tensões, dado por:

$$
\{S\}=\left\{\begin{array}{l}
S_{11} \\
S_{22} \\
S_{12}
\end{array}\right\}
$$

Enquanto $\bar{S}(p)$ é o termo que compreende os parâmetros de encruamento e da tensão de plastificação: 


$$
\bar{S}(p)=\frac{1}{3}\left(S_{y}+W p\right)^{2}
$$

em que $S_{y}$ é a tensão de plastificação do material, $W$ é o módulo elastoplástico tangente e $p$ o encruamento.

\subsubsection{Algoritmo de Von Mises bidimensional associativo}

Para solucionar a questão da plasticidade, é preciso calcular a evolução do encruamento e das deformações plásticas decorrentes de um novo nível de carregamento aplicado. Entretanto, em geral, o maior desafio é encontrar o valor do multiplicador plástico $\Delta \lambda$, pois as relações que regem os critérios e parâmetros resultam em equações não lineares para sua solução. O método iterativo utilizado para solução do problema foi o proposto por Mesquita (1998).

Tem-se a seguinte equação, que relaciona a tensão no estado de tensão anterior com o estado de tensão atual:

$$
\left\{S_{i+1}\right\}=\left\{S_{i}\right\}+\left[\mathscr{C}^{c}\right]\left(\left\{\Delta E_{i+1}\right\}-\left\{\Delta E_{i+1}^{p}\right\}\right)
$$

sendo $\left[\mathfrak{C}^{\mathfrak{C}}\right]$ o tensor constitutivo elástico de quarta ordem.

Considerando inicialmente que as deformações desenvolvidas são puramente elásticas $\Delta E_{i+1}^{p}=0$, é possível reescrever a equação (6.29) na forma de estado de tensão tentativa:

$$
\left\{S_{i+1}^{\text {ten }}\right\}=\left\{S_{i}\right\}+\left[\mathfrak{C}^{c}\right]\{\Delta E\}
$$

Isolando o termo $S_{i}$ na equação (6.30) e substituindo na equação (6.29), obtém-se:

$$
\left\{S_{i+1}\right\}=\left\{S_{i+1}^{t e n}\right\}-\left[\mathfrak{C}^{\mathfrak{c}}\right]\left\{\Delta E_{i+1}^{p}\right\}
$$

sendo $S_{i+1}^{\text {ten }}$ o vetor de tensões tentativa.

Ao estabelecer a direção do fluxo plástico com a superfície de plastificação, tem-se: 


$$
\left\{\Delta E_{i+1}^{p}\right\}=\frac{\partial f_{i+1}}{\partial S_{i+1}}=\Delta \lambda_{i+1}[P]\left\{S_{i+1}\right\}
$$

Ao realizar a substituição da equação (6.32) em (6.31), obtém-se:

$$
\left\{S_{i+1}\right\}=\left\{S_{i+1}^{t e n}\right\}-\left[\mathscr{C}^{c}\right] \Delta \lambda_{i+1}[P]\left\{S_{i+1}\right\}
$$

Isolando o termo $\left\{S_{i+1}\right\}$ da equação (6.33), é possível chegar na seguinte relação para correção das tensões:

$$
\left\{S_{i+1}\right\}=[\Xi]\left[\mathcal{C}^{\mathfrak{c}}\right]^{-1}\left\{S_{i+1}^{\text {ten }}\right\}
$$

sendo $[\Xi]$ a matriz tangente elástica modificada (algorítmica) por Simo e Taylor (1986).

Segundo Crisfield (1991), para o encruamento por deformação, a variação do encruamento é igual à variação da deformação plástica equivalente $\Delta \bar{E}_{i+1}^{p}$ :

$$
\Delta p_{i+1}=\Delta \bar{E}_{i+1}^{p}=\frac{2}{\sqrt{3}} \Delta \lambda_{i+1} R_{i+1}^{1 / 2}
$$

O novo nível de encruamento pode ser escrito de uma maneira implícita como:

$$
p_{i+1}=p_{i}+\frac{2}{\sqrt{3}} \Delta \lambda_{i+1} R_{i+1}^{1 / 2}
$$

Considerando a atualização do parâmetro de encruamento, a equação (6.28) pode ser modificada, sendo escrita para o instante atual, resultando em:

$$
\bar{S}\left(p_{i+1}\right)=\frac{1}{3}\left(S_{y}+W p_{i}+W \frac{2}{\sqrt{3}} \Delta \lambda_{i+1} R_{i+1}^{1 / 2}\right)^{2}
$$


Para o critério de plastificação no instante atual $\left(F_{i+1}\right)$, levando em consideração as atualizações das tensões com as deformações plásticas e encruamento atuais, e escrevendo $f_{i+1}=\left(\frac{1}{2}\left\{S_{i+1}\right\}^{t}[P]\left\{S_{i+1}\right\}\right)$, pode-se escrever:

$$
F_{i+1}=f_{i+1}-\bar{S}_{i+1}=0
$$

Segundo a formulação proposta por Mesquita (1998), para encontrar o valor de $\Delta \lambda_{i+1}$ que satisfaça a condição de consistência, aplica-se o método de Newton-Raphson. Um quadro resumo é descrito a seguir, baseado no quadro apresentado no trabalho do referido autor:

1. Definir uma tentativa inicial

$\Delta \lambda_{0}=0 \quad, \quad$ Tolerância $=\chi$

2. Definir as constantes
$C_{1}=\left(S_{1}^{t e n}+S_{2}^{t e n}\right)^{2}$
$C_{4}=2 G$
$C_{2}=\left(S_{1}^{t e n}-S_{2}^{t e n}\right)^{2}+\left(S_{3}^{t e n}\right)^{2}$
$C_{5}=S_{y}+W p_{i}$
$C_{3}=\frac{\mathbb{E}}{3(1-v)}$
$C_{6}=\frac{2}{\sqrt{3}} W$

3. Calcular F no ponto $\Delta \lambda_{0}$

$\mathrm{f}=\frac{1}{2}\left[\frac{C_{1}}{6\left(1+\Delta \lambda_{0} C_{3}\right)^{2}}+\frac{C_{2}}{2\left(1+\Delta \lambda_{0} C_{4}\right)^{2}}\right]$
$\bar{\sigma}=\frac{1}{3}\left[C_{5}+\Delta \lambda_{0} \mathrm{f}^{1 / 2} C_{6}\right]^{2}$

$\mathrm{F}=\mathrm{f}-\bar{\sigma}$

4. Calcular a derivada de $\mathrm{F}$ no ponto $\Delta \lambda_{0}$

$\mathrm{f}^{\prime}=-\frac{C_{1} C_{3}}{6\left(1+\Delta \lambda_{0}\right)^{2}}-\frac{C_{2} C_{4}}{2\left(1+\Delta \lambda_{0} C_{4}\right)^{2}}$

$\bar{\sigma}^{\prime}=\frac{1}{3} C_{6}\left[2 C_{5} \sqrt{\mathrm{f}}+\frac{1}{\sqrt{\mathrm{f}}} C_{5} \mathrm{f}^{\prime} \Delta \lambda_{0}+2 C_{6} \mathrm{f} \Delta \lambda_{0}+C_{6} \mathrm{f}^{\prime} \Delta \lambda_{0}^{2}\right]$

$\mathrm{F}^{\prime}=\mathrm{f}^{\prime}-\bar{\sigma}^{\prime}$

5. Calcular a nova aproximação $\Delta \lambda_{1}$

$\Delta \lambda_{1}=\Delta \lambda_{0}-\frac{\mathrm{F}}{\mathrm{F}^{\prime}}$

6. Se $\left|\left(\Delta \lambda_{1}-\Delta \lambda_{0}\right) / \Delta \lambda_{1}\right|<\chi=>\Delta \lambda_{1}$ é solução

Se não, fazer $\Delta \lambda_{0}=\Delta \lambda_{1}$ e voltar ao passo 3 . 
Desta forma, a solução para o problema da plasticidade é obtida com a resolução de um processo iterativo. Como critério de parada para o algoritmo, utilizou-se uma variação relativa da resposta obtida para o multiplicador plástico. Esta escolha foi adotada porque utilizar valores absolutos como critério de parada pode resultar em problemas de convergência, pois a ordem de grandeza da solução depende da ordem de grandeza do carregamento e das deformações plásticas desenvolvidas. 


\section{EXEMPLOS}

Neste item, são apresentados sete exemplos, objetivando a validação dos desenvolvimentos e implementações apresentados no presente texto. Em todos os exemplos os elementos de chapa utilizados são triangulares com aproximação cúbica e os de fibra apresentam aproximação linear. Para os exemplos que tratam de elastoplasticidade perfeita, foi adotado um módulo tangente quase nulo, dada a necessidade da existência de uma tangente não nula para convergência do método de Newton-Raphson, em caso de controle de força e não de deslocamento. Para gerar a malha dos exemplos analisados, foi utilizado o software Acadmesh.

\subsection{Viga em balanço - grandes deslocamentos}

Este exemplo foi proposto com o intuito de validar a correta implementação da formulação posicional, que contempla os efeitos da não linearidade geométrica.

Os resultados são comparados com resultados analíticos obtidos em Matiasson (1981), em que foram utilizadas integrais elípticas nos desenvolvimentos. As seguintes hipóteses foram adotadas no referido trabalho: o material foi considerado linear elástico, foram ignoradas deformações por esforço axial e cisalhamento, os membros foram considerados incialmente retos e com seção constante, e o plano de carregamento coincide com o plano de flexão.

Matiasson (1981) relacionou as grandezas adimensionais $u$ / L e $w / L$ com uma outra dada por $P L^{2} / \mathbb{E} I$ para uma viga engastada e livre submetida a uma carga na extremidade livre, conforme mostra a Figura 20. Sendo $u$ o deslocamento horizontal, $w$ o deslocamento vertical, $P$ para a carga aplicada, $L$ o comprimento da viga, $E$ o módulo de elasticidade e $I$ o momento de inércia. 


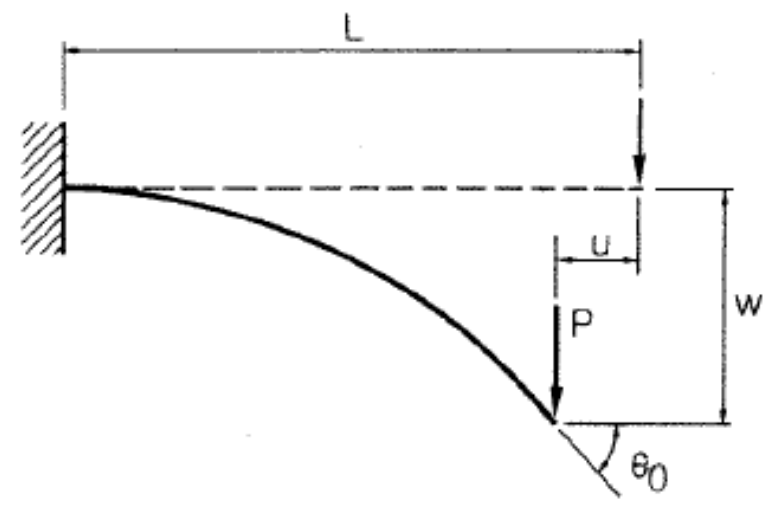

Figura 20 - Viga engastada e livre horizontal submetida a um carregamento vertical

(Fonte: Matiasson, 1981)

Para o presente exemplo foi adotado módulo de elasticidade $\mathbb{E}=3.10^{5} \mathrm{KN} / \mathrm{m}^{2}$ e uma malha com 448 elementos triangulares e 2176 graus de liberdade, distribuídos tal como apresentado no esquema da Figura 21:

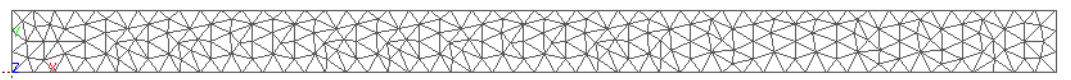

(a)

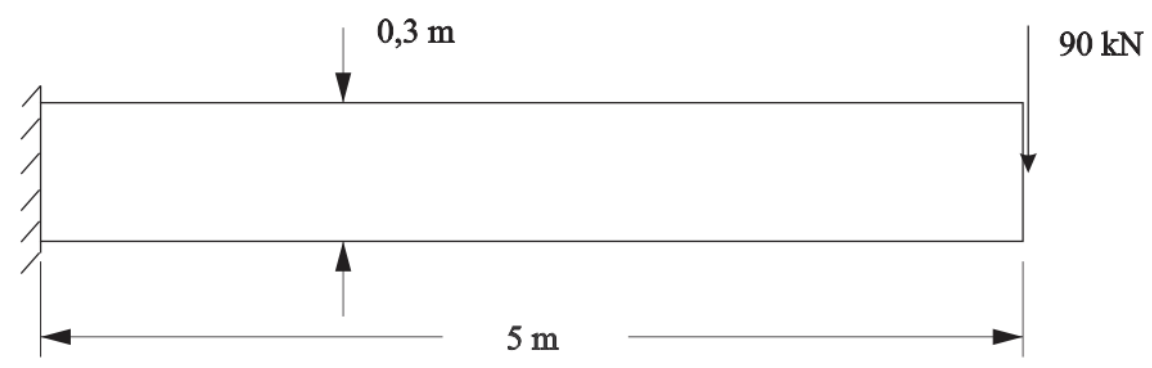

(b)

Figura 21 - (a) esquema dos elementos finitos (b) estrutura e condições de contorno e carregamento

Na Figura 22, apresenta-se um comparativo entre os resultados de deslocamento horizontal e vertical obtidos em Matiasson (1981) (analíticos) e no presente trabalho, para diferentes níveis de carregamento: 


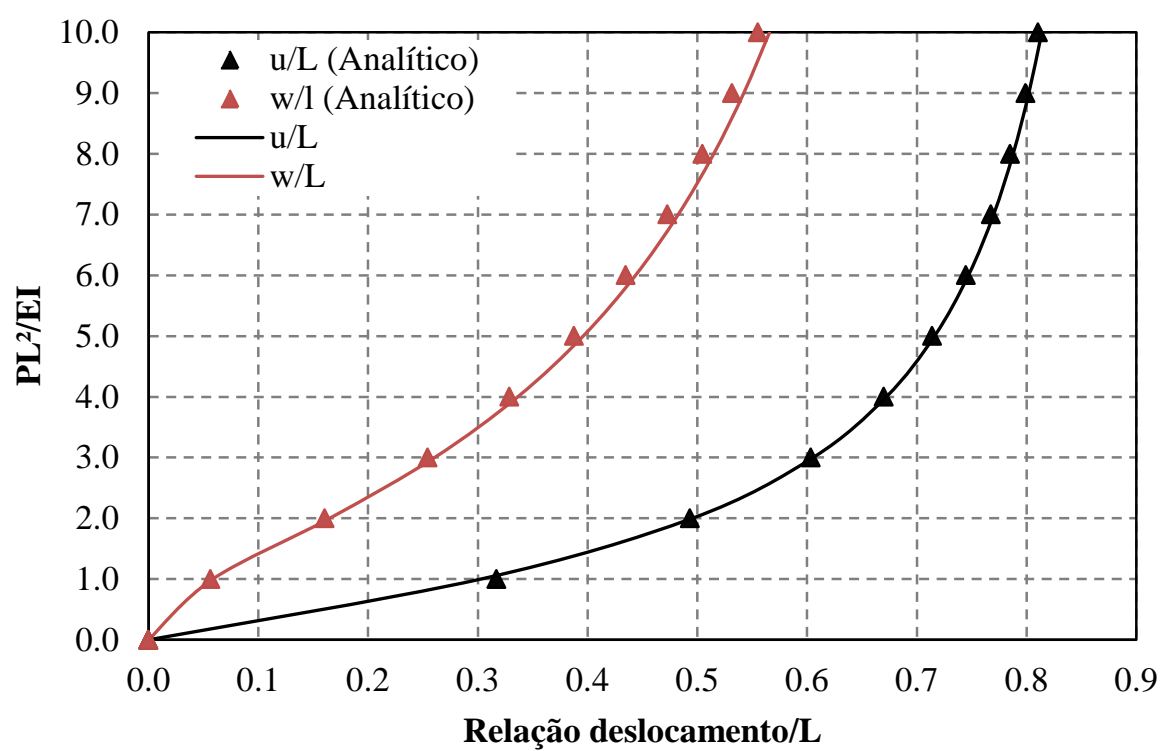

Figura 22 - Resultado comparativo para a viga engastada-livre

Além dos resultados do presente trabalho apresentarem o comportamento semelhante ao de Matiasson (1981), a variação máxima entre os resultados é pequena e desprezável, podendo tal discrepância ser devida às condições de aplicação do carregamento e das vinculações, pois o elemento finito de Matiasson (1981) é unidimensional de viga e do presente trabalho bidimensional de chapa.

Tabela 1 - Resultados comparativos

\begin{tabular}{c|ccccccc}
\hline \multirow{2}{*}{$\begin{array}{c}\text { Passo de } \\
\text { carga }\end{array}$} & \multicolumn{2}{|c|}{ Matiasson (1981) } & \multicolumn{2}{c|}{ Presente formulação } & \multicolumn{2}{c}{ Diferença relativa (\%) } \\
\cline { 2 - 7 } & $\mathbf{u} / \mathbf{L}$ & $\mathbf{w} / \mathbf{L}$ & $\mathbf{u} / \mathbf{L}$ & $\mathbf{w} / \mathbf{L}$ & $\mathbf{u} / \mathbf{L}$ & w/L \\
\hline 1 & 0,3172 & 0,05643 & 0,302752 & 0,0584576 & 4,5549 & 3,5931 \\
\hline 2 & 0,49346 & 0,16064 & 0,49528 & 0,16494 & 0,3688 & 2,6768 \\
\hline 3 & 0,60325 & 0,25442 & 0,605358 & 0,26051 & 0,3494 & 2,3937 \\
\hline 4 & 0,66996 & 0,32894 & 0,672158 & 0,336312 & 0,3281 & 2,2411 \\
\hline 5 & 0,71379 & 0,38763 & 0,716054 & 0,395926 & 0,3172 & 2,1402 \\
\hline 6 & 0,74457 & 0,43459 & 0,746934 & 0,44359 & 0,3175 & 2,0709 \\
\hline 7 & 0,76737 & 0,47293 & 0,769874 & 0,482484 & 0,3263 & 2,0202 \\
\hline 8 & 0,78498 & 0,50483 & 0,787668 & 0,514842 & 0,3424 & 1,9832 \\
\hline 9 & 0,79906 & 0,53182 & 0,801958 & 0,542224 & 0,3627 & 1,9563 \\
\hline 10 & 0,81061 & 0,555 & 0,813754 & 0,56574 & 0,3879 & 1,9351 \\
\hline
\end{tabular}

A presente formulação ainda é capaz de medir a não linearidade geométrica em vigas altas, por se tratar de um elemento finito de chapa, enquanto que o elemento finito de viga só 
é capaz de representar adequadamente vigas longas, ou seja, que possuem uma altura da seção pequena em relação ao comprimento.

\subsection{Comparação com a solução técnica de Resistência dos Materiais}

Para comprovar a correta implementação da formulação com a consideração do reforço de fibras, utiliza-se a solução técnica obtida da Resistência dos Materiais, em que são feitas as seguintes hipóteses: materiais homogêneos, isotrópicos, contínuos, coesos e lineares.

A Figura 23 mostra o esquema referente à estrutura e deslocamentos prescritos: aplicado na ponta direita da sestrutura:

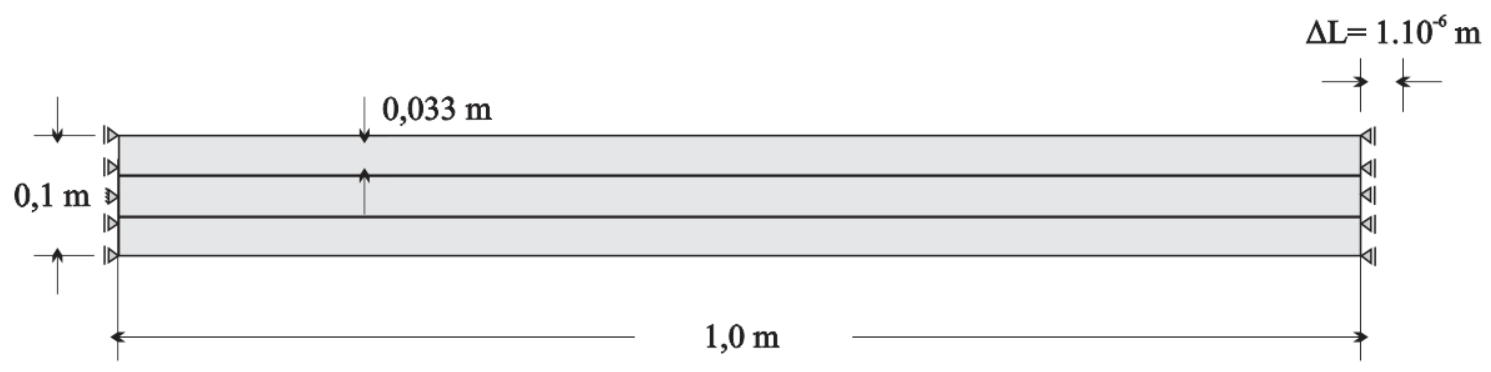

Figura 23 - Barra reforçada submetida a esforço de tração

A matriz apresenta espessura de $e=0,1 \mathrm{~m} ; v=0$, módulo de elasticidade $\mathbb{E}_{b}=2.10^{11} \mathrm{kN} / \mathrm{m}^{2}$. Já cada reforço apresenta área igual à $A_{r}=2,65 \cdot 10^{-4} \mathrm{~m}^{2}$ e módulo de elasticidade $\mathbb{E}_{r}=3.10^{12} \mathrm{kN} / \mathrm{m}^{2}$.

Como os materiais estão consolidados, os reforços apresentam o mesmo deslocamento, que, segundo a teoria clássica, pode-se relacionar com a tensão atuante, logo:

$$
\begin{gathered}
\Delta L=\frac{P L}{\mathbb{E}_{r} A_{r}} \\
\sigma_{r}=\frac{\Delta L \mathbb{E}_{r}}{L}
\end{gathered}
$$

Substituindo-se os valores adotados, tem-se pela teoria clássica:

$$
\sigma_{r}=3.10^{6} \mathrm{kN} / \mathrm{m}^{2}
$$


Para a solução pelo método dos elementos finitos, foram utilizados 10 elementos finitos de barra simples para simular os reforços e 70 elementos de chapa triangulares. Os deslocamentos prescritos foram aplicados diretamente nos nós da malha da chapa. O resultado é mostrado na Figura 24:

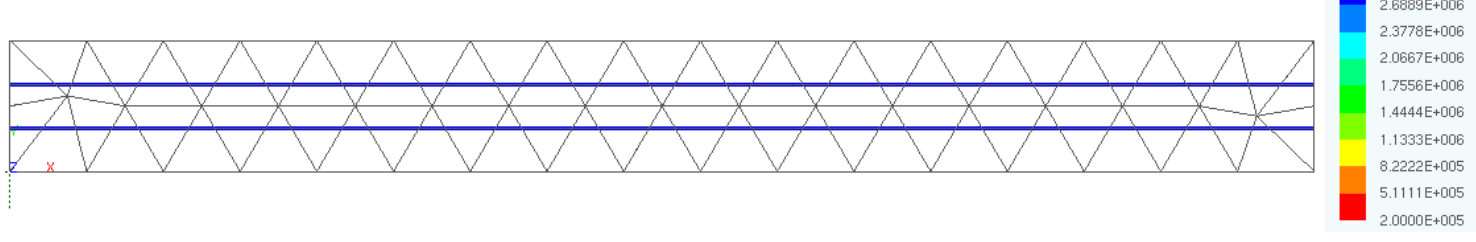

Figura 24 - Tensão no reforço pelo método dos elementos finitos

Como os deslocamentos prescritos foram aplicados diretamente sobre os nós da malha da chapa e não do reforço, aliado ao fato de que não houve diferença entre os valores obtidos para as tensões pelo método dos elementos finitos posicional e a teoria clássica, pode-se concluir que está correta a implementação da formulação. Considerando ainda a mesma estrutura sob as mesmas condições de vinculação e deslocamento, ao considerar-se uma tensão de ruptura do reforço como $\sigma_{R}=2,01 \times 10^{6} \mathrm{kN} / \mathrm{m}^{2}$, faz-se a análise do deslocamento da estrutura após esta tensão, desconsiderando-se totalmente a contribuição do reforço após este atingir o nível de tensão de ruptura:

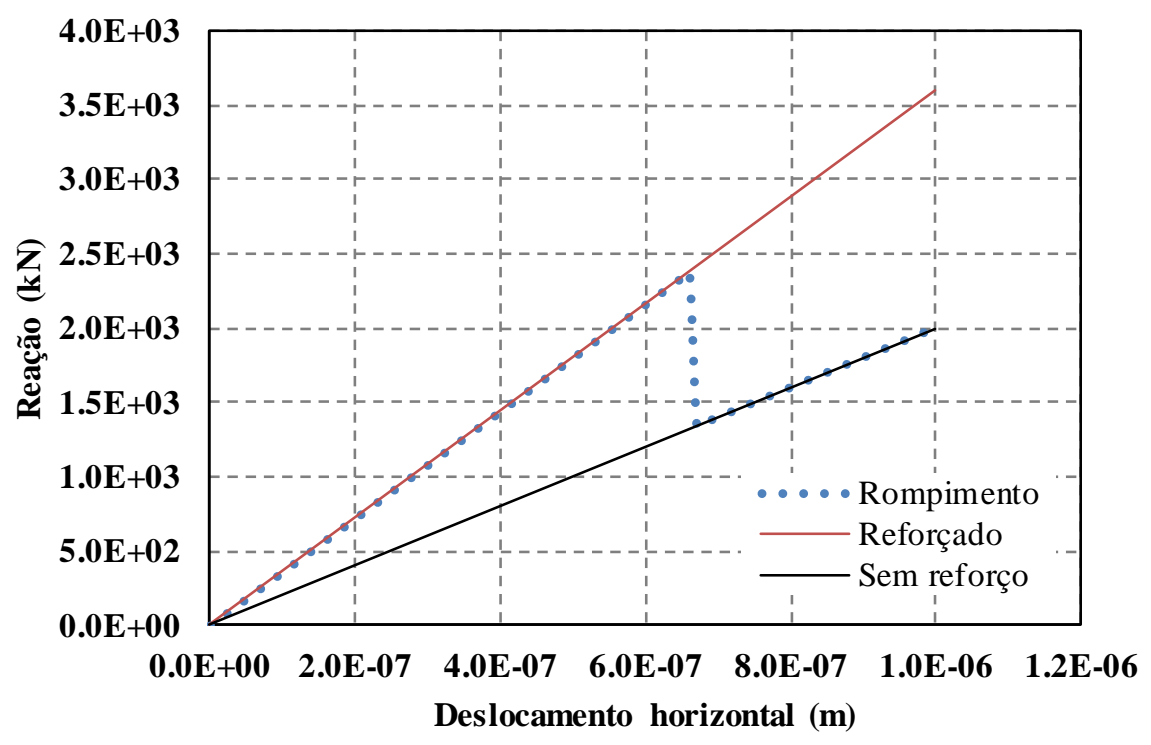

Figura 25 - Passo de carga $\mathrm{x}$ deslocamento horizontal 
Como a distribuição da tensão no reforço é constante ao longo de todo seu comprimento, todos os elementos falharam no mesmo instante de deslocamento. Ao romper, os elementos deixam de contribuir para a rigidez do sistema, devendo este então apresentar valores de reação iguais à situação da chapa sem reforço a partir deste ponto, assim como mostra o resultado obtido na Figura 25.

\subsection{Viga bi-apoiada elastoplástica submetida a carregamento uniformemente distribuído}

Para verificar a correta implementação da plasticidade na matriz, foi feita uma comparação dos resultados entre a presente formulação e o software comercial Ansys ${ }^{\circledR}$.

Dada a seguinte estrutura biapoiada (Figura 26):

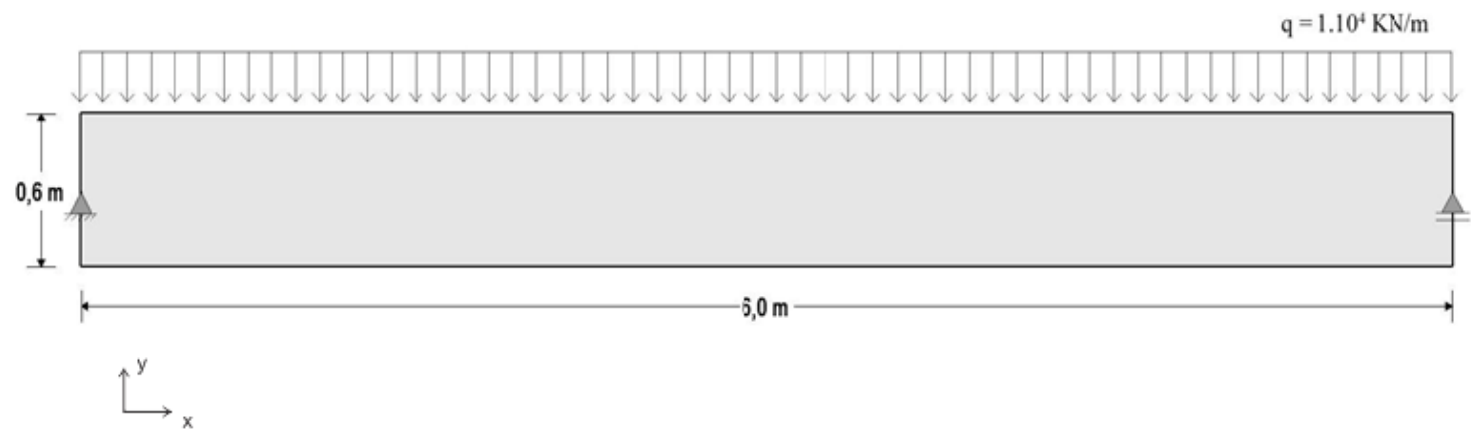

Figura 26 - Viga bi-apoiada submetida à flexão

sendo, para o material da viga, a tensão de plastificação $\sigma_{Y}=3 \times 10^{6} \mathrm{kN} / \mathrm{m}^{2}$, o módulo de elasticidade $\mathbb{E}=2 \times 10^{11} \mathrm{kN} / \mathrm{m}^{2}$ e o módulo tangente $W=5 \times 10^{10} \mathrm{kN} / \mathrm{m}^{2}$.

Para este exemplo, foi usada uma malha com 940 elementos e 8834 graus de liberdade. Para o Ansys $^{\circledR}$, foram utilizados cerca de 1300 elementos com aproximação quadrática. A Figura 27, Figura 28 e Figura 29 apresentam a comparação dos resultados obtidos, para a face inferior do centro do vão, no presente trabalho e utilizando-se o programa Ansys $^{\circledR}$, respectivamente, de deslocamento na direção $y$, tensão normal na direção $x$ e deformação plástica na direção $x$ : 


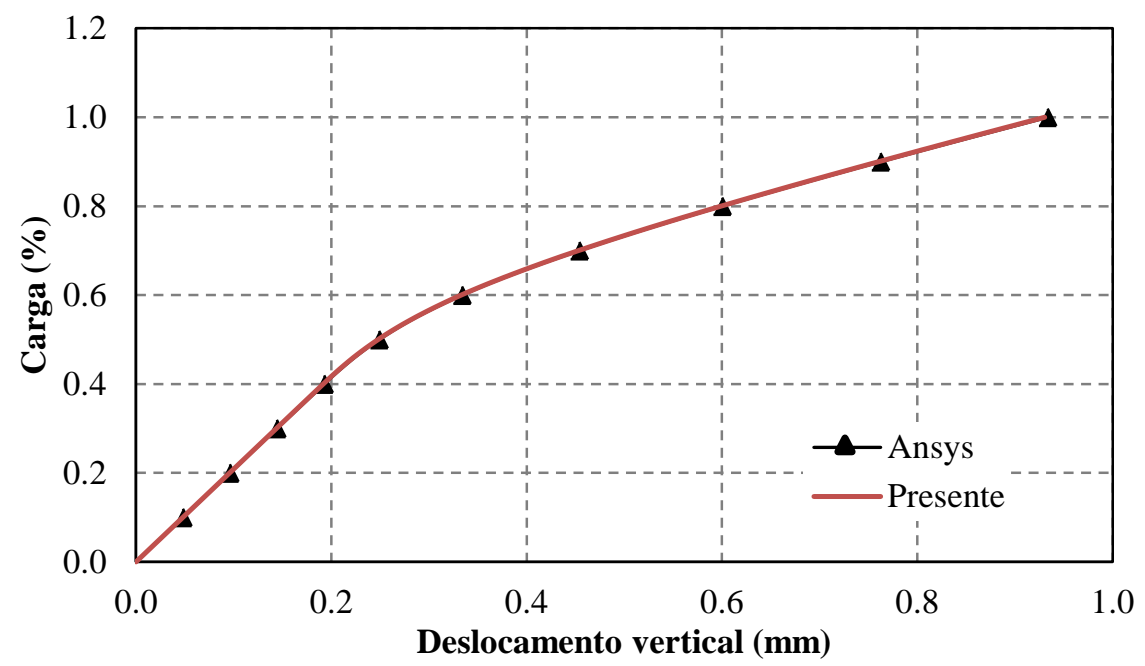

Figura 27 - Comparativo entre os valores de deslocamentos verticais (eixo y)

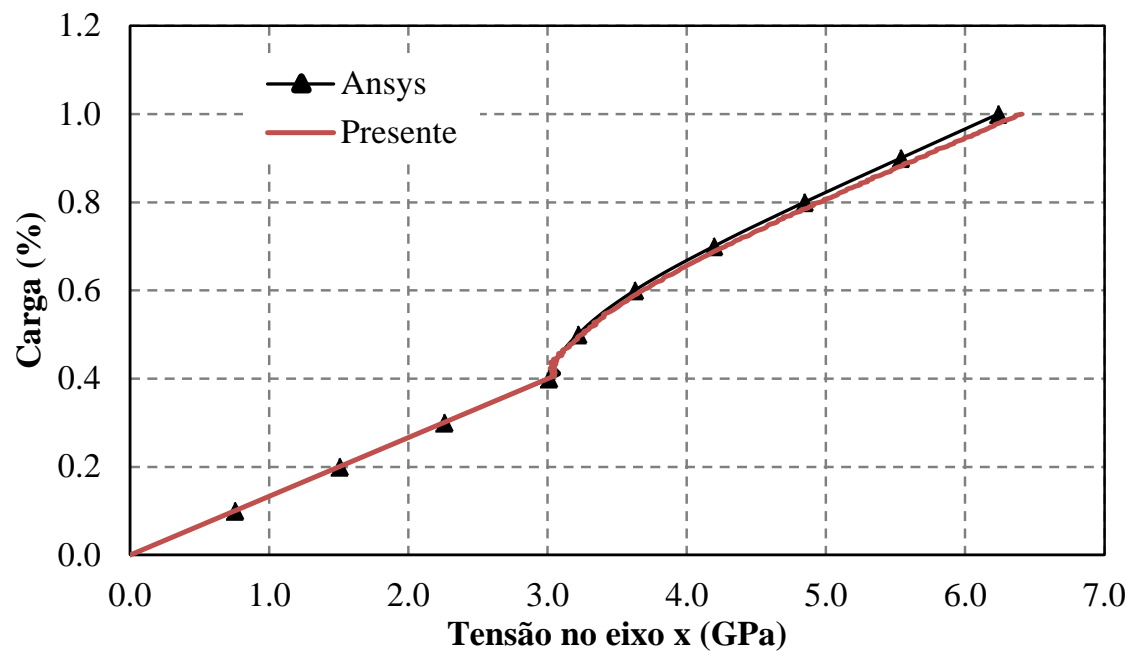

Figura 28 - Comparativo entre os valores de tensões na direção $x$

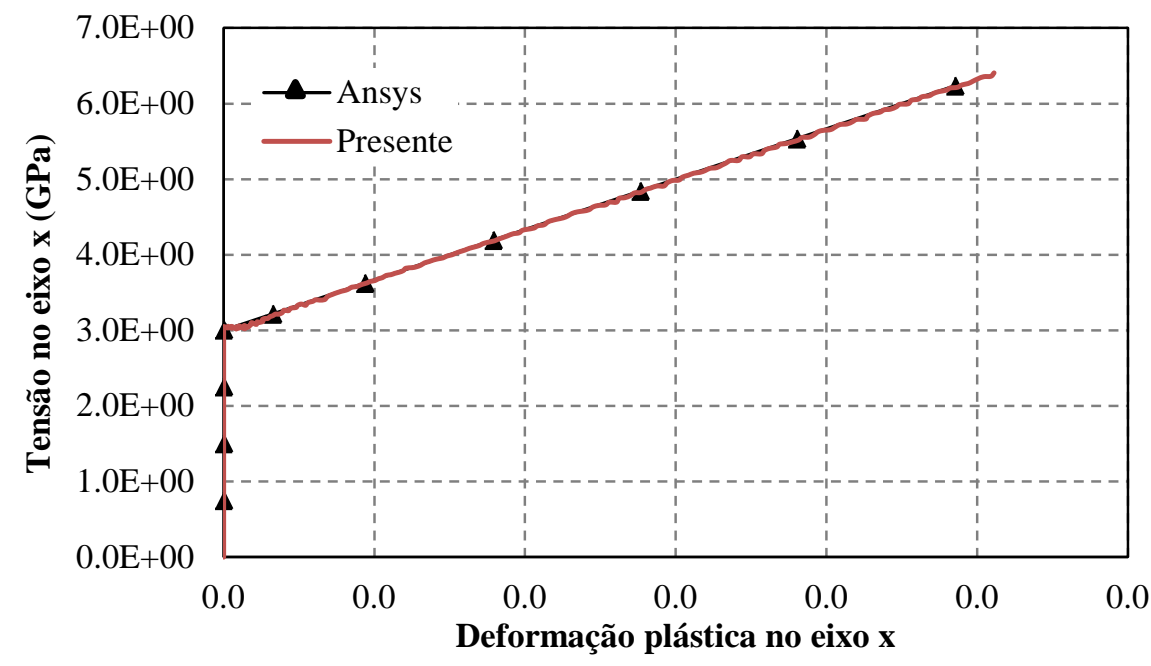

Figura 29 - Comparativo entre os valores de deformação plástica na direção x 
É possível observar que os resultados apresentam as mesmas tendências de comportamento ao entrar no regime plástico, bem como a intensidade de carregamento para qual o processo de plastificação inciou-se. Para os valores finais obtidos no Ansys ${ }^{\circledR}$ e no presente trabalho, as variações percentuais foram $0,4 \%$ para o deslocamento vertical; $4,7 \%$ para a tensão no eixo $x$ e 2,5\% para a deformação plástica. Analisando os resultados obtidos, pode-se concluir que a plasticidade na matriz foi implementada de forma correta.

\subsection{Momento de plastificação em viga engastada-livre}

Dado o exemplo demonstrado por Doltsinis (2010), conforme Figura 12, em que a tensão normal está completamente redistribuída na seção com valor constante igual à $\sigma_{Y}$, é possível calcular o momento de plastificação associado ao binário das forças resultantes na seção:

$$
M_{p}=\sigma_{Y} h^{2} b
$$

sendo $h$ a metade da altura da seção e $b$ a largura da seção transversal da viga, semelhante ao esquema da Figura 12. Adotando uma tensão de plastificação $\sigma_{Y}=3.10^{3} \mathrm{kN} / \mathrm{m}^{2}, h=0,2 \mathrm{~m}$ e largura da seção $b=0,1 m$, é possível concluir que o momento de plastificação para a seção adotada é $M_{p}=12 k N . m$.

O momento de plastificação é sempre o mesmo para uma mesma seção com mesmas propriedades, entretanto, o valor da carga aplicada na extremidade livre da viga que gera sempre o mesmo valor de momento no engaste depende do comprimento da viga. Adotandose três vigas com a seção adotada, mas com comprimentos de $3 \mathrm{~m}, 4 \mathrm{~m}$ e $5 \mathrm{~m}$; as cargas concentradas aplicadas associadas ao momento de plastificação são $4 k N$, $3 k N$ e 2, $4 k N$ respectivamente. Entretanto, as cargas foram aplicadas de forma distribuída uniformemente na extremidade livre da viga, correspondendo às cargas distribuídas na altura com valor de $10 \mathrm{kN} / \mathrm{m}, 7,5 \mathrm{kN} / \mathrm{m} e 6 \mathrm{kN} / \mathrm{m}$, conforme esquema básico da Figura 30: 


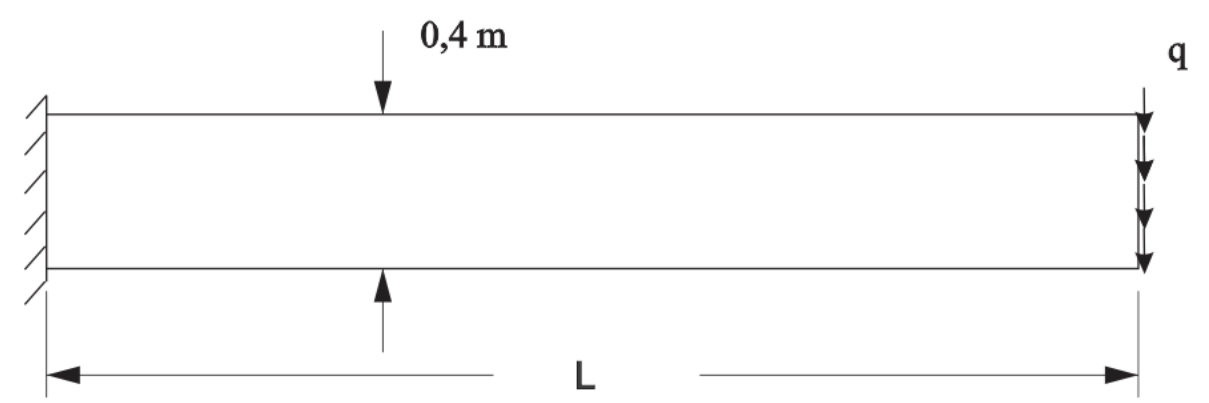

Figura 30 - Esquema da estrutura

Para a estrutura com vãos de $3 m, 4 m e 5 m$ foram utilizadas malhas com, respectivamente, 1290 elementos triangulares e 12002 graus de liberdade, 1372 elementos triangulares e 12788 graus de liberdade, 1262 elementos triangulares e 11828 graus de liberdade. A Figura 31 apresenta o gráfico da relação força aplicada x deslocamento vertical na extremidade livre da viga para os diferentes valores de comprimento adotados.

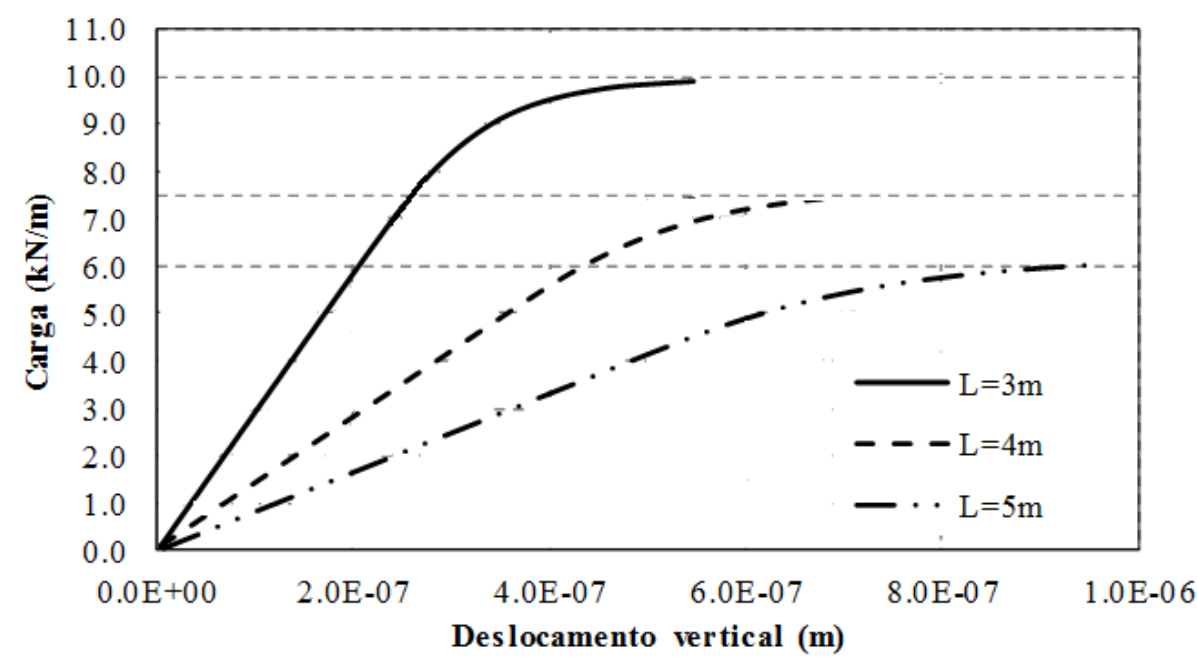

Figura 31 - Gráfico (carga x deformação) em vigas de diferentes comprimentos

É possível observar que houve concordância entre as cargas teóricas para a plastificação da seção da viga e o comportamento elastoplástico perfeito segundo a presente formulação para as cargas aplicadas nos diferentes comprimentos de viga nalisados. Desta forma, é possível concluir que o caráter elastoplástico perfeito foi alcançado de forma satisfatória para a representação da perda de instabilidade da estrutura pela formação da rótula plástica no engaste.

A Figura 32 mostra a distribuição da tensão no eixo $x$ ao longo da viga, equanto que a Figura 33 apresenta a deformação plástica no eixo $x$. 


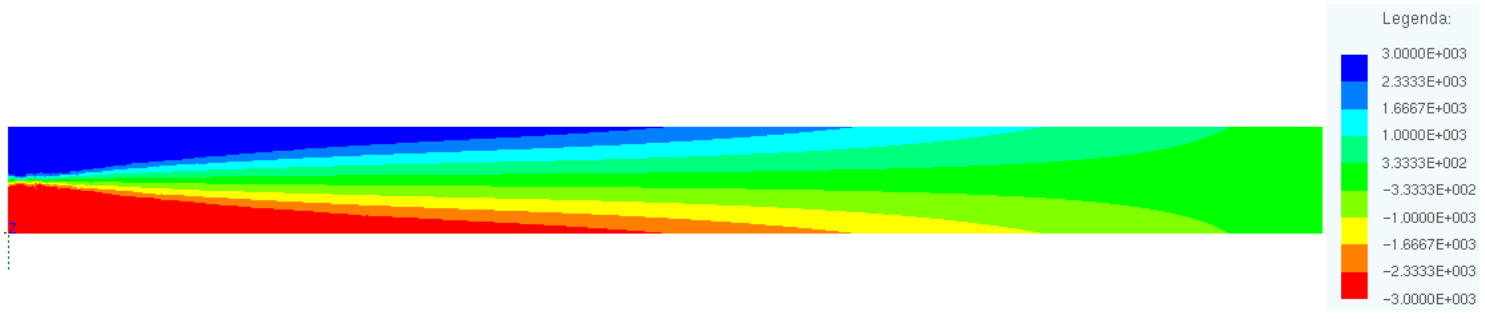

Figura 32 - Distribuição de tensão na matriz elastoplástica perfeita

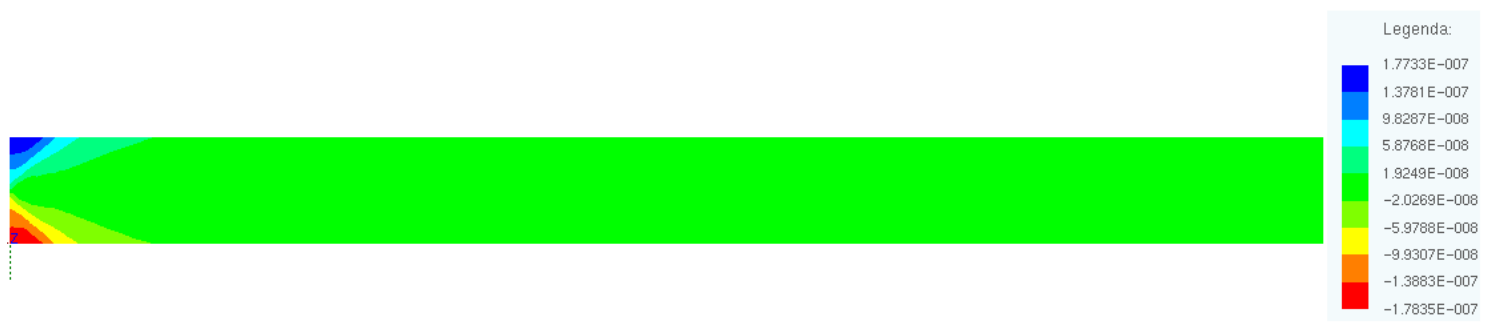

Figura 33 - Distribuição da deformação plástica equivalente na matriz elastoplástica perfeita

Conforme apresenta a Figura 32, é possível observar que a tensão está atingindo o valor de plastificação, mesmo próximo ao meio da seção e que isso resulta na formação da rótula plástica próximo ao engaste, conforme mostra a Figura 33, resultando assim na instabilidade do sistema.

\subsection{Plasticidade no reforço}

Neste exemplo, ao utilizar a mesma estrutura e condições de vinculação e deslocamentos do exemplo 7.2, deseja-se avaliar a formulação implementada no que se refere à plasticidade no reforço. Atribuindo um módulo tangente quase nulo e fixando a tensão de plastificação do reforço como a metade da tensão no último passo do caso elástico do exemplo 7.2, ou seja, $S_{Y}=1,5.10^{6} \mathrm{kN} / \mathrm{m}^{2}$, obteve-se o resultado na Figura 34 para a tensão normal no reforço de acordo com o nível de deslocamento aplicado: 


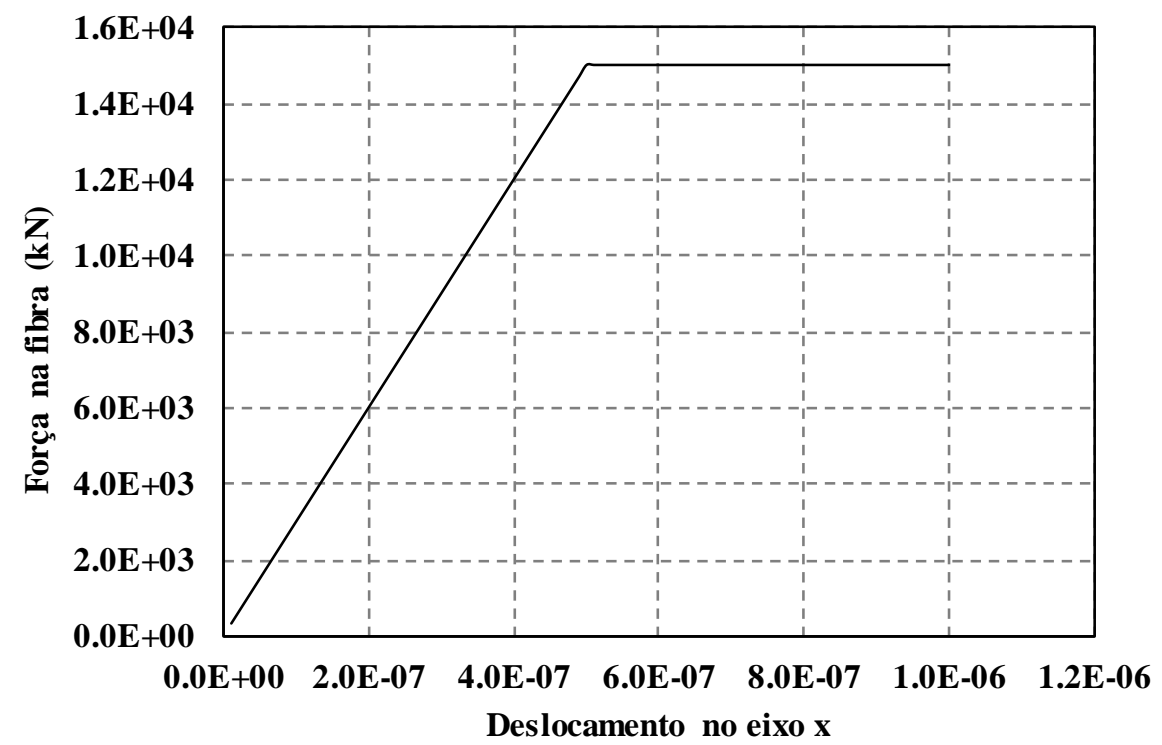

Figura 34 - Digrama de tensão x carga

Analisando o gráfico obtido, é possível verificar a coerência dos resultados, pois ao fixar a tensão de plastificação como a metade da tensão obtida no último passo para o caso elástico, a plastificação deve ocorrer na metade dos passos de carga. E como o modelo elastoplástico adotado foi o perfeito, o nível de tensão deve permanecer constante, por mais que se aumente o valor do deslocamento prescrito aplicado.

\subsection{Análise do mecanismo de plasticidade governante para as fibras}

O presente exemplo é inspirado no realizado por Nogueira et. al (2014), que visa analisar o comportamento de uma estrutura com fibras perfeitamente aderidas dispostas aleatoriamente e verificar o mecanismo governante da plastificação, seja por esforço normal na fibra ou cisalhamento na interface.

A Figura 35 ilustra a estrutura adotada e suas condições de contorno e carregamentos aplicados: 


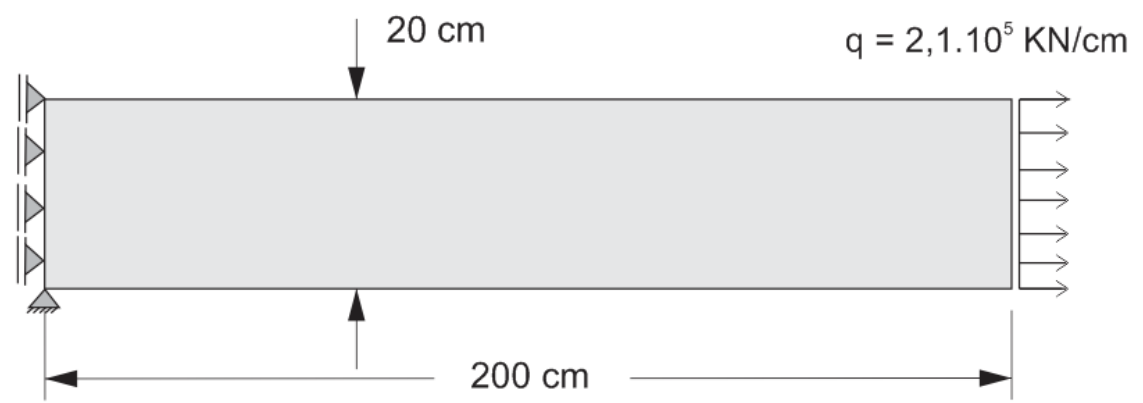

Figura 35 - Esquema da chapa tracionada

Para avaliar os diferentes mecanismos de plastificação, foram escolhidos dois tipos de fibra com as mesmas propriedades físicas, mas de comprimentos $L=3 \mathrm{~cm} \mathrm{e} 6 \mathrm{~cm}$. Ambas possuem módulo de elasticidade $\mathbb{E}_{f i b}=2,1.10^{7} \mathrm{KN} / \mathrm{cm}^{2}$, área $A_{r}=1 \mathrm{~cm}^{2}$ e perímetro $\rho=2 \mathrm{~cm}$.

Conforme as equações (5.48) e (5.49) e a Figura 11, previamente demonstradas no presente trabalho, e adotando que a tensão de plastificação para a interface fibra-matriz é $\tau_{\text {plast }}=6.10^{4} \mathrm{KN} / \mathrm{cm}^{2}$ e a tensão normal de plastificação na fibra perfeitamente aderida é $\sigma_{\text {plast }}=2.10^{5} \mathrm{KN} / \mathrm{cm}^{2}$, diferentes mecanismos regem a plastificação para cada comprimento de fibra, segundo a formulação implementada. Para ambos foi adotado módulo tangente quase nulo. Aplicando os valores adotados para as equações, tem-se:

- para as fibras de $3 \mathrm{~cm}$ :

$$
\begin{aligned}
& \bar{N}_{1} \leq \sigma_{a d m} A=>\bar{N}_{1}=2.10^{5} x(1)=2.10^{5} \mathrm{kN} \\
& \bar{N}_{2} \leq \tau_{a d m} \frac{l}{2} \rho_{f i b}=>\bar{N}_{2}=6.10^{4}\left(\frac{3}{2}\right)(2)=1,8.10^{5} \mathrm{kN}
\end{aligned}
$$

- para as fibras de $6 \mathrm{~cm}$ :

$$
\begin{aligned}
& \bar{N}_{1} \leq \sigma_{a d m} A=>\bar{N}_{1}=2.10^{5} x(1)=2.10^{5} \mathrm{kN} \\
& \bar{N}_{2} \leq \tau_{a d m} \frac{l}{2} \rho_{\text {fib }}=>\bar{N}_{2}=6.10^{4}\left(\frac{6}{2}\right)(2)=3,6.10^{5} \mathrm{kN}
\end{aligned}
$$

Em ambos os casos foi utilizada uma fração volumétrica de fibras de $50 \%$ em relação à estrutura. Para a situação das fibras com comprimento de $3 \mathrm{~cm}$, a força associada à plastificação da fibra é $N_{1}=2.10^{5} \mathrm{KN}$ e para a plastificação da interface é $N_{2}=1,8.10^{5} \mathrm{KN}$, 
sendo, portanto, que a plastificação se dá segundo a curva tensão-deformação da interface. Para a situação das fibras com comprimento de $6 \mathrm{~cm}$, a força associada à plastificação da fibra é $N_{1}=2.10^{5} \mathrm{KN}$ e para a plastificação da interface é $N_{2}=3,6.10^{5} \mathrm{KN}$, sendo, portanto, que a plastificação se dá conforme a curva tensão-deformação do esforço normal da fibra.

A Figura 36 apresenta as tensões nas fibras para os casos das fibras com comprimentos de $3 \mathrm{~cm}$ e $6 \mathrm{~cm}$, respectivamente:

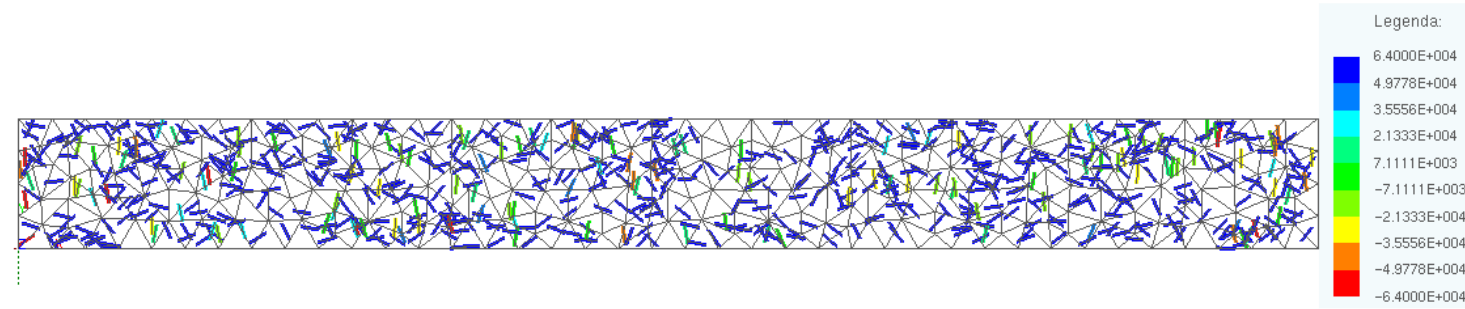

(a)

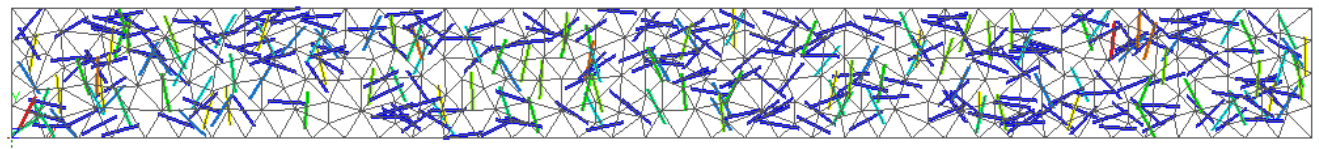

(b)

Figura 36 - (a) tensão normal nas fibras elastoplásticas de $3 \mathrm{~cm}$, (b) tensão normal nas fibras elastoplásticas de $6 \mathrm{~cm}$

A Figura 37 apresenta os deslocamentos horizontais na matriz com a consideração de fibras, de 3cm de comprimento, elásticas e elastoplásticas, respectivamente:

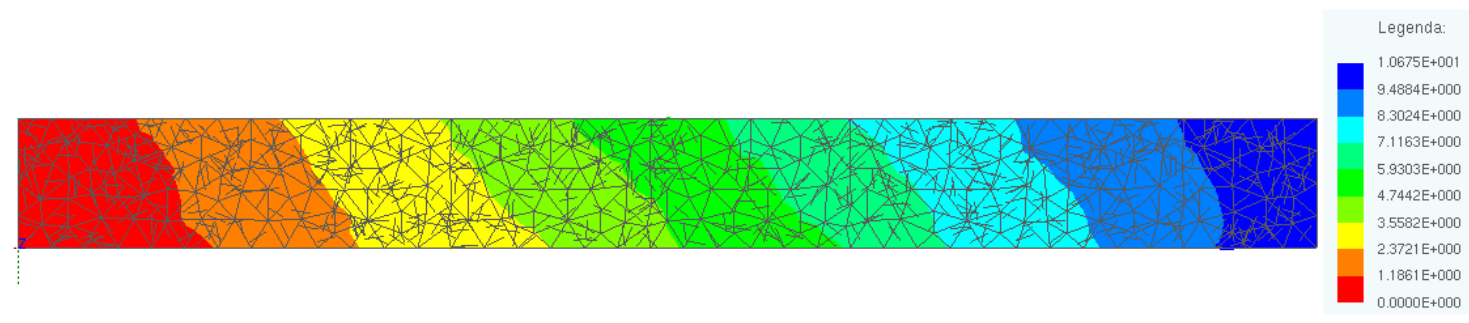

(a)

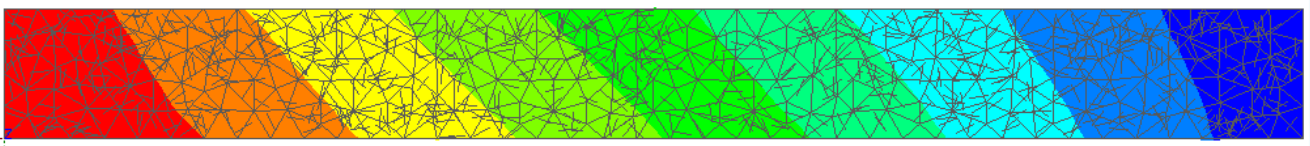

Legenda:

1.5279E+001

1. $3580 \mathrm{E}+00$ $1.1880 \mathrm{E}+001$ 
Figura 37 - (a) deslocamentos horizontais com fibras elásticas, (b) deslocamentos horizontais com fibras plásticas

De forma análoga, a Figura 38 apresenta os deslocamentos horizontais para as fibras de $6 \mathrm{~cm}$ de comprimento:

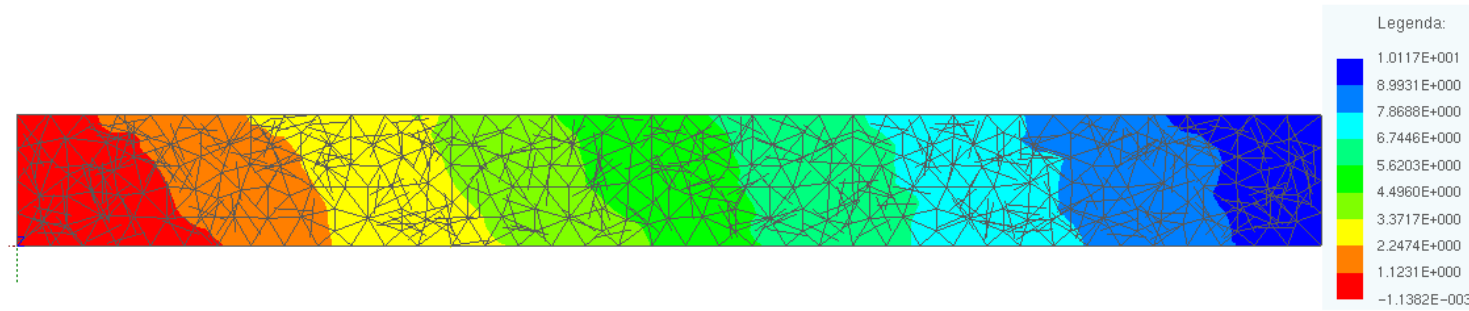

(a)

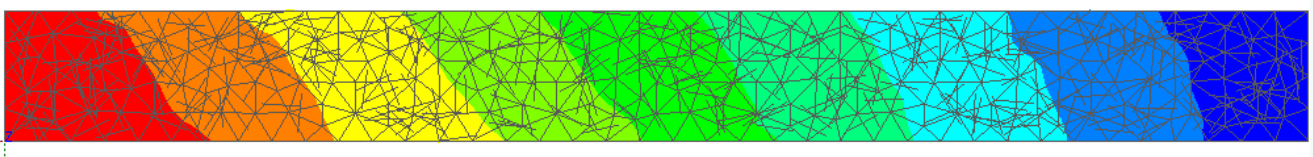

Legenda:

a)

(b)

Figura 38 - (a) deslocamentos horizontais com fibras elásticas, (b) deslocamentos horizontais com fibras plásticas

Analisando os resultados das Figura 37 e Figura 38, é possível observar que, para um mesmo caso de fibra, os deslocamentos horizontais foram maiores quando se considerou o comportamento elastoplástico das fibras e que a distribuição de deslocamento horizontal foi mais suave. Isto se deve ao fato de que as fibras consideradas elastoplásticas perfeitas só contribuem na rigidez até a tensão de plastificação, enquanto que as consideradas elásticas continuam a concentrar tensões nos níveis de carregamentos maiores.

Comparando os casos das fibras de $3 \mathrm{~cm}$ com as de $6 \mathrm{~cm}$ da Figura 36, é possível visualizar que as fibras menores apresentaram maiores deslocamentos. Isso acontece porque estas plastificaram pelo critério da tensão de interface, que apresenta uma tensão de plastificação inferior à tensão de plastificação da fibra, dessa forma, enrijecendo menos o meio do que no caso em que as fibras plastificaram segundo o critério do esforço normal. É possível observar também, como mostra a Figura 36, que as tensões nas fibras elastoplásticas de ambos os casos apresentam valores em torno da tensão de plastificação segundo cada curva de tensão-deformação. 


\subsection{Elastoplasticidade perfeita em viga engastada-livre reforçada}

Este exemplo tem o objetivo de apresentar as potencialidades da formulação obtida no que se refere à consideração do comportamento elastoplástico tanto para a matriz quanto para as fibras. Para o presente exemplo, foi adotada uma viga de comprimento $L=4 m$, o valor de metade da altura $h=0,2 m$ e largura da seção unitária, tensão de plastificação do material da matriz $S_{Y}=3.10^{3} \mathrm{kN} / \mathrm{m}^{2}$ e um deslocamento prescrito na extremidade livre, conforme apresentado no esquema da Figura 39.

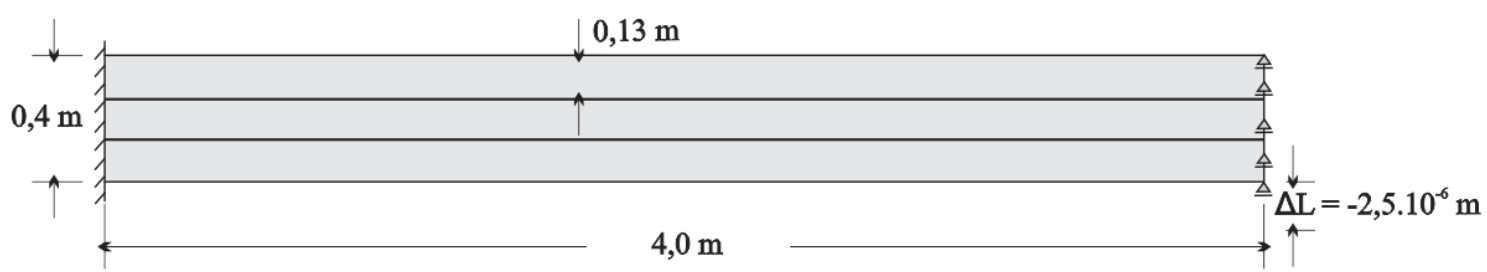

Figura 39 - Viga engastada-livre reforçada

O deslocamento prescrito utilizado tem seu valor suficiente para formar a rótula plástica na estrutura sem o reforço, conforme mostra a Figura 40. Entretanto, é possível observar que isto não ocorre com a consideração do reforço elástico na Figura 41.

(a)

(b)

Figura 40 - (a) tensão para a estrutura não reforçada (b) deformação plástica para a estrutura não reforçada 


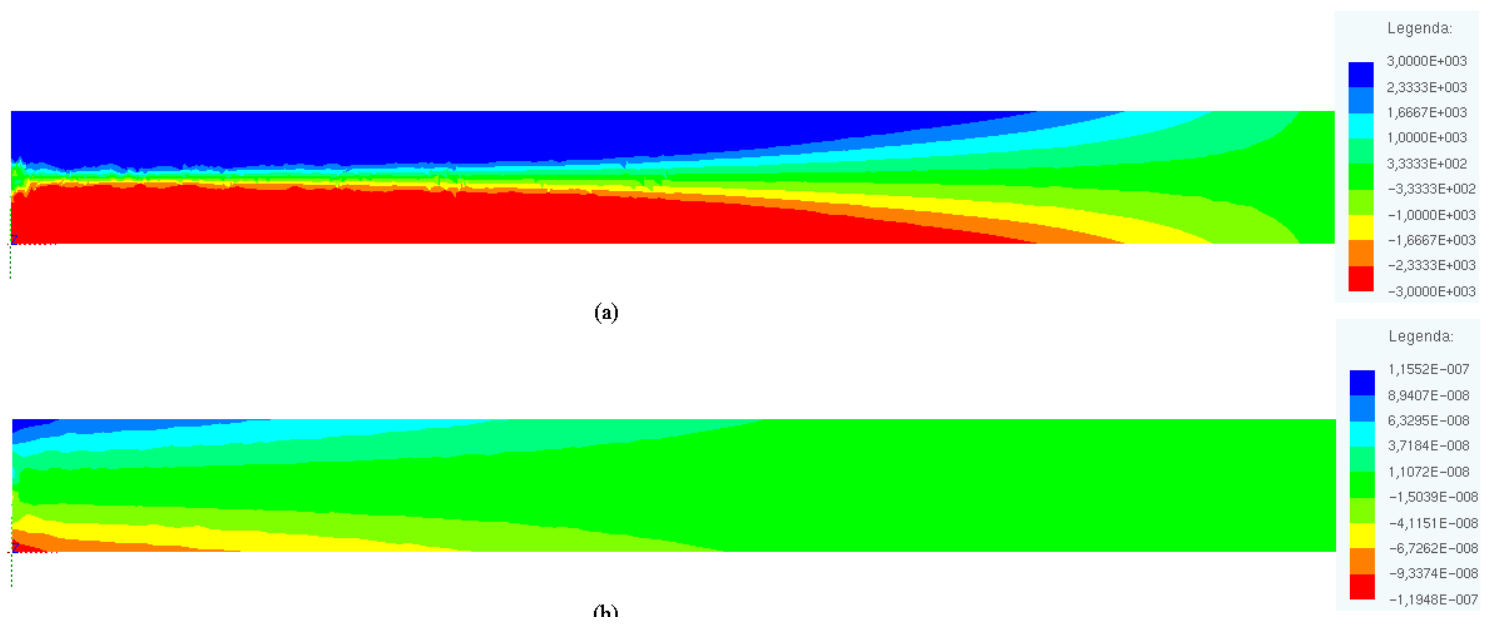

Figura 41 - (a) tensão para a estrutura com reforço elástico (b) deformação plástica para a estrutura com reforço elástico

Foram utilizados 400 elementos de fibra para simular o reforço e 476 elementos de chapa triangulares para a representação da matriz. A Figura 42 apresenta os gráficos do valor da reação total em função do deslocamento vertical prescrito para os casos de comportamento de fibra e chapa elásticas, a fibra elástica e chapa elastoplástica e com a fibra e a chapa elastoplásticos:

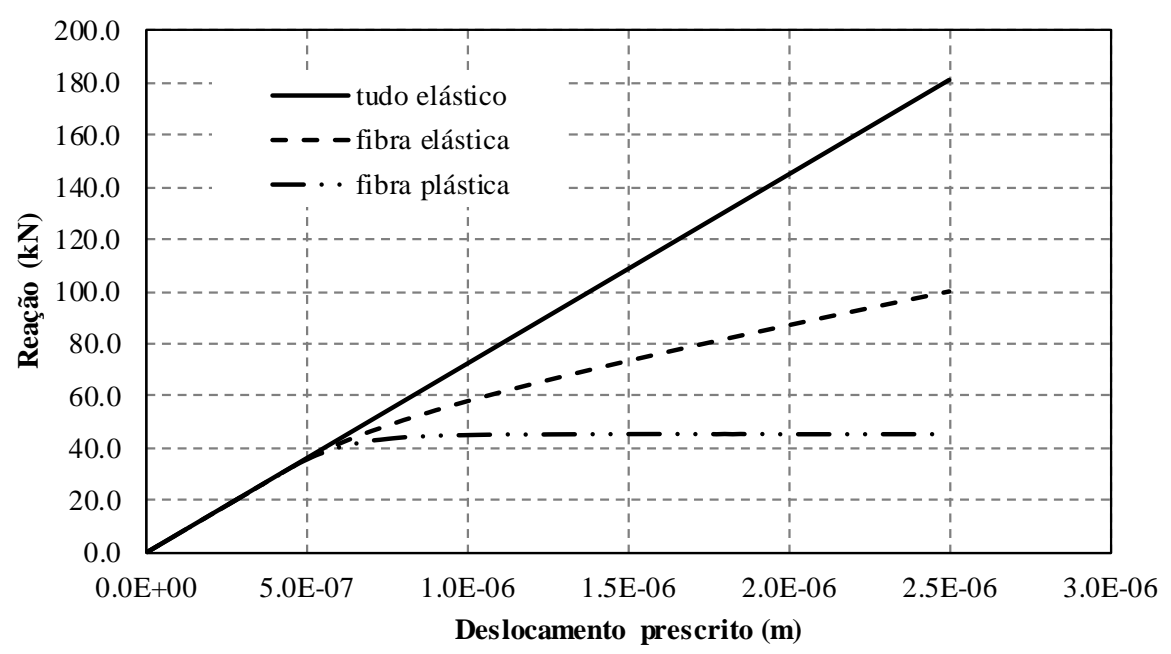

Figura 42 - Gráfico de reação x deslocamento

Analisando a Figura 42, é possível observar que, ao considerar o reforço elastoplástico perfeito, dado o deslocamento aplicado, houve também o escoamento do reforço, visto que a reação manteve-se inalterada a partir de aproximadamente um terço do deslocamento 
aplicado. Conforme o esperado, ao adotar a fibra como elástica, a reação continua a crescer, porém num ritmo inferior ao caso com chapa e reforço elásticos, pois a matriz entrou no regime plástico perfeito, apresentando um sistema menos rígido.

A Figura 43 apresenta o diagrama de tensão no reforço próximo ao engaste em função do deslocamento vertical prescrito adotado:

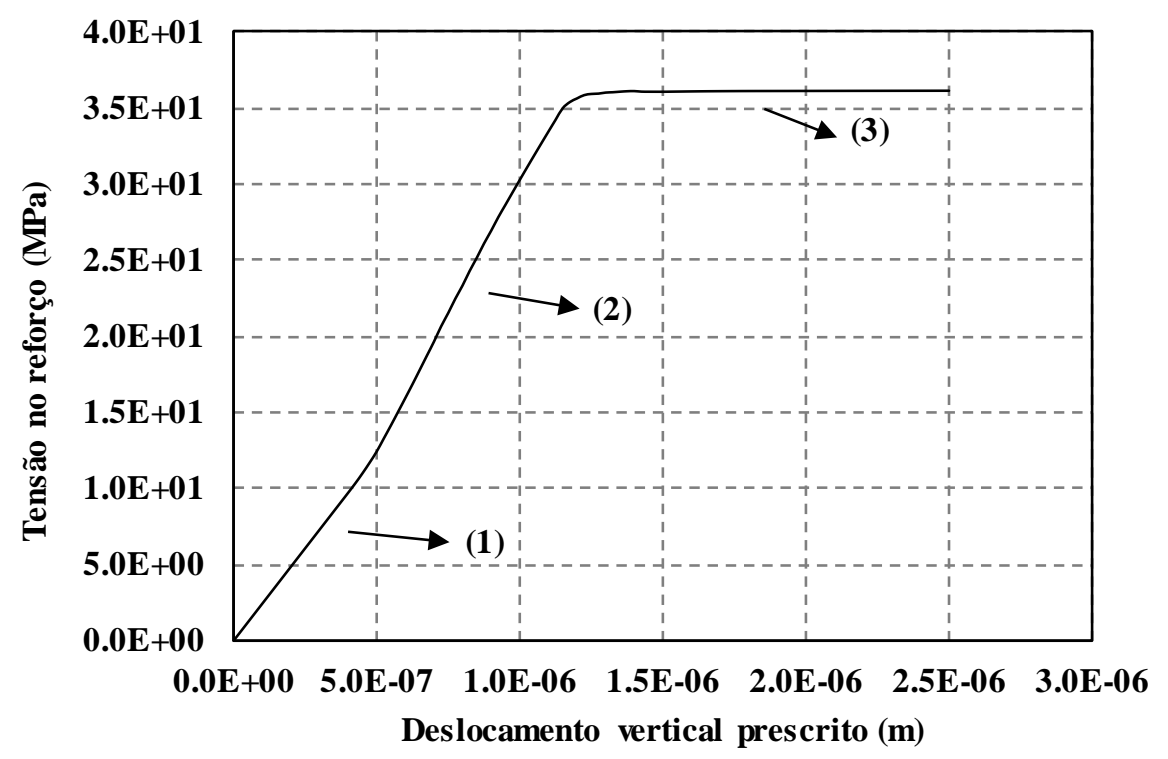

Figura 43 - Gráfico de tensão no reforço x deslocamento

Analisando a Figura 43 é possível observar no trecho (1) uma não linearidade, que ocorre pela plastificação da matriz, e não do próprio material. Este fato é corroborado pelo fato de que a partir deste instante, no trecho (2), a inclinação do gráfico com a horizontal aumenta, por haver uma maior transferência de esforço para o material da fibra, pois, ao ocorrer a plastificação da matriz, esta perde rigidez. Apenas no trecho (3) ocorre a não linearidade do gráfico em decorrência da plastificação do próprio reforço, adotado como elastoplástico perfeito.

Apenas para efeito de comparação dos resultados elásticos da matriz e da fibra obtidos no presente trabalho com resultados da teoria técnica de homogeneização da seção é feita a comparação entre os resultados.

A homogeneização é feita com uma correção na inércia do reforço segundo a relação entre os módulos de elasticidade $n=\mathbb{E}_{\text {reforço }} / \mathbb{E}_{\text {chapa }}$. Como os módulos de elasticidade do reforço e da chapa utilizados são, respectivamente, $2.10^{12} \mathrm{kN} / \mathrm{m}^{2}$ e $2.10^{11} \mathrm{kN} / \mathrm{m}^{2}$, temos que $n=10$. 
Calculando-se a inércia do reforço $I_{r}$ e da chapa $I_{c h}$, sendo que a área do reforço é $A_{r}=0,03 m^{2}$ com largura unitária e, conseqüentemente, altura $h_{r}=0,03 m$ :

$$
\begin{gathered}
I_{r}=n\left(\frac{h_{r}^{3} b}{12}+A_{r} \text { dist }^{2}\right)=10\left(\frac{0,03^{3}(1)}{12}+0,03(0,06667)^{2}\right)=1,1356 \cdot 10^{-3} \mathrm{~m}^{4} \\
I_{c h}=\frac{b(2 h)^{3}}{12}=\frac{1(2(0,2))^{3}}{12}=5,333.10^{-3} \mathrm{~m}^{4}
\end{gathered}
$$

Como se trata de duas barras de reforço, a inércia homogeneizada é dada por:

$$
I_{T}=I_{c h}+2 I_{r}=5,3333 \cdot 10^{-3}+2\left(1,1356.10^{-3}\right)=7,6045 \cdot 10^{-3} m^{4}
$$

Segundo a teoria da linha elástica, o valor do deslocamento para a borda livre segundo a reposta da linha elástica para a estrutura adotada é dado por $d=P L^{3} / 3 E I_{T}$. Conhecidos os valores de deslocamento no último passo, comprimento do vão, módulo de elasticidade e inércia, e realizando as devidas substituições, é possível chegar a um valor de reação de 178, $23 k N$ para a solução clássica. Ao analisarmos a Figura 42, é possível observar que o resultado obtido pelo código para o valor da reação segundo as mesmas condições é $180,93 k N$, resultando numa diferença relativa de $1,51 \%$ entre os valores obtidos.

Com isso, é possível verificar que o presente código computacional está coerente com a teoria clássica, que considera pequenos deslocamentos e materiais lineares elásticos, entretanto, vai além e permite analisar meios reforços com não linearidade física tanto na chapa quanto no reforço, além de representar corretamente estruturas com grandes deslocamentos, contemplando, assim, dois tipos diferentes de não linearidade. 


\section{CONSIDERAÇÕES FINAIS}

O presente trabalho aborda o equacionamento do fenômeno da não linearidade física e geométrica em compósitos planos reforçados com fibras. A formulação de elementos finitos utilizada é a posicional, que tem como parâmetros nodais as posições dos nós e utiliza uma descrição lagrangeana total para o equilíbrio não linear geométrico.

O equilíbrio estático do sistema foi obtido pelo princípio da energia potencial total estacionária e a resolução do sistema não linear foi obtida pelo método iterativo-incremental de Newton-Raphson.

A lei constitutiva de Saint-Venant Kirchhoff foi adotada, que utiliza a medida de deformação de Green-Lagrange e o tensor de tensões de Piola-Kirchhoff de segunda espécie.

A inserção do reforço no meio foi feita com um elemento finito de barra, cuja contribuição no meio é feita segundo as funções de forma do elemento finito de chapa e uma compatibilização na contribuição nos graus de liberdade deste, não havendo acréscimo de graus de liberdade no sistema.

O modelo de plasticidade adotado para a matriz foi de von Mises associativo e a solução da equação não linear resultante de sua condição de consistência foi obtida segundo solução iterativa pelo método de Newton-Raphson. O modelo adotado para as fibras, em que se considera a possibilidade de falha nas fibras ou na interface fibra-matriz apresentou bons resultados, abrindo possibilidades de análises futuras.

A eficiência e correta implementação das formulações adotadas pôdem ser comprovadas pelos diversos exemplos demonstrados, em que os resultados obtidos apresentaram valores próximos aos valores teóricos e comportamento consistente ao longo de todas as análises. Para a elastoplasticidade perfeita, o controle de deslocamentos de mostrou mais estável nos resultados e com tempo de processamento inferior ao do controle de forças.

O código computacional desenvolvido no presente trabalho permite avaliar diferentes mecanismos envolvidos na plasticidade do reforço, além de representar corretamente a plasticidade na chapa e a interação entre as duas fases elastoplásticas. O reforço pode ser considerado de forma aleatório ou fixo e alinhado. 


\subsection{Sugestões para trabalhos futuros}

A estrutura, distribuição das fibras e modelo de plasticidade utilizados são planos, sendo assim, pode-se generalizar para o caso tridimensional, aumentando a possibilidade de representações das mais variadas estruturas.

O trabalho discretiza apenas fibras no meio, podendo-se enventualmente inserir juntamente elementos finitos que simulem partículas e vazios, culminando em uma simulação cada vez mais real dos materiais heterogêneos.

A implementação de um integrador temporal é uma possibilidade de trabalho futuro, possibilitando análises de problemas em que tais efeitos sejam significativos aos resultados. Com um eventual uso de um integrador temporal, torna-se interessante a paralelização do código obtido, uma vez que o custo computacional despendido nessas análises com consideração do comportamento dinâmico seria muito maior, se comparadas aos casos estáticos.

Por fim, a implementação de um modelo de dano seria um assunto de extrema importância, pois, como visto anteriormente, uma das principais funções do uso de fibras é o controle de fissuração, além de este fenômeno poder ter sua ocorrência simultânea com a plasticidade. 


\section{Referências Bibliográficas}

ARAÚJO, F. A. Contribuição ao emprego da mecânica do dano para a análise do comportamento dinâmico não-linear de vigas de concreto armado. [s.l.] Escola de Engenharia de São Carlos - Universidade de São Paulo, 2003.

ARQUEZ, A. P. Aplicação de laminado de polímero reforçado com fibras de carbono (PRFC) inserido em substrato de microconcreto com fibras de aço para reforço à flexão de vigas de concreto armado. [s.l.] Escola de Enegnharia de São Carlos - Universidade de São Paulo, 2010.

ASSAN, A. E. Método dos elementos finitos: primeiros passos. Campinas: UNICAMP, 2002.

AZEVEDO, A. P. Resistência e ductilidade das ligações laje-pilar em lajes-cogumelo de concreto de alta resistência armado com fibras de aço e armadura transversal de pinos. [s.l.] Escola de Enegnharia de São Carlos - Universidade de São Paulo, 1999.

AZIM, M. et al. Energy Absorption Capacity of Reinforced Concrete Beam-Column Connections, with Ductility Classes Low. American Journal of Civil Engineering and Architecture, v. 2, n. 1, p. 42-52, 2 mar. 2014.

BARZEGAR, F.; MADDIPUDI, S. GENERATING REINFORCEMENT IN FE MODELING OF CONCRETE STRUCTURES. Journal of Structural Engineering-Asce, v. 120, n. 5, p. 1656-1662, 1994.

BASTOS, P. S. S. Análise experimental de dormentes de concreto protendido reforçados com fibras de aço. [s.l.] Escola de Enegnharia de São Carlos - Universidade de São Paulo, 1999.

BENTUR, A.; MINDESS, S. Fibre reinforced cementitious composites. Nova Iorque: Elsevier Science Publishers, 2007.

BONET, J. et al. Finite element analysis of air supported membrane structures. Computer Methods in Applied Mechanics and Engineering, v. 190, n. 5-7, p. 579-595, nov. 2000.

BONET, J.; WOOD, R. D. Nonlinear Continuum Mechanics for Finite Element Analysis. Nova Iorque: Cambridge University Press, 1997.

CACHIM, P. Numerical modelling of fibre-reinforced concrete fatigue in bending. International Journal of Fatigue, v. 24, n. 2-4, p. 381-387, abr. 2002.

CALLISTER JR., W. D. Ciência e engenharia de materiais. 7. ed. Rio de Janeiro: LTC Livros Técnicos e Científicos Editora S.A., 2013.

CHANDRASHEKHARA, K.; BANGERA, K. M. Linear and geometrically non-linear analysis of composite beams under transverse loading. Composites Science and Technology, v. 47, n. 4, p. 339-347, jan. 1993.

CODA, H. B. An exact FEM geometric non-linear analysis of frames based on position description. 17H INTERNATIONAL CONGRESS OF MECHANICAL ENGINEERING., 2003.

CODA, H. B.; PACCOLA, R. R. A positional FEM Formulation for geometrical non-linear analysis of shells. Latin American Journal of Solids and Structures, v. 5, n. 3, p. 205-223, 2008.

CODA, H. B.; PACCOLA, R. R. Improved finite element for 3D laminate frame analysis including warping for any cross-section. Applied Mathematical Modelling, v. 34, n. 4, p. 1107-1137, 2010. 
CRISFIELD, M. A. Non-Linear Finite Element Analysis of Solids and Structures Vol.1. West Sussex: John Wiley \& Sons Ltd., 2000.

DANIEL, I. .; ISHAI, O. Engineering Mechanics of Composite Materials. Nova Iorque: Oxford University Press, Inc., 2006.

DOLTSINIS. Elements of Plasticity. 2. ed. Southampton: WIT Press, 2010.

DUTRA, V. F. P. et al. A micromechanical approach to elastic and viscoelastic properties of fiber reinforced concrete. Cement and Concrete Research, v. 40, n. 3, p. 460-472, mar. 2010.

EKANE, E. B. Estudo de fissuração em concreto armado com fibras e armadura convencional. [s.l.] Escola de Enegnharia de São Carlos - Universidade de São Paulo, 1999.

FEENSTRA, P. H.; BORST, R. DE. A composite plasticity model for concrete. International Journal of Solids and Structures, v. 33, n. 5, p. 707-730, fev. 1996.

FERRARI, V. J. Reforço à flexão de vigas de concreto armado com manta de polímero reforçado com fibras de carbono (PRFC) aderido ao subestrato de transição constituído por compósito cimentício de alto desempenho. [s.l.] Escola de Enegnharia de São Carlos Universidade de São Paulo, 2007.

FISH, J. et al. Computational plasticity for composite structures based on mathematical homogenization: Theory and practice. Computer Methods in Applied Mechanics and Engineering, v. 148, n. 1-2, p. 53-73, ago. 1997.

FONSECA, T. C. C. S. Reforço e incremento da rigidez à flexão de ligações viga-pilar de struturas de concreto pré-moldado com polímero reforçado com fibra de carbono (PRFC). [s.l.] Escola de Engenharia de São Carlos - Universidade de São Paulo, 2007.

FURLAN JR, S. Vigas de concreto com taxas reduzidas de armadura de cisalhamento: influência do emprego de fibras curtas e de protensão. [s.l.] Escola de Engenharia de São Carlos - Universidade de São PAulo, 1995.

GADALA, M. S.; ORAVAS, G. A. Numerical solutions of nonlinear problems of continuaI. Computers \& Structures, v. 19, n. 5-6, p. 865-877, jan. 1984.

GOMES, H. M.; AWRUCH, A. M. Some aspects on three-dimensional numerical modelling of reinforced concrete structures using the finite element method. Advances in Engineering Software, v. 32, n. 4, p. 257-277, 2001.

GRECO, M. et al. Nonlinear positional formulation for space truss analysis. Finite Elements in Analysis and Design, v. 42, p. 1079-1086, 2006.

GRECO, M.; CODA, H. B. Positional FEM formulation for flexible multi-body dynamic analysis. Journal of Sound and Vibration, v. 290, n. 3-5, p. 1141-1174, 2006.

GUIMARÃES, A. E. P. Análises de pilares de concreto de alta resistência com adição de fibras metálicas submetidos à compressão centrada. [s.l.] Escola de Enegnharia de São Carlos - Universidade de São Paulo, 1999.

HAMEED, R. et al. Damage model for concrete reinforced with sliding metallic fibers. International Journal of Mechanics and Materials in Design, v. 7, n. 1, p. 83-97, 2011.

HAMEED, R. et al. Metallic fiber-reinforced concrete behaviour: Experiments and constitutive law for finite element modeling. Engineering Fracture Mechanics, v. 103, p. 124-131, 2013.

HARRIS, B. Engineering Composite Materials. London: The institute of materials, 1999.

HASHIN, Z.; SHTRIKMAN, S. A variational approach to the theory of the elastic behaviour 
of multiphase materials. Journal of the Mechanics and Physics of Solids, v. 11, n. 2, p. 127-140, mar. 1963.

HILL, R. Theory of mechanical properties of fibre-strengthened materials: II. Inelastic behaviour. Journal of the Mechanics and Physics of Solids, v. 12, n. 4, p. 213-218, set. 1964.

HOLANDA, K. M. A. Análise dos mecanismos resistentes e das similaridades de efeitos da adição de fibras de aço na resistência e na ductilidade à punção de lajes-cogumelo e ao cisalhamento em vigas de concreto. [s.l.] Escola de Enegnharia de São Carlos Universidade de São Paulo, 2002.

HOLZAPFEL, G. A. Nonlinear solid mechanics: a continuum approach for engineering. Chichester: John Wiley \& Sons, 2000.

JONES, R. M. Mechanics of Composite Materials. 2. ed. Blacksburg: Taylor \& Francis, 1999.

KANT, T.; KOMMINENI, J. R. C0 Finite element geometrically non-linear analysis of fibre reinforced composite and sandwich laminates based on a higher-order theory. Computers \& Structures, v. 45, n. 3, p. 511-520, out. 1992.

KHAN, A. S.; HUANG, S. Continuum Theory of Plasticity. Nova Iorque: John Wiley \& Sons Ltd., 1995.

LANIR, Y. Mechanistic micro-structural theory of soft tissues growth and remodeling: tissues with unidirectional fibers. Springer-Verlag Berlin Heidelberg, 2014.

LANIR, Y.; NANAMI, R. Reliability of structure tensors in representing soft tissues structure. Journal of the Mechanical Behaviour of Biomedical Materials, p. 222-228, 2015.

LI, F.; LI, Z. Continuum damage mechanics based modeling of fiber reinforced concrete in tension. International Journal of Solids and Structures, v. 38, n. 5, p. 777-793, fev. 2001.

LUBLINER, J. Plasticity Theory. Berkeley: University of California, 2005.

MACIEL, D. N. Análise de problemas elásticos não lineares geométricos empregando o método dos elementos finitos posicional. [s.l.] Escola de Engenharia de São Carlos Universidade de São Paulo, 2008.

MAGAGNIN FILHO, N. Placas laminadas em materiais compostos de fibras longas. [s.l.] Escola de Enegnharia de São Carlos - Universidade de São Paulo, 1996.

MAIRE, J. F.; CHABOCHE, J. I. A new formulation of continuum damage mechanics (CDM) for composite materials. Aerospace Science and Technology, v. 4, p. 247-257, 1997.

MARQUES, G. Estudo e desenvolvimento de código computacional baseado no MEF para análise dinâmica não linear geométrica de sólidos bidimensionais. [s.l.] Escola de Engenharia de São Carlos - Universidade de São Paulo, 2006.

MATIASSON, K. NUMERICAL RESULTS FROM LARGE DEFLECTION BEAM ELLIPTIC INTEGRALS AND FRAME PROBLEMS ANALYSED BY. Short Communications, p. 145-153, 1981.

MEHTA, P. K.; MONTEIRO, P. J. M. Concrete: microstructure, properties and materials. 3. ed. Nova Iorque: The McGraw-Hills Companies, Inc., 2006.

MENDONÇA, P. T. R. Materiais compostos e estruturas-sanduíche. Barueri: Manole Ltda, 2005. 
MESQUITA, A. D. Uma formulação do método dos elementos finitos aplicada à análise elastoplástica de cascas. [s.l.] Escola de Engenharia de São Carlos - Universidade de São Paulo, 1998.

MILLER, K. et al. Total Lagrangian explicit dynamics finite element algorithm for computing soft tissue deformation. Communications in Numerical Methods in Engineering, v. 23, n. 2, p. 121-134, 14 ago. 2006.

MILLER, K. P. Estudo da fluência em vigas de concreto reforçado com fibras de aço, com aplicação de conceitos da mecânica da fratura. [s.l.] Escola de Enegnharia de São Carlos - Universidade de São Paulo, 2008.

MINSKI, R. L. Aprimoramento de formulação de identificação e solução do impacto bidimensional entre estrutura e anteparo rígido. [s.l.] Escola de Engenharia de São Carlos - Universidade de São Paulo, 2008.

MOURA, C. A. Aplicação de formulação baseada no Método dos Elementos Finitos Posicional na análise bidimensional elástica de compósitos particulados. [s.l.] Escola de Engenharia de São Carlos - Universidade de São Paulo, 2015.

NAAMAN, A. E. et al. Fiber pullout and bond slip. I: analytical study. Journal of Structural Engineering-Asce, v. 117, p. 2769-2790, 1991.

NOGUEIRA, G. V et al. Consideração do deslizamento na análise de sólidos elásticos bidimensionais reforçados por fibras através do método dos elementos finitos posicional. Cilamce, p. 100, 2014.

OGDEN, W. R. Non-linear elastic deformations. Chichester: Ellis Horwood, 1984.

PACCOLA, R. R. Análise não linear física de placas e cascas anisotrópicas laminadas acopladas ou não com meio tridimensional viscoelástico através da combinação entre o MEC e o MEF. [s.l.] Escola de Engenharia de São Carlos - Universidade de São Paulo, 2004.

PAI, P. F.; ANDERSON, T. J.; WHEATER, E. A. Large-deformation tests and totalLagrangian finite-element analyses of flexible beams. International Journal of Solids and Structures, v. 37, n. 21, p. 2951-2980, maio 2000.

PANDA, S.; RAY, M. C. Active control of geometrically nonlinear vibrations of functionally graded laminated composite plates using piezoelectric fiber reinforced composites. Journal of Sound and Vibration, v. 325, n. 1-2, p. 186-205, ago. 2009.

PANDOLFI, A.; VASTA, M. Fiber distributed hyperelastic modeling of biological tissues. Mechanics of Materials, v. 44, p. 151-162, 2012.

PASA, V. F. Análise do comportamento de estruturas de concreto armado reforçado com fibras de aço via método dos elementos finitos. [s.l.] Universidade Federal do Rio Grande do Sul, 2007.

PASCON, J. P. Sobre modelos constitutivos não lineares para materiais com gradação funcional exibindo grandes deformações: implementação numérica em formulação não linear geométrica. [s.l.] Escola de Engenharia de São Carlos - Universidade de São Paulo, 2012.

PENG, X.; MEYER, C. A continuum damage mechanics model for concrete reinforced with randomly distributed short fibers. Computers \& Structures, v. 78, n. 4, p. 505-515, dez. 2000.

PEREIRA, D. P. Análise não linear geométrica de sólidos elásticos tridimensionais reforçados com fibras através do método dos elementos finitos. [s.l.] Escola de Engenharia de São Carlos - Universidade de São Paulo, 2015. 
PETERSON, A.; PETERSSON, H. On finite element analysis of geometrically nonlinear problems. Computer Methods in Applied Mechanics and Engineering, v. 51, n. 1-3, p. 277-286, set. 1985.

PROENÇA, S. P. B. Análise não-linear de estruturas. [s.l.] Escola de Engenharia de São Carlos - Universidade de São Paulo, 2013.

RADTKE, F. K. F.; SIMONE, A.; SLUYS, L. J. A computational model for failure analysis of fibre reinforced concrete with discrete treatment of fibres. Engineering Fracture Mechanics, v. 77, n. 4, p. 597-620, mar. 2010.

RAFIEE, M. et al. Geometrically nonlinear free vibration of shear deformable piezoelectric carbon nanotube/fiber/polymer multiscale laminated composite plates. Journal of Sound and Vibration, v. 333, n. 14, p. 3236-3251, jul. 2014.

REIS, A. P. A. Reforço de vigas de concreto armado submetidas a pré-carregamento e ações de longa duração com aplicação de concreto de alta resistência e concretos com fibras de aço. [s.l.] Escola de Enegnharia de São Carlos - Universidade de São Paulo, 2003.

SAMPAIO, M. S. M. Análise não linear geométrica de cascas laminadas reforçadas com fibras. [s.l.] Escola de Engenharia de São Carlos - Universidade de São Paulo, 2014.

SEOW, P. E. C.; SWADDIWUDHIPONG, S. Failure surface for concrete under multiaxial load - a unified approach. Journal of Materials in Civil Engineering, v. 17, n. 2, p. 219228, 2005.

SHAKUR SHAHABI, H. et al. Metallic glass-steel composite with improved compressive plasticity. Materials \& Design, v. 59, p. 241-245, jul. 2014.

VANALLI, L. O MEC e o MEF aplicados à análise de problemas viscoplásticos em meiso anisotrópicos e compostos. [s.l.] Escola de Engenharia de São Carlos - Universidade de São Paulo, 2004.

VANALLI, L. et al. A simple method for non-linear analysis of steel fiber reinforced concrete. Acta Scientiarum-Technology, v. 32, n. 4, p. 367-374, 2010.

VANALLI, L. et al. A simple method for non-linear analysis of steel fiber reinforced concrete. Acta Scientiarum-Technology, v. 32, n. 4, p. 367-374, 2010.

VANALLI, L.; PACCOLA, R. R.; CODA, H. B. A simple way to introduce fibers into FEM models. Communications in Numerical Methods in Engineering, v. 24, n. 7, p. 585-603, 2008.

VASTA, M.; GIZZI, A.; PANDOLFI, A. On three-and two-dimensional fiber distributed models of biological tissues. Probabilistic Engineering Mechanics, v. 37, p. 170-179, 2014.

VASTA, M.; PANDOLFI, A.; GIZZI, A. A Fiber Distributed Model of Biological Tissues. Procedia IUTAM, v. 6, p. 79-86, 2013.

VOYIADJIS, G. Z.; KATTAN, P. I. Mechanics of small damage in fiber-reinforced composite materials. Composite Structures, v. 92, n. 9, p. 2187-2193, ago. 2010.

WONG, M. B.; TIN-LOI, F. Geometrically nonlinear analysis of elastic framed structures. Computers \& Structures, v. 34, n. 4, p. 633-640, jan. 1990.

YAZDANI, S.; SCHREYER, H. L. Combined Plasticity and Damage Mechanics Model for Plain Concrete. Journal of Engineering Mechanics-Asce, v. 116, p. 1435-1450, 1990. 